\title{
Evaluating Cumulative Ecosystem Response to Restoration Projects in the Columbia River Estuary, Annual Report 2006
}

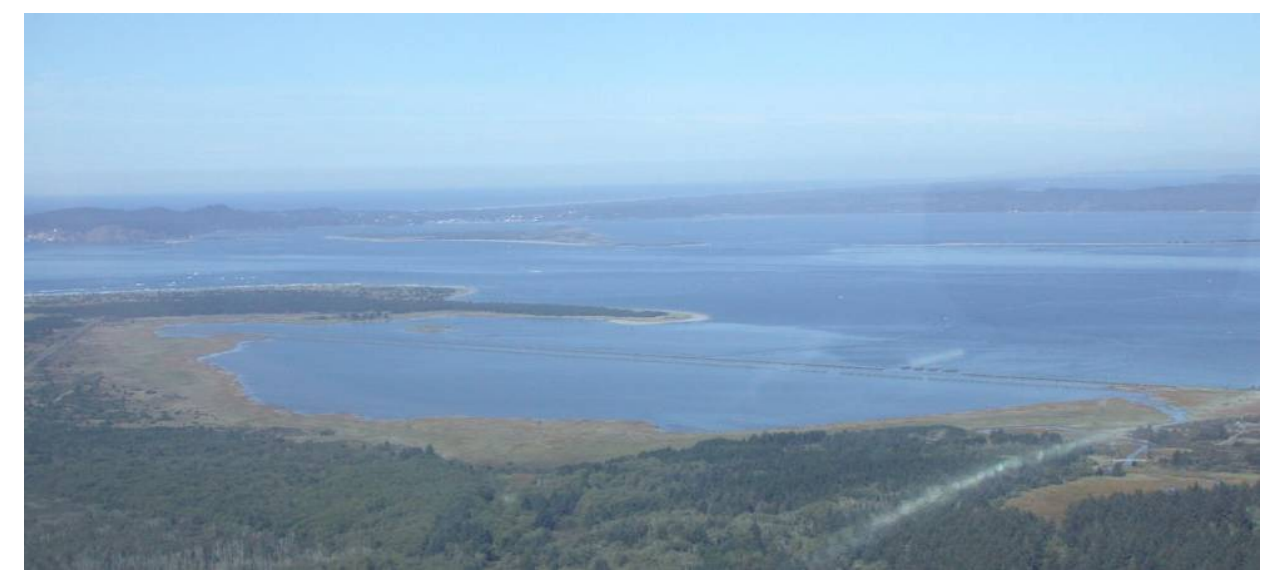

FINAL REPORT

December 10, 2007

Prepared for:

U.S. Army Corps of Engineers, Portland District

Under a Related Services Agreement with

The U.S. Department of Energy

Contract DE-AC05-76RLO 1830

Prepared by:

Pacific Northwest National Laboratory, Marine Sciences Laboratory

NOAA Fisheries, Pt. Adams Biological Field Station

Columbia River Estuary Study Taskforce 


\section{DISCLAIMER}

This report was prepared as an account of work sponsored by an agency of the United States Government. Neither the United States Government nor any agency thereof, nor Battelle Memorial Institute, nor any of their employees, makes any warranty, express or implied, or assumes any legal liability or responsibility for the accuracy, completeness, or usefulness of any information, apparatus, product, or process disclosed, or represents that its use would not infringe privately owned rights. Reference herein to any specific commercial product, process, or service by trade name, trademark, manufacturer, or otherwise does not necessarily constitute or imply its endorsement, recommendation, or favoring by the United States Government or any agency thereof, or Battelle Memorial Institute. The views and opinions of authors expressed herein do not necessarily state or reflect those of the United States Government or any agency thereof.

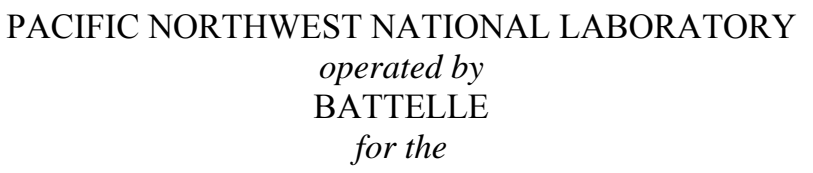

\section{UNITED STATES DEPARTMENT OF ENERGY}

under Contract DE-AC05-76RL01830

Cover Photo: View of the Columbia River estuary looking north with Trestle Bay in the foreground. 


\title{
Evaluating Cumulative Ecosystem Response to Restoration Projects in the Columbia River Estuary, Annual Report 2006
}

\author{
Edited by Gary E. Johnson ${ }^{\mathrm{a}}$ \\ Amy B. Borde ${ }^{\mathrm{a}}$ \\ Earl M. Dawley ${ }^{b}$ \\ Heida L. Diefenderfer ${ }^{\mathrm{a}}$ \\ Blaine D. Ebberts ${ }^{\mathrm{c}}$ \\ Douglas A. Putman ${ }^{\mathrm{c}}$ \\ G. Curtis Roegner ${ }^{\mathrm{d}}$ \\ Ronald M. Thom ${ }^{\mathrm{a}}$ \\ John Vavrinec III ${ }^{\mathrm{a}}$ \\ Allan H. Whiting ${ }^{\mathrm{e}}$
}

FINAL REPORT

December 10, 2007

Prepared for the

U.S. Army Corps of Engineers, Portland District

Under a Related Services Agreement with

The U.S. Department of Energy

Contract DE-AC05-76RLO 1830

Prepared by:

Pacific Northwest National Laboratory, Marine Sciences Laboratory NOAA Fisheries, Pt. Adams Biological Field Station

Columbia River Estuary Study Taskforce

\footnotetext{
${ }^{a}$ Pacific Northwest National Laboratory, Richland, Washington

${ }^{\mathrm{b}}$ NOAA Fisheries (retired)

${ }^{c}$ U.S. Army Corps of Engineers, Portland District, Portland, Oregon

d NOAA Fisheries, Hammond, Oregon

e Columbia River Estuary Study Taskforce, Astoria, Oregon
} 



\section{Preface}

This research was conducted under the auspices of the U.S. Army Corps of Engineers (USACE) Pacific Northwest Division's Anadromous Fish Evaluation Program (study code EST-P-02-04). It is related to and complements other estuary research (study codes EST-02-P-01 and EST-02-P-02). This study was funded by the USACE Portland District (Ref. No. W66QKZ50397907) under an agreement with the U.S. Department of Energy, and was conducted by Pacific Northwest National Laboratory (PNNL), operated by Battelle. Subcontractors to PNNL included the Columbia River Estuary Study Taskforce, the University of Washington, and Mr. Earl Dawley. The National Marine Fisheries Service was funded separately by the USACE to collaborate on this project.

This report is the third annual report of a six-year project to develop a methodology to evaluate the cumulative effects of habitat restoration projects in the Columbia River estuary. The report contains chapters by particular authors on specific topics addressed in this project. The chapters are formatted as stand-alone manuscripts that will eventually be submitted to peer-reviewed journals. The chapters are at various stages of development as manuscripts because the stages of data collection and analysis vary. The purpose of this format is to expedite publishing of USACE-funded research.

\section{Recommended citation for the entire report:}

Johnson, G.E. (ed.) 2007. Evaluating Cumulative Ecosystem Response to Restoration Projects in the Columbia River Estuary, Annual Report 2006. PNNL-16561. Report to the U.S. Army Corps of Engineers, Portland District, by Pacific Northwest National Laboratory, Richland, Washington.

Recommended citation for a chapter in the report:

Roegner, G.C., E.M. Dawley, A.H. Whiting, and B.D. Ebberts. 2007. "Monitoring juvenile salmon use and fish community structure in restored wetland habitat." Chapter 7, pp. 7.1-7.7 in Johnson, G. (ed.), Evaluating Cumulative Ecosystem Response to Restoration Projects in the Columbia River Estuary, Annual Report 2006. PNNL-16561. Report to the U.S. Army Corps of Engineers, Portland District, by Pacific Northwest National Laboratory, Richland, Washington. 


\section{Executive Summary}

This report is the third annual report of a six-year project to evaluate the cumulative effects of habitat restoration actions in the Columbia River estuary (CRE). The project is being conducted for the U.S. Army Corps of Engineers (USACE) by the Marine Sciences Laboratory of the Pacific Northwest National Laboratory, the Pt. Adams Biological Field Station of the National Marine Fisheries Service, and the Columbia River Estuary Study Taskforce.

Because of the size and complexity of the estuarine landscape and the meta-populations of salmonids in the Columbia River basin, measurement of the cumulative effects of ecological restoration projects in the Columbia River estuary is a formidable task. Despite the challenges, developing and implementing appropriate indicators and methods to measure cumulative effects will enable estuary managers to track the overall effectiveness of investments in estuarine restoration projects. This project has been designed to develop methods to quantify the cumulative effects of multiple restoration activities in the CRE. These methods will be applicable elsewhere.

In this multi-year study, we are developing a weight of evidence approach for cumulative effects analysis. The field research in 2005 and 2006 developed three sources of data for cumulative effects analysis using a weight-of-evidence approach: in-depth paired site studies (marsh and swamp), core indicators at all monitored restoration project and reference sites, and cumulative effects indicators. Core indicators include water surface elevation, temperature, vegetation cover, fish abundance, etc. Examples of cumulative effects indicators are nutrient and macrodetritus flux and connected channel edge length. Studies are paired on several levels: habitat type (tidal swamp versus marsh), trajectory (restoration versus reference site), action (tide gate versus culvert versus dike breach), and metric (multiple simultaneous).

The objectives for the 2006 research pertain directly to the three lines of evidence for the cumulative effects analysis: statistical tests and hydraulic and geographic information systems modeling. This research is being used to resolve uncertainties in indicators of fundamental processes, develop predictive structure/function relationships, and create estimators for cumulative effects based on the concept of net ecosystem improvement. These data will be applied in future study years in an integrative effort involving a hydrodynamic model, an additive geographic information system and adaptive management framework, and statistical tests for cumulative effects using data from multiple restoration sites.

We addressed the overall objectives with field work in 2006 that, coupled with previous field data, had specific objectives and resulted in some important findings that are summarized here by chapter in this report. Each chapter of the report contains data on particular monitored variables for pre- and post-restoration conditions.

\section{Chapter 2 - Hydrology}

Objective: Monitor hydrological variation at two study locations before and after tidal reconnection. 
Need: Monitoring variation in water properties during pre- and post-restoration periods is a necessary measure of salmonid habitat change and is important to explain and predict responses to restoration, including channel morphology and floral and faunal community structures. Collection of hydrologic data also has important implications for restoration managers; changes in the timing, frequency, and volumes of tidal hydrology resulting from restoration treatments can help inform management decisions for the ecological maintenance of the site over time.

Results: In the Grays River system at the Kandoll site, data-logging sensors have been continuously monitoring water-level and temperature since summer 2005. Tide gate removal and dike breaching activity during 2005 had an immediate effect on water-level fluctuations within the Kandoll site. In the restored area upstream of the new culverts, water-level fluctuations changed from a weak tidal signal to a full semidiurnal pattern and maximum amplitudes increased from $\sim 1.0 \mathrm{~m}$ to $\sim$ $3.0 \mathrm{~m}$. As a result of this tidal reconnection, the tidal prism, inundation levels, and flux of water through the system were greatly increased. Also, temperatures at all stations rapidly coincided, indicating widespread hydrologic reconnection. The storm events of winter 2005-2006 were clearly recorded in the hydrography measurements.

The Vera Slough project entailed the replacement of two tide gates designed to increase connectivity with Youngs Bay and the Columbia River, while maintaining a certain degree of flood protection. The tide gates were replaced on 12 October 2005. Measurements were initiated in May 2005 and are ongoing. Tide gate replacement resulted in an increase in tidal amplitude from $0.50 \mathrm{~m}$ to about $0.75 \mathrm{~m}$ inside Vera Slough. The truncated vertical amplitudes indicate the effectiveness of the tide gates at limiting full tidal connection, while providing flood control and improved circulation and access to wetland habitats for juvenile salmonids in the area. During the post-replacement period, mean daily water temperature deviation between reference and restoration sample sites was generally $<1{ }^{\circ} \mathrm{C}$, whereas prior to the restoration action the deviation was as high as $4{ }^{\circ} \mathrm{C}$.

\section{Chapter 3 - Longitudinal Channel Structure}

Objective: Examine the effects of large woody debris (LWD) on tidal forested wetland channel morphology.

Need: Knowledge of channel morphology and the role of LWD in spruce-dominated tidal wetlands is lacking, complicating efforts to establish goals for the structural characteristics sought by restoration projects. It is unlikely, based on the unique combination of seasonally extreme flows and high diurnal tidal ranges, that the channel-forming capability of Columbia River hydraulics can be inferred from other systems.

Results: Accumulations of LWD in the tidal forested wetland channels at the Kandoll reference site were dense. In contrast, upper Seal Slough within Kandoll Farm, an area of pastureland sparsely forested in places with Picea sitchensis and Alnus rubra, contained no LWD prior to the implementation of restoration actions for hydrological reconnection in 2005. Since culvert replacement at Kandoll in 2005, however, the developing channel network in the non-forested restoration area has exposed previously buried logs. In the tidal forested wetland channels, pools are located immediately upstream of each $\log$ jam or beaver dam. The shallower area or "tail-out" of each pool is usually located upstream of the pool (downstream of the next log jam or beaver dam). 
This suggests that the incoming flood tide, in plunging over the log jams and beaver dams once the water-level exceeds their elevation, plays a larger role in structuring channels longitudinally than does the ebb tide. We conclude that the morphology of forested tidal channels of a tributary to the Columbia River estuary may be viewed as a special case of the forced step-pool class, which has been defined and documented in high-gradient forest systems with unidirectional flow, although it must be cautioned that results of our surveys be interpreted in light of the regulated condition of the Columbia River and the short timeframe of evaluation.

\section{Chapter 4 - Early Morphological Change}

Objective: Document cross-sectional dimensions of tidal channels in the Columbia River estuary immediately before and after tidal reconnections.

Need: Surveys documenting equilibrium morphologies or the effects of various hydrologic restoration measures (dike breaching or tide gate or culvert replacement) on channel morphology have not been published for the Columbia River estuary.

Results: Before and after cross-sectional dimensions were measured at the restoration and reference sites. The reference channels show little change from before to after implementation of restoration actions in adjacent areas. At the restoration sites, tidal channel incision was greatest inside of the culvert, less inside of the tide gate, and even less inside the dike breach. However, these examples are not on exactly comparable channels, and the tide gate is in a different watershed than the culvert and dike breaches. Future reports will include channel geometry and carbon dating data.

\section{Chapter 5 - Vegetation}

Objective: Characterize the plant communities at tidal swamp and marsh habitats and restoration sites before and after tidal reconnection restoration actions.

Need: Swamps and marshes provide different habitat characteristics for salmon with respect to plant productivity, detritus, associated invertebrate prey, and refugia characteristics, such as coniferous versus deciduous dominants. Vegetation monitoring is critical to document effects from the restoration action.

Results: At Kandoll, species richness increased at the site from 27 species in 2005 (prerestoration) to 41 in 2006 (post-restoration). Six species had an average percent cover greater than $10 \%$, although many species ( $51 \%$ ) had an average percent cover of less than $1 \%$. We observed low similarities between the Kandoll restoration plots and the Kandoll reference site, reflecting major differences between these areas in 2006.

In the Kandoll reference site, a tidal, forested swamp, three tree species dominate with one standing out above the others. Picea sitchensis (Sitka spruce) has the highest density, frequency, and basal area of any tree on the site. Thuja plicata (Western redcedar) is next with four times lower relative dominance than the Sitka spruce. Although Western redcedar has lower frequency and density than the third tree, Alnus rubra (red alder), it makes up for this with greater basal area; red alder is the second most frequent and dense tree species in the forested wetland. 
The sample plots at Kandoll Farm included a broad range of species with varying degrees of wetland-adapted characteristics. Elevation differences were related to differences in the depth, frequency, and duration of hydrologic inundation, which in turn affected growing conditions for plant species. Additionally, the hydrologic regime changed considerably from 2005 to 2006 due to the increase in tidal flow as a result of the restoration action. In response to these changes plant species composition is shifting from more upland and wet pasture species to plants that are adapted to wetter conditions, although vegetation changes will take many years to mature.

At Vera, the assemblages at the restoration and reference sites were only $24.5 \%$ similar using a weighted similarity coefficient in 2005. This indicates that there is also a major difference between the Vera restoration and reference sites, both in species composition and in species abundances. The permutational multivariate analysis of variance showed that the treatment (site) and covariable (elevation) both had significant effects on herbaceous species composition (in all cases, $\mathrm{p}=0.0002$ ).

\section{Chapter 6 - Spruce Swamps as Salmon Habitat}

Objective: Measure temperature and water velocity and determine prey resources for juvenile salmonids within tidal forested spruce swamps in the Gray's River watershed in southwestern Washington.

Need: Little attention has been given to tidal forested wetlands as salmon habitat throughout the Pacific Northwest, though in the past, it is likely that salmon (Oncorhynchus sp.) used forested wetlands as part of the matrix of available habitats in the estuary. The characteristics of these habitats with respect to salmonid habitat parameters, such as velocity, temperature, and general suitability for salmonid rearing remain largely unreported.

Results: A total of 9 Chinook, 1 chum, and 15 coho salmon were collected and their stomach contents evaluated over the course of three sampling days (4/10,5/23, and 6/1) in 2006. At Kandoll restored and reference sites, Chinook salmon were eating Chironomidae. At Seal Slough, two of the Chinook salmon were eating Corophium. Chum and coho diets included Chiromonidae, Heteroptera, and other insects. Data remain to be analyzed for this chapter.

\section{Chapter 7 - Fish Presence and Community Structure}

Objective: Describe salmonid presence and fish community structure in two restoration sites undergoing tidal reconnection.

Need: Wetland habitats are important for juvenile salmon during ocean-, reservoir-, and streamtype migration life histories, because they provide prey resources and protection from predation. Primary goals for the restoration of wetland habitats in the CRE are to increase opportunity, connectivity, and capacity functions for juvenile salmonids.

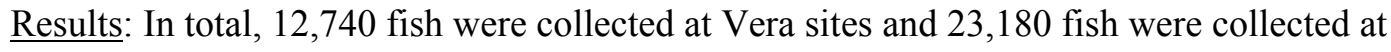
Kandoll sites. These totals include all sampling sites and both pre- and post-restoration conditions (2005 and 2006). Species composition was dominated by threespine stickleback. The data to date indicate that the Grays River system supports three species of migrating juvenile salmon: Oncorhynchus tshawytscha, O. keta, and O. kisutch. Salmon presence was species specific, but extended from March (or earlier) through June. At the Kandoll restoration site, we captured 6 salmon 
before tide gate removal, but 276 post-removal. All three salmon species utilized the habitat after tidal reconnection. In contrast, fish community structure and salmon presence at the Vera Slough tide gate replacement exhibited a more modest change between pre- and post-tide gate replacement ( 5 pre and 6 post). We captured few salmon either year, which we suspect is because the site lies off of the main migration route from the Youngs Bay system. However, a few salmon were found inside the tide gate post-replacement, so salmon opportunity appears to be increased, albeit modestly. Future sampling will allow us to evaluate benefits to salmon of the improved physical/biological conditions.

\section{Chapter 8 - Flux}

Objective: Determine the fluxes of nutrients and organic matter before and after tidal reconnections in the Columbia River estuary.

Need: It is generally thought that restoration of sources of macrodetritus and the processing of nutrients, trapping of sediments, and export of invertebrate fish prey can be achieved through restoration of tidal exchange and subsequent re-development of productive tidal wetland systems. As yet this outcome has not been tested in the CRE, and there are few studies throughout the world that focus on exchange from restored tidal wetland systems.

Results: We measured the instantaneous concentration of material, horizontal velocity, and crosssectional area of the mouths of tidal sloughs draining wetland restoration sites. Overall, concentrations of dissolved nutrients tended to be significantly higher than values reported at another Pacific Northwest estuary (Puget Sound, as reported in Thom 1989 and Thom and Albright 1990). In comparing our two restoration sites, Vera sites (both the reference and restoration sites) have generally had higher concentrations than the Kandoll sites.

\section{Chapter 9 - Summary and Management Implications}

The report concludes with a summary of the findings and a discussion of management implications. The results of this study have implications for the USACE and resource managers in the Columbia River estuary, as well as estuaries in the Pacific Northwest and nationally. With substantial work already underway to restore aquatic habitats in the CRE to help recover salmon populations, detecting the cumulative effects of multiple restoration projects on the CRE ecosystem is a critical problem. Restoration projects are typically expensive, and the return on investment in terms of benefits to the ecosystem often is not well documented or understood. In systems where restoration is conducted at a variety of sites, however, these projects may add up to produce a systemwide cumulative benefit. Assessing cumulative effects is critical to understanding whether there has been a net improvement in the ecosystem from restoration actions or whether actions are only effective in a site-specific manner. The problem lies primarily in how to document this effect, especially in large and complex ecosystems like the CRE. This study is undertaking a systematic approach to develop a cumulative effects assessment methodology for multiple restoration projects in the Columbia River estuary. The key management implication from this study will be the capability to assess whether CRE habitat restoration is having a measurable, cumulative effect on the CRE ecosystem and, ultimately, contributing to the recovery of listed salmonids in the Columbia River basin. 


\section{Acknowledgments}

The editor and authors of the chapters in this report gratefully acknowledge contributions to this project by:

- Scott McEwen of the Lower Columbia River Estuary Partnership

- Ian Sinks of the Columbia Land Trust

- John Skalski and Lia Stamatiou of the University of Washington

- Shon Zimmerman, James Cotton, Dick Ecker, and Jan Slater of Pacific Northwest National Laboratory

- Pete Heltzel and Harry Rectenwald of CREST. 


\section{Abbreviations and Acronyms}

AGOM above ground organic matter

BGOM below ground organic matter

cfs cubic feet per second

CLT Columbia Land Trust

CPUE catch per unit effort

CRE Columbia River Estuary (rkm 0-235)

CREDDP Columbia River Estuary Data

Development Program

CREST Columbia River Estuary Study

Taskforce

CTD Instrument package including sensors to measure conductivity, temperature, and depth

DO dissolved oxygen

EAB Environmental Advisory Board

EPA U.S. Environmental Protection Agency

ESA Endangered Species Act

FCRPS Federal Columbia River Power System

GIS geographic information system

GPS global positioning system

LCREP Lower Columbia River Estuary

Partnership

LWD large woody debris

MBF million board feet

MS-222 tricaine methane sulfonate

$\mathbf{M}^{3} / \mathbf{s} \quad$ million cubic feet per second

NGS National Geodetic Survey

NMS non-metric multi-dimensional acaling

NOAA National Oceanic and Atmospheric Administration
NOAA Fisheries - NOAA National Marine Fisheries Service (formerly NMFS)

NPRC Northwest Power and Conservation Council

NRC National Research Council

OPUS Online Positioning User Service

PNNL Pacific Northwest National Laboratory

psu practical salinity units

rkm river kilometer

RTK real-time kinematic

SSE Seal Slough East

SSW Seal Slough West

sd standard deviation

USACE U.S. Army Corps of Engineers

USGS U.S. Geological Survey

WRDA Water Resources Development Act 


\section{Contents}

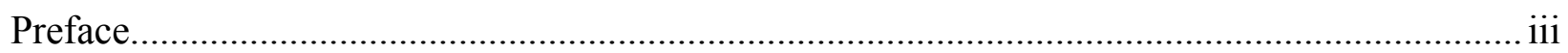

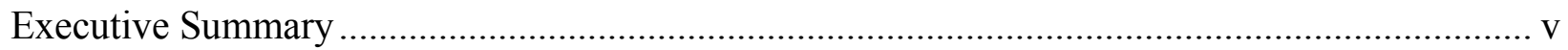

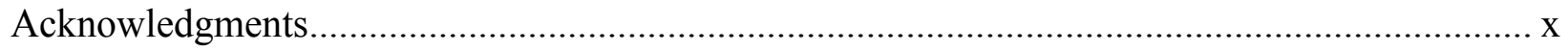

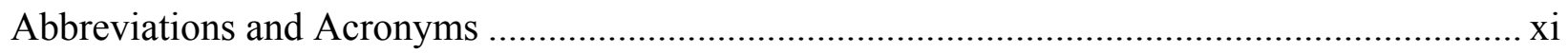

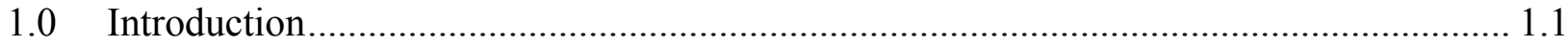

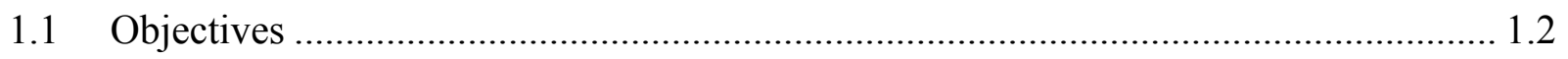

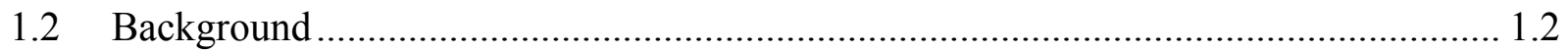

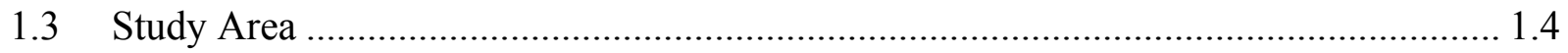

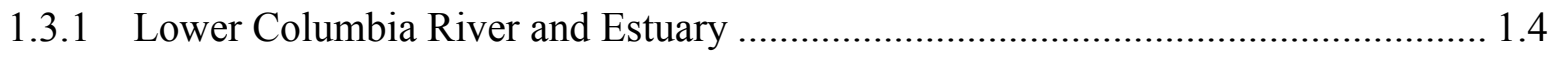

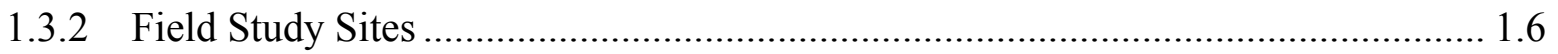

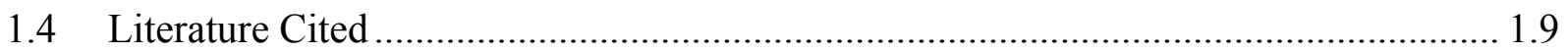

2.0 Hydrological Changes to Wetland Restoration Sites after Tidal Reconnection in the

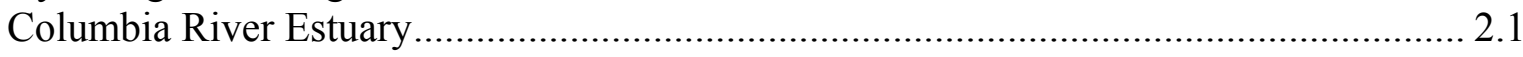

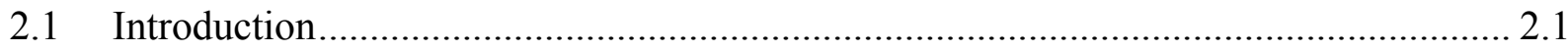

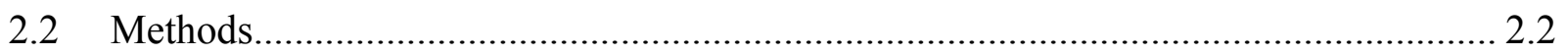

2.2.1 Grays River System/Kandoll Farm Restoration Site ....................................... 2.2

2.2.2 Vera Slough System....................................................................................... 2.2

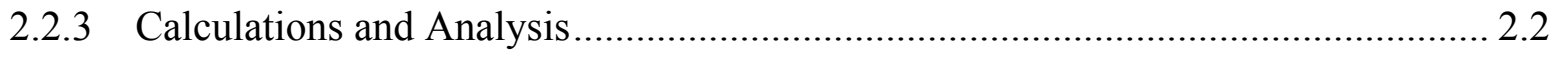

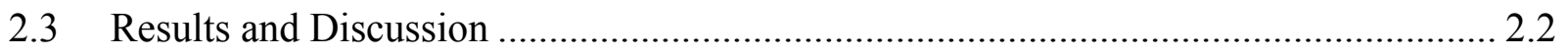

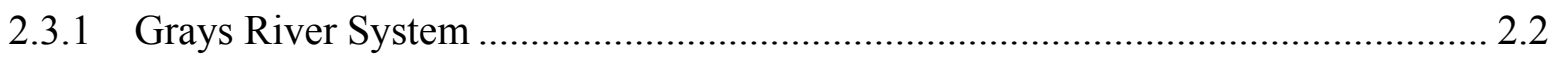

2.3.2 Vera Slough System................................................................................ 2.7

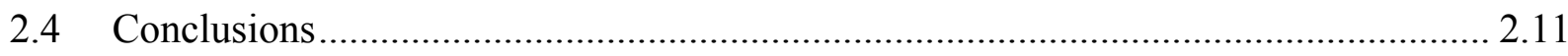

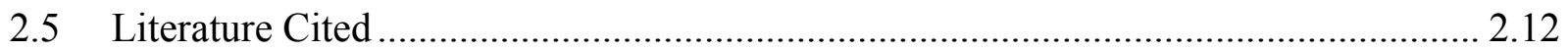

3.0 Longitudinal Channel Structure, Fallen Trees, and Restoration in Tidal Forested Wetlands of the Columbia River Estuary ................................................................ 3.1

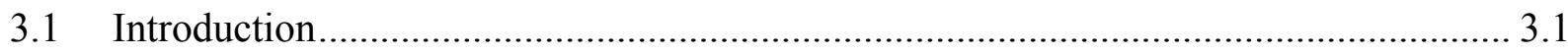

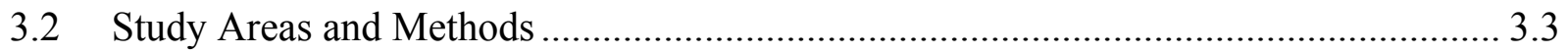

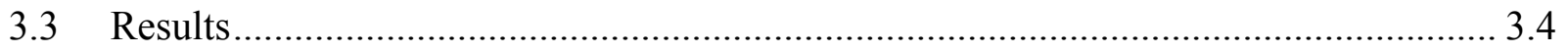

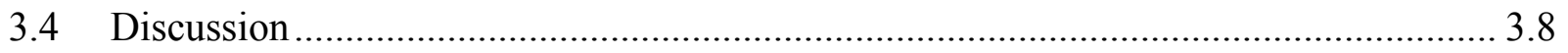

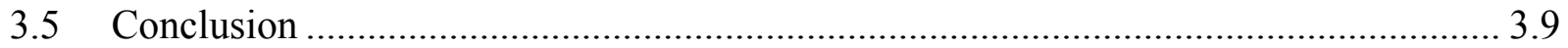

3.6 Literature Cited ............................................................................................... 3.10

4.0 Early Morphological Response to Dike Breaching and Culvert and Tide Gate Replacement in the Columbia River Estuary.............................................................. 4.1

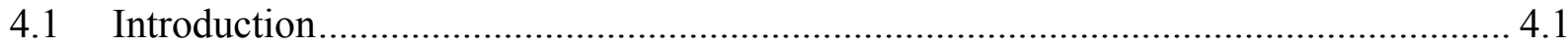

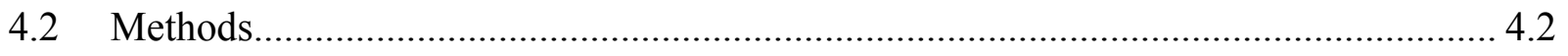

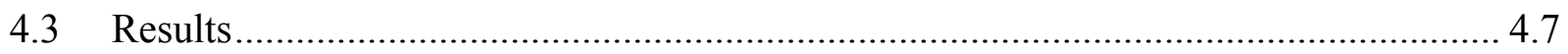

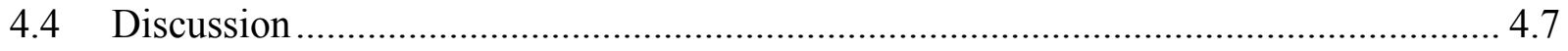




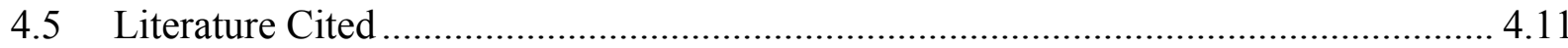

5.0 Vegetation Cover, Elevation, and Post-Restoration Change Analysis .............................. 5.1

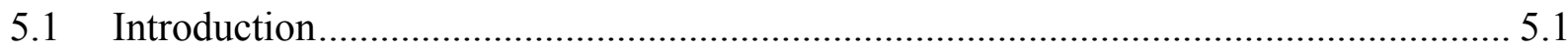

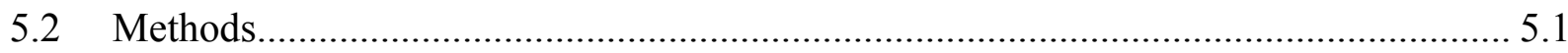

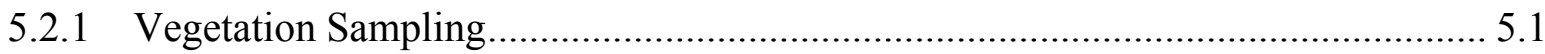

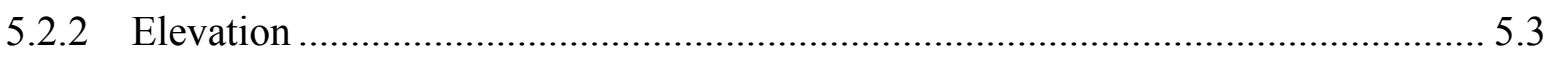

5.2.3 Vegetation Laboratory Analyses.................................................................... 5.3

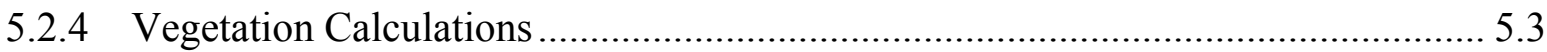

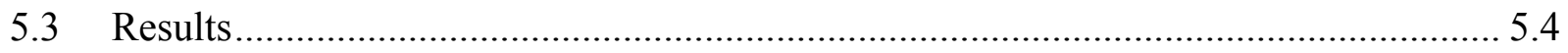

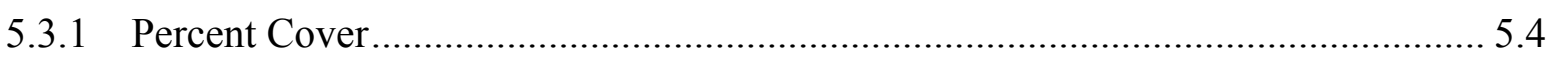

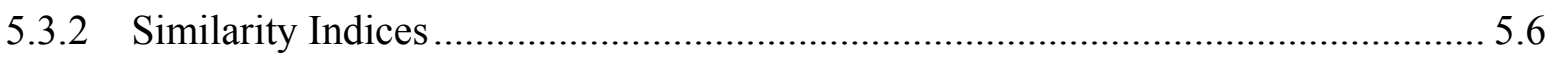

5.3.3 Permutational Multivariate Analysis (PERMANOVA) ………………................. 5.7

5.3.4 Nonmetric Multidimensional Scaling (NMS)..................................................... 5.7

5.3.5 Point-Intercept Transect (Kandoll Restoration) ..................................................... 5.7

5.3.6 Tree Morphometrics (Kandoll Reference)............................................................ 5.7

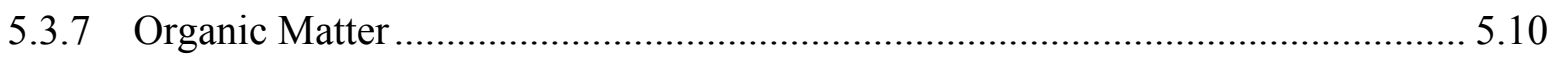

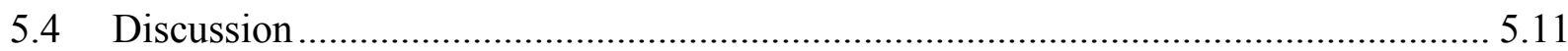

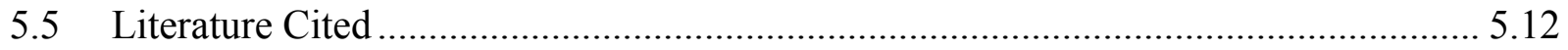

6.0 Selected Salmon Habitat Characteristics of Picea sitchensis-Dominated Tidal

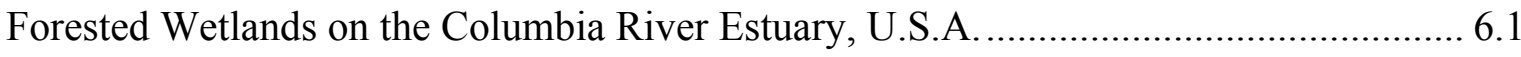

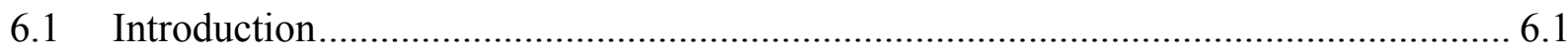

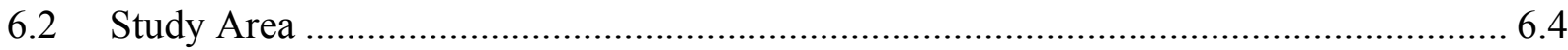

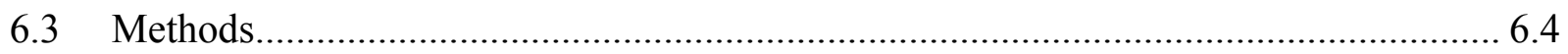

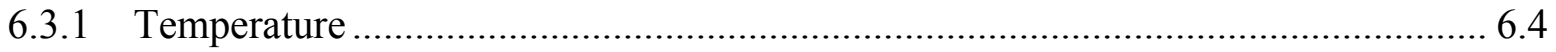

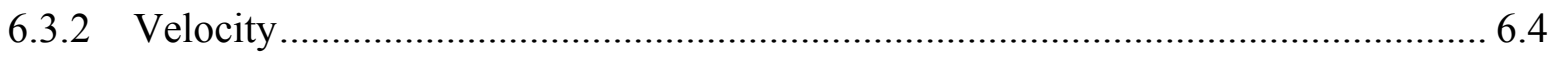

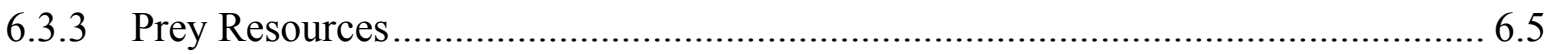

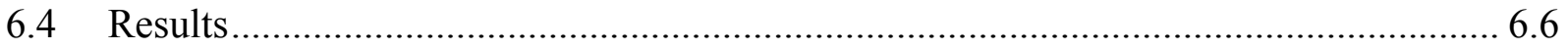

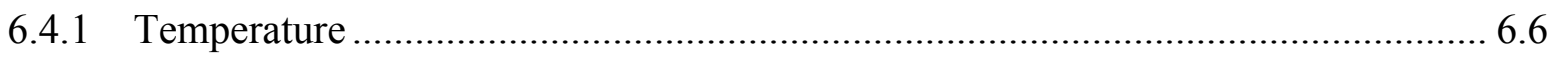

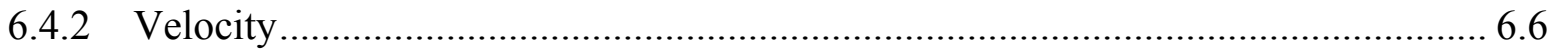

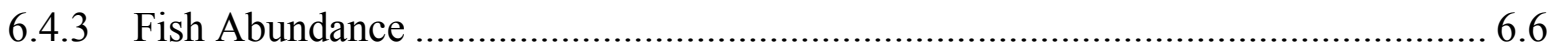

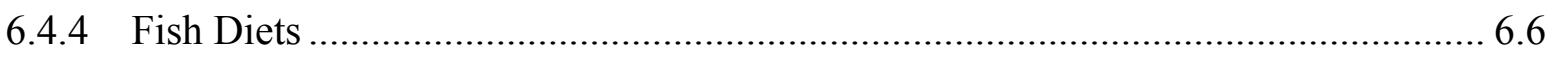

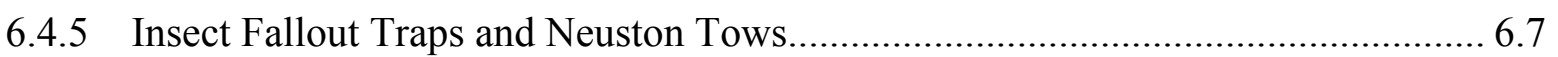

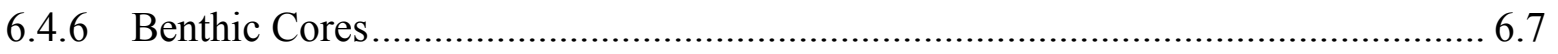

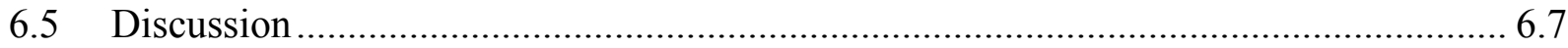

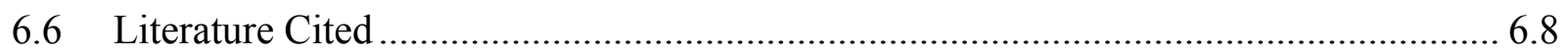

7.0 Monitoring Juvenile Salmon Use and Fish Community Structure in Restored

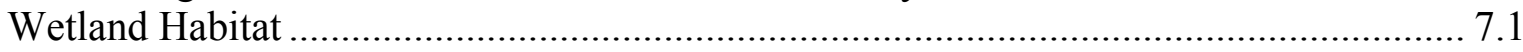

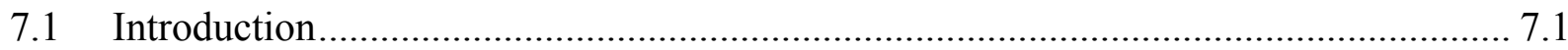

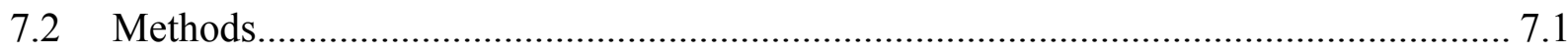

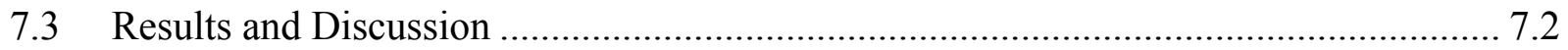


7.3.1 Species Composition................................................................................ 7.3

7.3.2 Salmon Presence/Absence and Size................................................................. 7.3

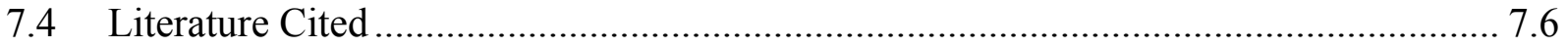

8.0 Material Fluxes through Restored Wetlands....................................................... 8.1

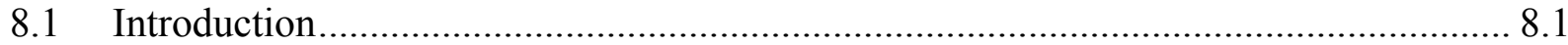

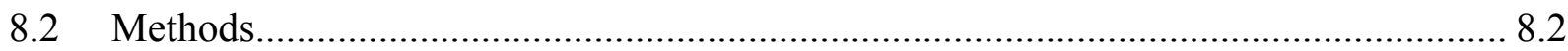

8.2.1 Discrete Sampling during a Tidal Cycle ........................................................ 8.2

8.2.2 Neuston Net Samples............................................................................... 8.2

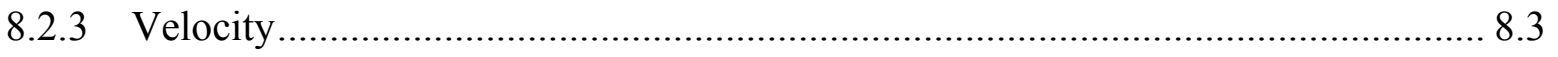

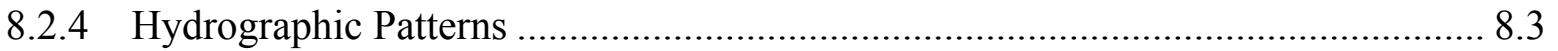

8.2.5 Calculations of Flux and Net Transport........................................................ 8.3

8.2.6 Horizontal Transects ................................................................................. 8.3

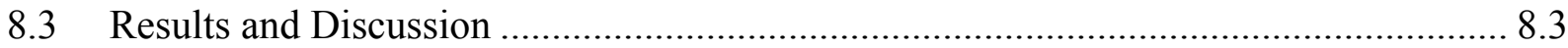

8.3.1 Discrete Sampling during Tidal Cycle.......................................................... 8.3

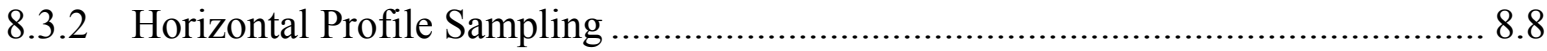

8.4 Literature Cited ..................................................................................... 8.10

9.0 Summary and Management Implications ....................................................... 9.1

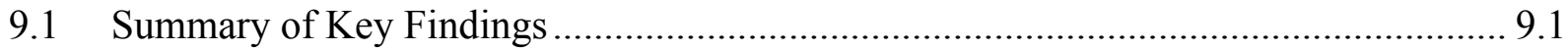

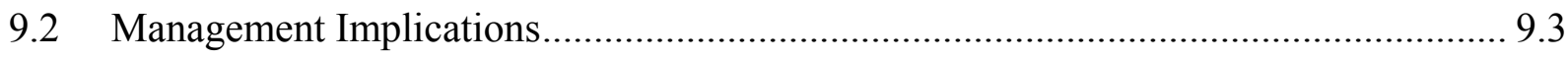

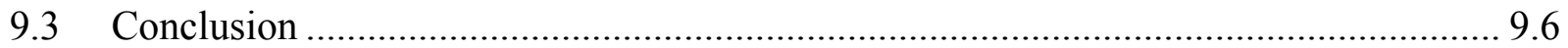

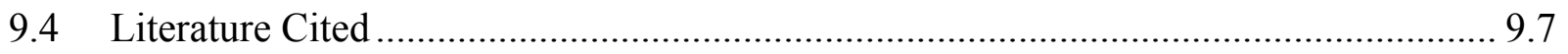




\section{Figures}

Figure 1.1. The Columbia River Estuary from Bonneville Dam to the Pacific Ocean.............. 1.1

Figure 1.2. Vera Slough Tide gate Replacement Site (left polygon) and Reference Site Separated by the Astoria Regional Airport on Youngs Bay, Oregon ..................... 1.7

Figure 1.3. Tide gates at Vera Slough Before and After Replacement................................. 1.8

Figure 1.4. Kandoll Farm Dike Breach and Culvert Replacement Site and Reference Site, between Seal Slough and the Grays River in Washington ................................ 1.8

Figure 1.5. Tide gate at Kandoll Farm before (left) and Culverts after (right) Replacement ..... 1.9

Figure 3.1. Columbia Land Trust Protection and Restoration Properties in the Vicinity of the Deep River and Grays River on Grays Bay of the Columbia River in Washington State.

Figure 3.2. Wood in Seal Slough side Channel.

Figure 3.3. Longitudinal Surveys of Forested Wetland Channels in Seal Slough, Secret River, and Crooked Creek.

Figure 3.4. Logs Exposed By Channel Network Development Following Dike Breaching at Two Grays River Restoration Sites.

Figure 4.1. Survey Sites on the Columbia River Estuary .................................................. 4.3

Figure 4.2a. Sampling Schematic for Kandoll....

Figure 4.4. Tide Gate with 48-in Culvert on Seal Slough at Kandoll Road and Tide Gates at Vera Slough.

Figure 4.5. Channel Cross Sections before and after (a) Tide Gate Replacement

(b) Culvert Replacement and (c) Dike Breaching.

Figure 4.6. Cross Sections at Reference Channels before and after Nearby Restoration and Enhancement Actions

Figure 4.7. Three Dike Breaches on the Grays River: 2005 4.10

Figure 5.1. Vegetation Sampling Grid at Seal Slough in the Kandoll Farm Restoration Site.... 5.2

Figure 5.2. Vegetation Plot Design for Forested Wetlands .....

Figure 5.3. Non-Metric Multidimensional Scaling of 2005 and 2006 Species Composition Data.

Figure 5.4. Amounts of Above-Ground Biomass, Live and Dead, Measured at Each Site...... 5.10

Figure 5.5. Comparison of Live to Dead Biomass at each Site.

Figure 5.6. Amounts of Below-Ground Organic Matter Measured at each Site 5.11

Figure 6.1. Juvenile Chinook Salmon Diets at Restoration and Reference Sites on Seven Sampling Days April-June, 2006. 
Figure 6.2. Juvenile Chum and Coho Salmon Diets at Restoration and Reference Sites on Seven Sampling Days April-June, 2006.

Figure 7.1. Salmonid Catch and Mean Size (+ s.d.) at Kandoll Farm Restoration and Reference Sites in 2006

Figure 8.1. Nitrogen:Phosphorus Ratios for the Kandoll Sites in Three Sampling Periods in 2006.

Figure 8.2. Nitrogen:Phosphorus ratios for the Vera Sites in Three Sampling Periods in 2006.

Figure 8.3. Transect of the Seal Slough/Grays River System.

Figure 8.4. Transect of the Vera Slough System. 8.10 


\section{Tables}

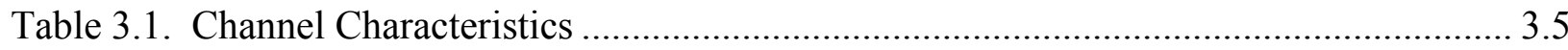

Table 5.1. Average Percent Cover of the Dominant Plant Species at the Kandoll Restoration Site Sampling Locations (SSE and SSW) ............................................ 5.4

Table 5.2. Plant Species Average Percent Cover at Kandoll Restoration and Kandoll Reference (KR) in 2005 and 2006

Table 5.3. Weighted Similarity Index for 2005 and 2006 between Kandoll Restored and Kandoll Reference (KR) and between Vera Restored (VS) and Vera Reference (VR).

Table 5.4. Species Composition of Fields between Channels, before and after Dike Breaching.

Table 5.5. Description of Reference Site Based on Individual Tree Data from Fixed-Area Plots

Table 6.1. Velocities in a Tidal Forested Wetland Channel. 6.6

Table 7.1. Catch, Number of Individuals (N), Number of Species (S) and Shannon-Wiener Diversity Index ( $\left.\mathrm{H}^{\prime}\right)$.

Table 7.2. Catch, Number of Individuals (N), Number of Species (S) and Shannon-Wiener Diversity Index

Table 8.1. Average Concentrations (SD) of Total Dissolved Carbon for Kandoll and Vera Sites in Three Sampling Periods in 2006.

Table 8.2. Average Concentrations (SD) of Phosphate for Kandoll and Vera Sites in Three Sampling Periods in 2006

Table 8.3. Average Concentrations (SD) of the Silicate $\left(\mathrm{SiO}_{4}\right)$ for Kandoll and Vera Sites in Three Sampling Periods in 2006

Table 8.4. Average Concentrations (SD) of the Nitrite for Kandoll and Vera Sites in Three Sampling Periods in 2006

Table 8.5. Average Concentrations (SD) of the Nitrate for Kandoll and Vera Sites in Three Sampling Periods in 2006

Table 8.6. Average Concentrations (SD) of the Ammonia for Kandoll and Vera Sites in Three Sampling Periods in 2006 


\subsection{Introduction}

This report is the third annual report of a six-year project to evaluate the cumulative effects of habitat restoration actions in the 235-km Columbia River estuary (CRE; Figure 1.1). The project is being conducted for the U.S. Army Corps of Engineers (USACE) by the Marine Sciences Laboratory of the Pacific Northwest National Laboratory, the Pt. Adams Biological Field Station of the National Marine Fisheries Service (NOAA Fisheries), and the Columbia River Estuary Study Taskforce (CREST).

Because of the size and complexity of the estuarine landscape (Small 1990) and the meta-populations of salmonids in the Columbia River basin (Bottom et al. 2005), measurement of the cumulative effects of ecological restoration projects in the Columbia River estuary is a formidable task. Despite the challenges presented by this system, developing and implementing appropriate indicators and methods to measure cumulative effects will enable estuary managers to track the overall effectiveness of investments in estuarine restoration projects. This project is intended to both develop methods for quantifying the effects of restoration projects and lay a foundation for future effectiveness ${ }^{\mathrm{a}}$ evaluation and validation ${ }^{\mathrm{b}}$ of cumulative restoration activities in the CRE.

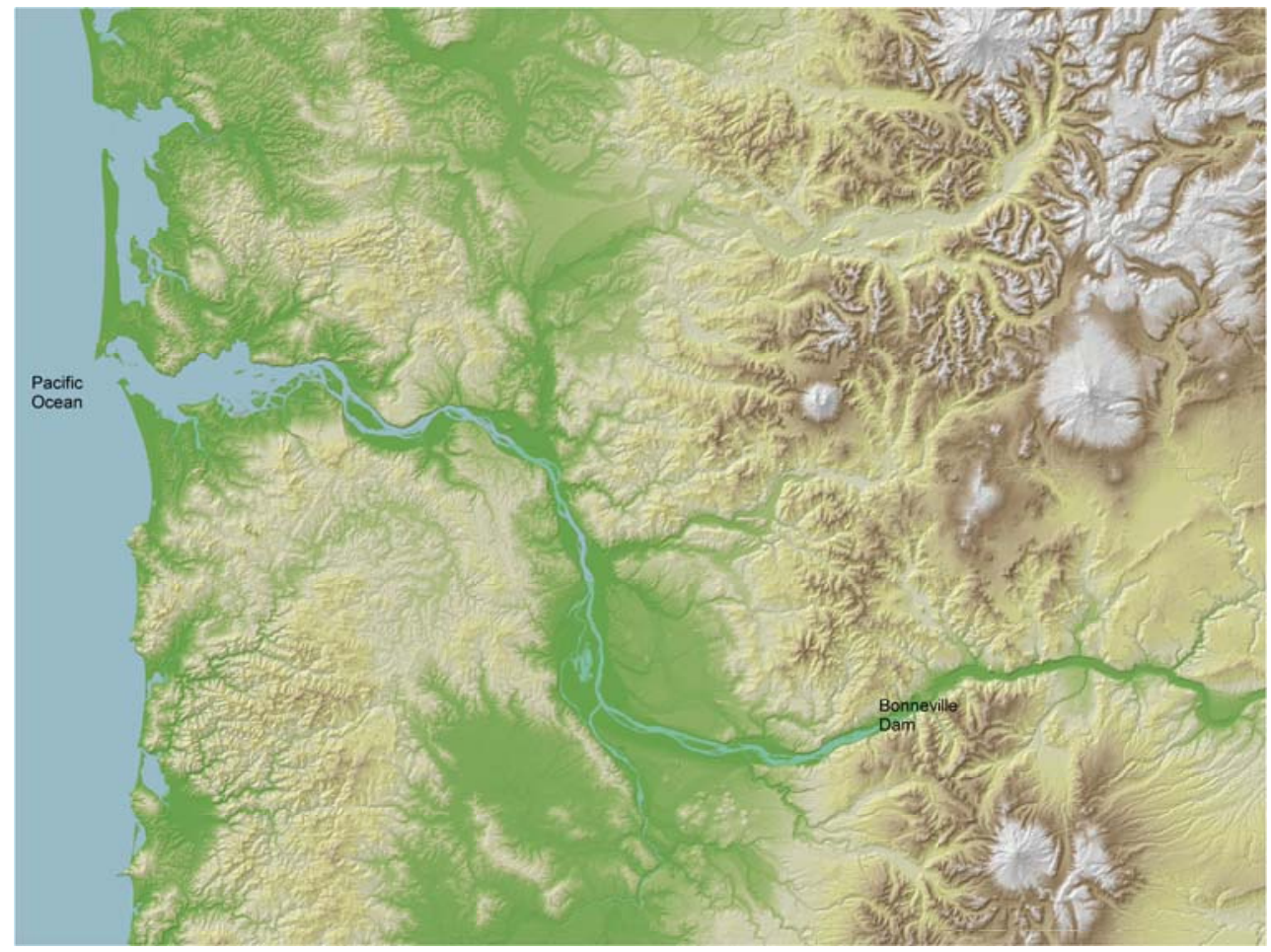

Figure 1.1. The Columbia River Estuary from Bonneville Dam to the Pacific Ocean

${ }^{\text {a }}$ Effectiveness Monitoring = Activities designed and undertaken to assess how well a particular restoration project performs relative to reference site(s).

${ }^{\mathrm{b}}$ Validation Monitoring = Monitoring directed at testing cause-and-effect relationships between management activities and monitoring indicators (Busch and Trexler 2003). 
The primary goal of this multi-year study is to develop a framework and methodology to measure and evaluate the cumulative effects of multiple habitat restoration actions in the CRE, funded and implemented by numerous entities, aimed in part at increasing population levels of Columbia River basin salmonids listed under the Endangered Species Act (ESA). This monitoring framework and methodology will ensure comparable data sets across multiple restoration monitoring efforts estuary-wide. A first step in this process was the development of the monitoring protocols manual (Roegner et al. 2006). The management implications of this research are two-fold in that it is expected to provide techniques allowing decision-makers to 1) evaluate the ecological performance of the collective habitat restoration effort in the CRE and its effects on listed salmonids, and 2) apply knowledge from comparable datasets to prioritize future habitat restoration projects. The cumulative effects methodology developed in this study will have application nationwide because such methodologies do not yet exist in ecological science.

\subsection{Objectives}

The overall objectives of the 2006 study period were to continue to develop techniques to assess cumulative effects and to initiate development of an adaptive management system to support the USACE's habitat restoration monitoring efforts in the CRE. The adaptive management effort will be reported separately because it is still in preparation. Field work in 2006, coupled with previous field data, is tied to cumulative effects research because the field work tested and refined monitoring protocols, compared core monitored indicators between restored and reference sites, and reduced uncertainty in ecological relationships. Thus, to support cumulative effects methods development, 2006 field studies had the following specific objectives (report chapter numbers are in parentheses):

- Monitor hydrological variation at two study locations before and after tidal reconnection (Ch. 2)

- Examine the effects of large woody debris on tidal forested wetland channel morphology (Ch. 3)

- Document cross-sectional dimensions of tidal channels in the Columbia River estuary immediately before and after tidal reconnections through a suite of restoration actions, including dike breaching and tide gate and culvert replacement (Ch. 4)

- Characterize the plant communities at tidal swamp and marsh habitats before and after tidal reconnection restoration actions. (Ch. 5)

- Measure temperature and water velocity and determine prey resources for juvenile salmonids within tidal forested spruce swamps in the Gray's River watershed in southwestern Washington, USA (Ch. 6)

- Describe salmonid presence and fish community structure in two restoration sites undergoing tidal reconnection (Ch. 7)

- Determine the flux of nutrients and organic matter before and after tidal reconnections at dikes in the Columbia River estuary (Ch. 8)

\subsection{Background}

The U.S. Army Corps of Engineers is working with federal, state, and local agencies and nongovernmental organizations to restore estuarine habitats in the Columbia River estuary. Most of these 
restoration activities involve the hydrologic reconnection of portions of the estuarine system currently isolated from the flow of water and the movement of salmonids by dikes, tide gates, culverts, and other barriers. The USACE's vision is to improve CRE functionality through habitat restoration efforts using an ecosystem-based approach and, thus, to aid in rebuilding ESA-listed salmonid stocks of the Columbia River basin (Johnson et al. 2003).

The restoration of damaged ecosystems is not without uncertainty. Relevant uncertainties can be grouped into two types: 1) uncertainty regarding responses of ecosystems to restorative actions, and 2) uncertainty associated with random, uncontrollable events affecting restoration outcomes (Diefenderfer et al. 2005b). It is therefore difficult to accurately predict when and whether an ecosystem will meet restoration goals, even using methods developed to assess the trajectory of development after restoration actions (Kentula et al. 1992; Thom 1997). Because of this, and the fact that a restoration program of this size is expensive, information that helps to improve predictability is critically needed.

A comprehensive literature review found no published formal methods to quantify the cumulative effects of multiple restoration projects across one estuary (Diefenderfer et al. 2005a). The review confirmed that this study is unique in three ways: 1) others have monitored the cumulative effects of estuarine degradation but not restoration, 2) others have monitored estuarine restoration at the project level, but not cumulatively across multiple projects, and 3) others have evaluated cumulative effects in forests and wetlands, but not for estuaries. This effort appears to be the first attempt to quantify whether the restoration of multiple estuarine sites has a measurable cumulative effect on the health and functionality of the estuarine ecosystem (Diefenderfer et al. 2005a).

The application of a consistent protocol throughout a region appears to be an important step toward achieving a cumulative assessment of restoration effects (e.g., Neckles et al. 2002). Regional performance curves can be developed when a protocol is applied consistently across many sites in order to assess restoration efforts. An example of such a protocol is the Estuarine Habitat Assessment Protocol, which is in wide use in Puget Sound (Simenstad et al. 1990). The Florida Everglades and Louisiana coastal wetlands studies provide examples of statistical sampling designs and decision-support modeling systems covering large geographic scales (National Research Council [NRC] 2003; Steyer et al. 2003). Recently, information on the CRE has become available through a draft geographic information systems (GIS) database developed to aid in the prioritization of projects for restoration (Evans et al. 2006). This database can be utilized for comparing the configuration and condition of proposed restoration sites within watershed-level (Hydrologic Unit Code 6) hydrologic units throughout the estuary.

In the first annual report (Diefenderfer et al. 2005a), the following definitions of cumulative impacts and cumulative effects from Leibowitz et al. (1992) were adopted (paraphrased):

Cumulative restoration impacts are the net sum of all changes in selected habitat metrics of all restoration projects occurring over time and space, including those changes in the foreseeable future of the development of these projects.

Cumulative restoration effects are the net change in ecosystem-wide metrics and ecosystem state resulting from cumulative restoration impacts.

The concept of the "net ecosystem improvement" of previously degraded sites was also introduced, which is defined as "following development [and associated restoration], there is an increase in the size and 
natural functions of an ecosystem or natural components of the ecosystem" (Thom et al. 2005). Given the present degraded condition of many coastal sites, combined with pressure for development, it can be argued that net ecosystem improvement is critical to the sustainability of coastal systems as defined by the World Commission on Environment and Development (1987). In summary, during 2004, Diefenderfer et al. (2005a) performed a literature review of cumulative effects research methods, synthesized potential approaches to estuarine cumulative effects research, analyzed Columbia River estuary habitat use by juvenile salmonids, enhanced the Columbia River estuary conceptual model, and developed core monitoring indicators and associated protocols for the Columbia River estuary.

During 2005, Diefenderfer et al. (2006) tested the monitoring protocols and sampling methods, and continued development of a sampling design supporting an estuary-wide cumulative effects analysis and adaptive management framework. The assessment methodology was applied in 2005 before and after restoration actions at two restoration sites and two reference sites in the Columbia River Estuary, Vera Slough and Kandoll Farm, as paired site studies of marsh and swamp habitats. Post-restoration research was continued in 2006 to support the ongoing development of a technical approach to assess the cumulative effects of multiple aquatic habitat restoration projects in the CRE.

In this multi-year study, we are developing a weight of evidence approach for cumulative effects analysis. The field research in 2005 and 2006 developed three sources of data for cumulative effects analysis using a weight-of-evidence approach: in-depth paired site studies (marsh and swamp), core indicators at all monitored restoration project and reference sites, and cumulative effects indicators. Core indicators include water surface elevation, temperature, vegetation cover, fish abundance, etc. Examples of cumulative effects indicators are nutrient and macrodetritus flux and connected channel edge length. Studies are paired on several levels: habitat type (tidal swamp versus marsh), trajectory (restoration versus reference site), action (tide gate versus culvert versus dike breach), and monitored indicator (multiple indicators measured simultaneously).

The objectives for the 2006 research listed in Section 1.1 that are the subject of this annual report pertain directly to the three lines of evidence for the cumulative effects analysis: statistical tests and hydraulic and geographic information systems modeling. This research is being used to resolve uncertainties in indicators of fundamental processes, develop predictive structure/function relationships, and create estimators for cumulative effects based on the concept of net ecosystem improvement. These data will be applied in future study years in an integrative effort involving a hydrodynamic model, an additive geographic information system and adaptive management framework, and statistical tests for cumulative effects using data from multiple restoration sites.

\subsection{Study Area}

\subsubsection{Lower Columbia River and Estuary}

The study area is an open system, defined in space by the extent of tidal influence on the Columbia River from Bonneville Dam to the mouth (Figure 1.1). A number of publications provide descriptive information about the estuary study area, including the Salmon at River's End report by Bottom et al. (2005), Fresh et al.'s (2004) Role of the Estuary in the Recovery of Columbia River Basin Salmon and Steelhead, and the Ecosystem-Based Approach to Habitat Restoration Projects report by Johnson et al. (2003). Important earlier compendiums include The Columbia River Estuary and Adjacent Ocean Waters 
by Pruter and Alverson (1972); "Columbia River Estuary" in Changes in Fluxes in Estuaries: Implications from Science to Management by Dyer and Orth (1994); and "Columbia River: Estuarine System" by Small (1990), which contains reviews of earlier work supported by the Columbia River Estuary Data Development Program (CREDDP) on physical and biological processes (CREDDP 1984a, 1984b). Another comprehensive environmental study of the lower Columbia River was the Bi-State Water Quality Study (TetraTech 1996; Fuhrer et al. 1996), completed as part of the process to include the Columbia River estuary in the U.S. Environmental Protection Agency (EPA)'s National Estuary Program. The brief study area description that follows draws from these major works and other literature to provide context for the CRE cumulative effects study.

The Columbia River, with a drainage basin area of $660,480 \mathrm{~km}^{2}$ (Simenstad et al. 1990), has the fourth highest average river discharge at the mouth and the sixth largest watershed in the United States (U.S. Geological Survey [USGS] 1990). The width of the Columbia River is less than $2 \mathrm{~km}$ some $84 \mathrm{rkm}$ from the Pacific Ocean, nearly $15 \mathrm{~km}$ wide at rkm 32, and approximately $3 \mathrm{~km}$ wide at the jetties at the river mouth (Neal 1972). The river bottom is below sea level at Bonneville Dam and the estuary contains scattered deep areas. Historically, unregulated flows were estimated to range from a minimum of 2,237 million cubic feet per second $\left(\mathrm{m}^{3} / \mathrm{s}\right)(79,000 \mathrm{cfs})$ in the fall to maximum flood flows of over $28,317 \mathrm{~m}^{3} / \mathrm{s}$ during spring freshets (Sherwood et al. 1990). Since the 1930s, however, the timing of the Columbia River's discharge has been progressively regulated due to construction and operation of 28 major dams and approximately 100 minor dams on the river's drainage; these dams reduce spring freshet flows and increase fall/winter flows. Hydrographic modeling estimated that the spring freshet (May-July) flow reduction attributable to flow regulation is $33.1 \%$, and the total reduction in freshet mean flow when climate and water withdrawal are included is 43\% of pre-1900 flows (Jay and Hickey 2001).

Despite alterations to river discharge patterns by the Federal Columbia River Power System (FCRPS) and other factors, the estuary is still river-dominated because of relatively high flow volumes. However, the semi-diurnal tidal range in the estuary is relatively large at $3.6 \mathrm{~m}$ and oceanic tides affect water levels throughout the entire lower reach to Bonneville Dam (rkm 235) (Neal 1972; Sherwood and Creager 1990). Maximum seawater intrusion during low river flow is variable but less than $37 \mathrm{~km}$ (Neal 1972).

The landscape context of the estuary may be described by its representative ecoregions, according to the EPA classification (Omernik and Gallant 1986): Coast Range, Puget Lowland, Willamette Valley, and Cascades. The classification on the Oregon side has been refined for the purpose of water quality management to include Coastal Mountains, Coastal Lowlands, Willamette Valley Plains, and Western Cascades (Clarke et al. 1991). The study area, broadly defined for the purposes of terrestrial ecology and plant communities, contains five physiographic provinces: the Southern Washington Cascades, Western Cascades, Puget Trough, Willamette Valley, and Coast Ranges (Franklin and Dyrness 1988).

Because the metropolitan areas of Vancouver, WA, and Portland, OR, as well as smaller cities such as Longview, WA, and Astoria, OR, span the Columbia River estuary, many pressures from urban development are currently present or have existed in the past. Modifications to riparian areas, tributaries, and the main stem of the river via activities associated with dredging, bridge construction, and port development have dramatically altered the characteristics of the river and estuary. The direct impacts of these physical alterations to juvenile salmon and other biota are largely unknown. Thus, the CRE study area is river-dominated and tidally influenced with highly variable and dynamic conditions. 


\subsubsection{Field Study Sites}

Field studies during 2005 and 2006 were conducted within two general regions in the estuary: tidal freshwater and tidal brackish water. Plant communities representing the salmon habitat types that were historically most common in each of these regions and most likely to be restored today were chosen for field studies: tidal freshwater swamps in the tidal freshwater region and tidal brackish marsh in the brackish water region. Large areas of swamps and marshes have been lost in the estuary and due to the differences between these systems, particularly those associated with plant dominants (e.g., tree species in the swamps versus herbaceous or shrubby plants in marshes), they can be expected to have different responses to restoration treatments. Swamps and marshes also provide different habitat characteristics for salmon, with respect to plant productivity (detritus and associated invertebrate prey) and refugia characteristics (coniferous versus deciduous dominants).

Within each of the salmon habitat types, studies were conducted in one natural reference site and one restoration site. Data from the reference sites were used to help interpret data collected from the restoration sites as per standard procedures for post-restoration monitoring recommended in our first annual report (Diefenderfer et al. 2005a). Site selection was based in part on the timing of planned restoration, because the monitoring protocols recommend collecting data before and after implementation of restoration measures. In order to maintain the cumulative effects study schedule, it was imperative that field studies begin in 2005 on sites where it was possible to collect baseline data and likely that restoration actions would be implemented by the end of the year. Another critical factor in site selection was the type of restoration action. The main objective was to monitor as many typical hydrological reconnection actions as possible, such as dike breaches and tide gate replacements. Reference sites corresponding to each site were identified on the basis of a qualitative assessment of geographic proximity, ecological similarity, hydrological similarity, and likelihood that the plant associations at the reference areas would be representative of the endpoint(s) of restoration trajectories at the restored sites. The following sites were the object of field work in 2005 and 2006.

Vera Slough on Youngs Bay in Oregon, with low salinities, was selected to represent the brackish marsh restoration (Figure 1.2). The property, which is near Warrenton, Oregon, is owned by the Port of Astoria and restoration is being planned and managed by the Columbia River Estuary Study Taskforce (CREST). Following baseline data collection in the spring and summer of 2005, in October of 2005 the two top-hinged tide gates restricting flow into the slough were replaced (Figure 1.3) by two 5 -ft $\mathrm{x} 5$-ft square tide gates of different models (one side-hinge and one top-hinge, both with lighter lids and fishpassable doors). These models are currently experimental allowing managers to manipulate the amount of tidal intrusion onto the site. Several manipulations occurred on both gates during the field season to increase the level of tidal influence, thereby affecting the tidal flood elevations. Objectives of the project included the following: increase fish access to backwater slough habitat; lower temperatures; improve dissolved oxygen (DO) conditions; increase salinity intrusion; develop estuarine plant communities; and increase food-web productivity. 


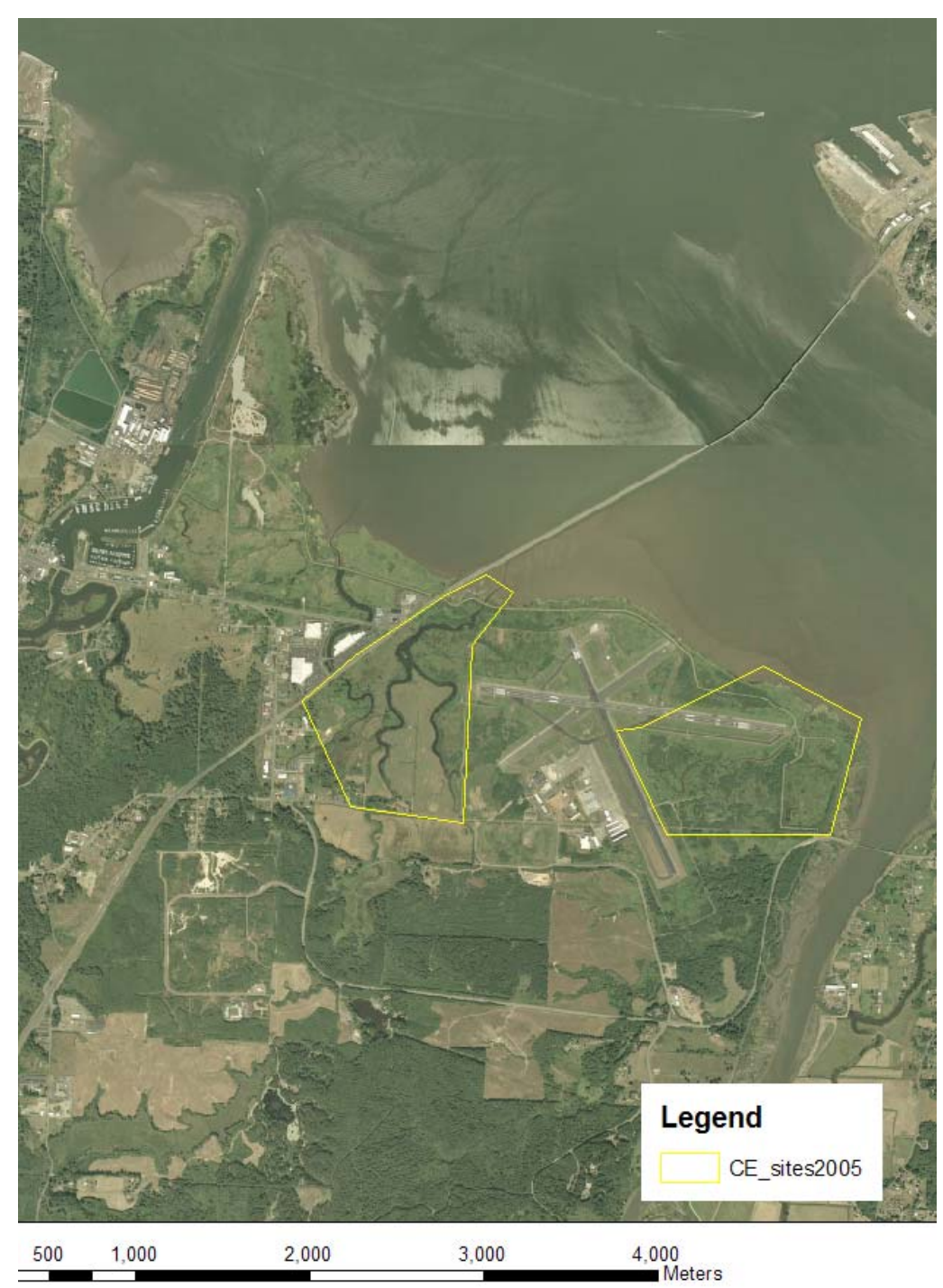

Figure 1.2. Vera Slough Tide Gate Replacement Site (left polygon) and Reference Site (right polygon) Separated by the Astoria Regional Airport on Youngs Bay, Oregon

Kandoll Farm on the Grays River in Washington was selected to represent the tidal freshwater swamp restoration (Figure 1.4). The property is owned by the Columbia Land Trust (CLT) and restoration was being planned and managed by CLT with engineering by Ducks Unlimited. Following baseline data collection in the spring and summer of 2005, the two small tide gates restricting flow into the slough were replaced with 13-ft-diameter culverts (Figure 1.5), and the dike along the Grays River was breached in three places in September 2005. Objectives of the project included permanently protecting and restoring 163 acres of diked tideland and approximately 1 mile of shoreline in order to increase access to swamp habitat, lower water temperatures, raise dissolved oxygen levels, and increase food web productivity. Kandoll Farm is part of the Grays River complex, which includes 927 acres of permanently protected habitat lands - spruce forested wetlands (swamps), floodplain channels, and emergent/scrub-shrub wetlands. The CLT has restored salmonid access to 400 acres of formerly diked floodplain habitat and enhanced 116 acres within the Seal Slough-Grays River parcel (reference site) through the removal of logging road crossings of tidal channels (Ian Sinks, pers. comm.). 


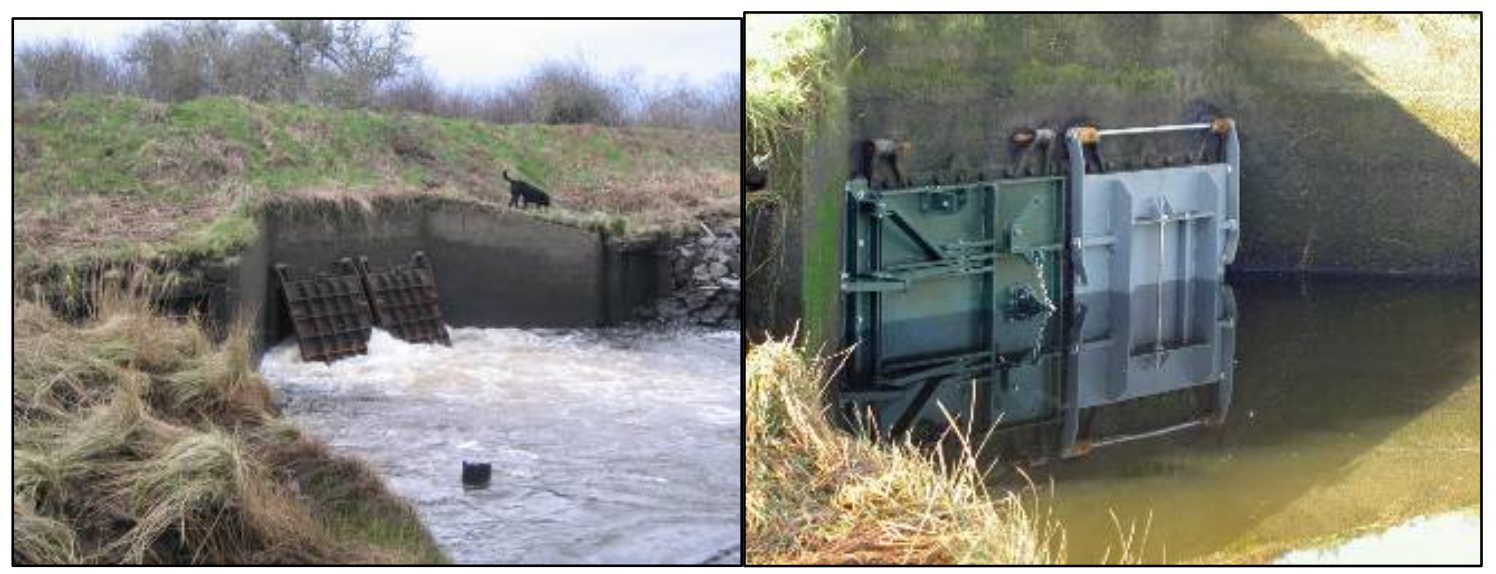

Figure 1.3. Tide Gates at Vera Slough Before (left; open) and After (right; closed) Replacement (photos courtesy of CREST)

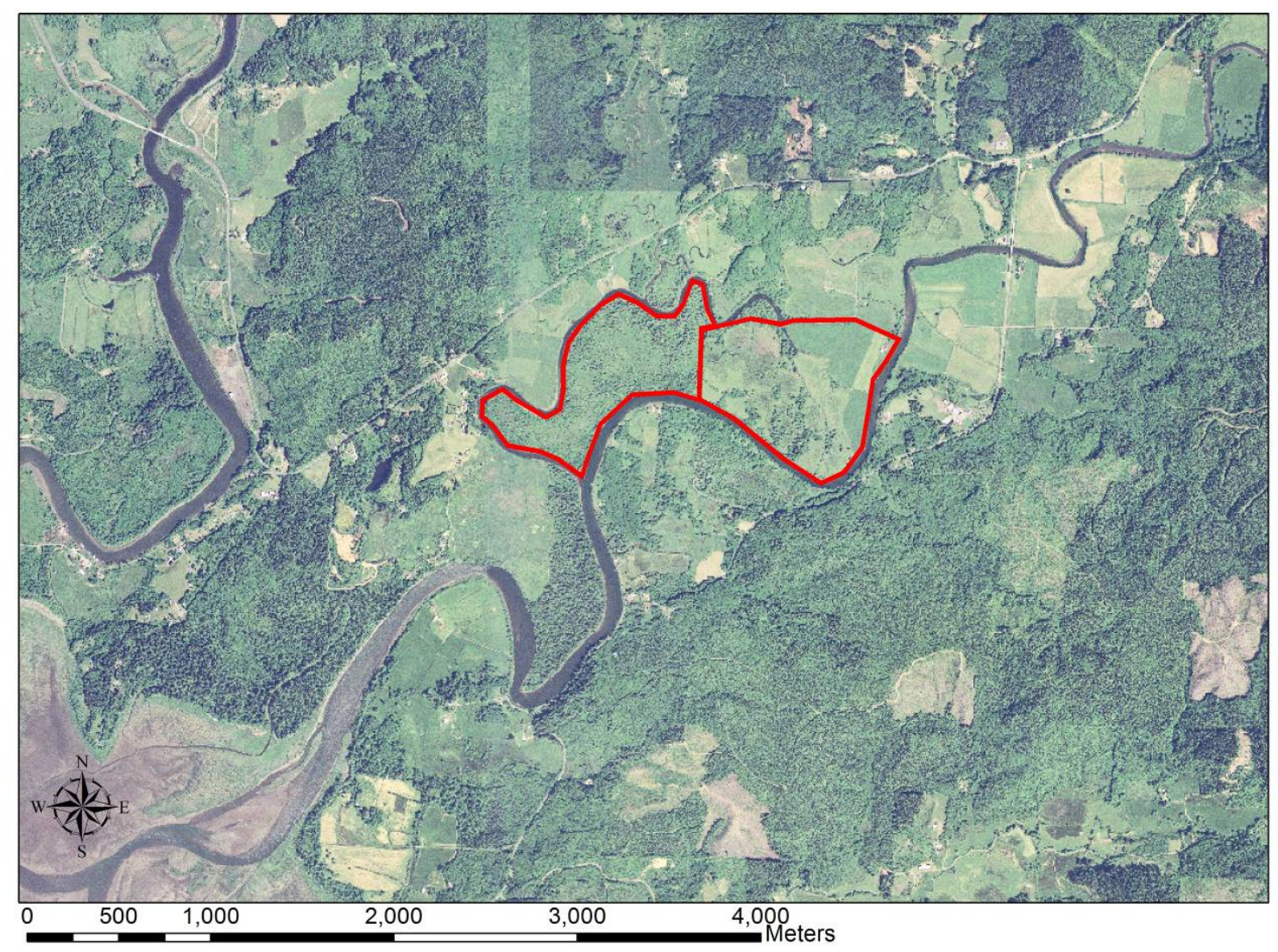

Figure 1.4. Kandoll Farm Dike Breach and Culvert Replacement Site (right side of polygon) and Reference Site (left side of polygon), between Seal Slough and the Grays River in Washington 


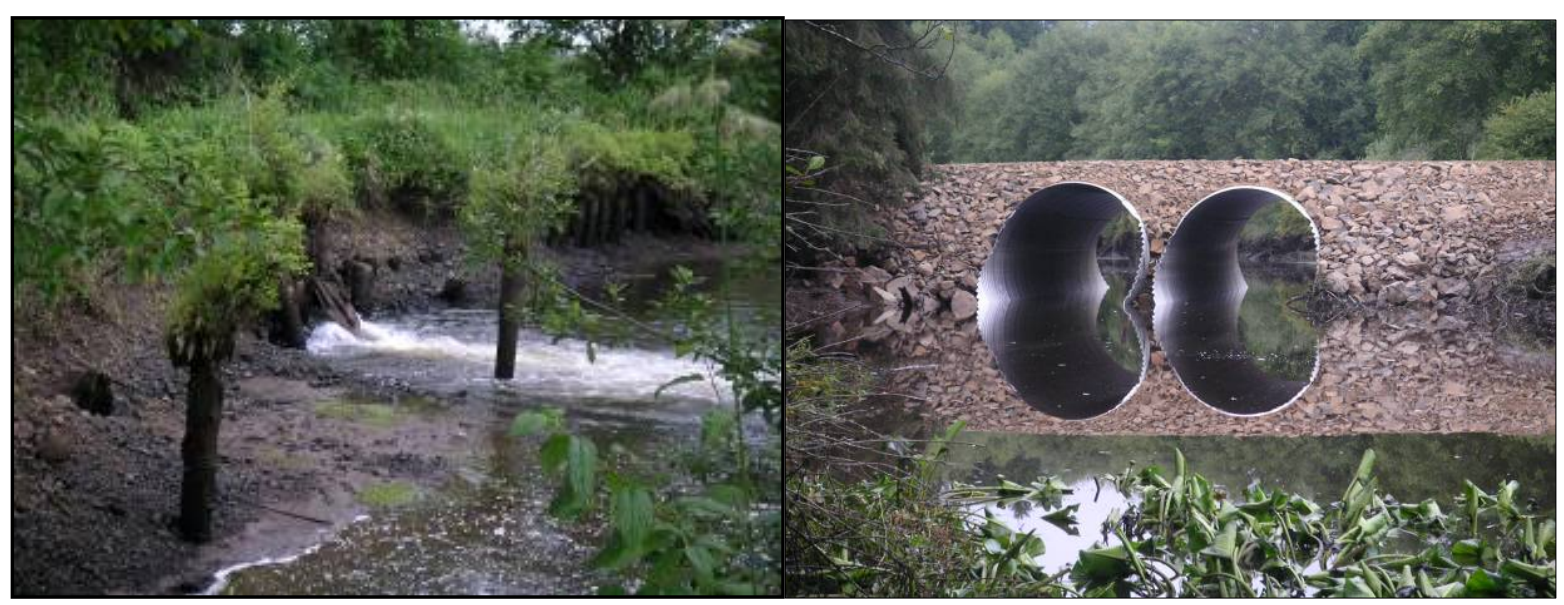

Figure 1.5. Tide Gate at Kandoll Farm before (left) and Culverts after (right) Replacement

\subsection{Literature Cited}

Bottom, D.L., C.A. Simenstad, J. Burke, A.M. Baptista, D.A. Jay, K.K. Jones, E. Cassillas, and M.H. Schiewe. 2005. Salmon at River's End: the Role of the Estuary in the Decline and Recovery of Columbia River Salmon. NOAA Tech. Memo. NMFS-NWFSC-68, NOAA National Marine Fisheries Service, Seattle, Washington.

Busch, D.E. and J.C. Trexler (eds). 2003. Monitoring Ecosystems- Interdisciplinary Approaches for Evaluating Ecoregional Initiatives, Island Press, Washington, D.C.

Clarke, S.E., D. White and A.L. Schaedel. 1991. Oregon, USA, ecological regions and subregions for water quality management. Environmental Management 15(6): 847-856.

Columbia River Estuary Data Development Program (CREDDP). 1984a. Index to CREDDP Data. Compiled by H.T. Mercier. S. Bell, ed. Columbia River Estuary Study Taskforce, Astoria, Oregon.

Columbia River Estuary Data Development Program (CREDDP). 1984b. Abstracts of Major CREDDP Publications. Compiled by D. Fox. Columbia River Estuary Study Taskforce, Astoria, Oregon.

Diefenderfer, H.L., G.C. Roegner, R.M. Thom, E.M. Dawley, A.H. Whiting, G.E. Johnson, K.L. Sobocinski, M.G. Anderson, and B.D. Ebberts. 2005a. Evaluating Cumulative Ecosystem Response to Restoration Projects in the Columbia River Estuary, Annual Report 2004. PNNL15102, prepared by Pacific Northwest National Laboratory for the U.S. Army Corps of Engineers, Portland District, Portland, Oregon.

Diefenderfer, H.L., Thom, R.M. and K.D. Hofseth, 2005b. "A Framework for Risk Analysis in Ecological Restoration Projects.” In: R.J.F. Bruins and M.T. Heberling (Eds), Economics and Ecological Risk Assessment: Applications to Watershed Management, CRC Press, Boca Raton, Florida.

Diefenderfer, H.L., R.M. Thom, A.B. Borde, G.C. Roegner, A.H. Whiting, G.E. Johnson, E.M. Dawley, J.R. Skalski, J. Vavrinec, and B.D. Ebberts. 2006. Evaluating Cumulative Ecosystem Response to Restoration Projects in the Columbia River Estuary, Annual Report 2005. PNNL-15934 prepared by Pacific Northwest National Laboratory for the U.S. Army Corps of Engineers, Portland District.

Dyer, K.R. and R.J. Orth, eds. 1994. Changes in Fluxes in Estuaries: Implications from Science to Management. Proceedings of ECSA22/ERF Symposium, 13-18 September 1992, Institute of Marine Studies, University of Plymouth. Olsen \& Olsen, Fredensborg. 
Evans N.R., R.M. Thom, G.D. Williams, J. Vavrinec, III, K.L. Sobocinski, L.M. Miller, A.B. Borde, V.I. Cullinan, J.A. Ward, C.W. May, and C. Allen. 2006. Lower Columbia River Restoration Prioritization Framework, PNWD-3652, prepared for the Lower Columbia River Estuary Partnership by Battelle-Pacific Northwest Division, Richland, Washington.

Franklin, J.F. and C.T. Dyrness. 1988. Natural Vegetation of Oregon and Washington. OSU Press. Corvallis, Oregon.

Fresh, K.L., E. Casillas, L.L. Johnson and D.L. Bottom. 2004. Role of the Estuary in the Recovery of Columbia River Basin Salmon and Steelhead: an Evaluation of Selected Factors on Population Viability. NOAA Technical Memorandum, Northwest Fisheries Science Center, National Marine Fisheries Service, NOAA, Seattle, WA, May 2004.

Fuhrer, G.J., D.Q. Tanner, J.L. Morace, S.W. McKenzie and K.A. Skach. 1996. Water Quality of the Lower Columbia River Basin: Analysis of Current and Historical Water-Quality Data through 1994. U.S. Geological Survey Water-Resources Investigations Report 95-4294, prepared in cooperation with the Lower Columbia River Bi-State Water-Quality Program, Portland, Oregon. Available URL: www.lcrep.org

Jay, D.A., and B.M. Hickey. 2001. "Non-stationary internal tides in the Columbia River plume area." In J. Geophys. Res.

Johnson G.E., R.M. Thom, A.H. Whiting, G.B. Sutherland, T. Berquam, B.D. Ebberts, N.M. Ricci, J.A. Southard, and J.D. Wilcox. 2003. An Ecosystem-Based Approach to Habitat Restoration Projects with Emphasis on Salmonids in the Columbia River Estuary. PNNL-14412, Final report submitted to the Bonneville Power Administration, Portland, Oregon, November 2003, by Pacific Northwest National Laboratory, Richland, Washington.

Johnson, G., H. Diefenderfer, T. Berquam, B. Ebberts, C. Tortorici, and J. Wilcox. 2004. Plan for Research, Monitoring, and Evaluation of Salmon in the Columbia River Estuary. Final draft report August 10, 2004, PNNL-14632, prepared for the Bonneville Power Administration, by the Pacific Northwest National Laboratory, Richland, Washington.

Kentula, M.E., R.P. Brooks, S.E. Gwin, C.C. Holland, A.D. Sherman and Jj.C. Sifneos. 1992. An Approach to Improving Decision Making in Wetland Restoration and Creation. EPA/600/R92/150, U.S. Environmental Protection Agency Environmental Research Laboratory, Corvallis, Oregon.

Leibowitz, S.G., B. Abbruzzese, P.R. Adamus, L.E. Hughes, and J.T. Irish. 1992. A Synoptic Approach to Cumulative Impact Assessment: A Proposed Methodology. EPA/600/R-92/167. U.S. Environmental Protection Agency, Environmental Research Laboratory, Corvallis, Oregon.

National Research Council (NRC). 2003. Adaptive Monitoring and Assessment for the Comprehensive Everglades Restoration Plan. The National Academies Press, Washington, DC.

Neal, V.T. 1972. Physical Aspects of the Columbia River and Its Estuary. In Pruter, A.T. and D.L. Alverson, (eds). The Columbia River Estuary and Adjacent Ocean Waters: Bioenvironmental Studies. University of Washington Press, Seattle, Washington.

Neckles, H. A., M. Dionne, D.M. Burdick, C.T. Roman, R. Buchsbaum, and E. Hutchins. 2002. A Monitoring Protocol to Assess Tidal Restoration of Salt Marshes on Local and Regional Scales. Restoration Ecology 10(3):556-563.

Omernik, J.M. and A.L. Gallant. 1986. Ecoregions of the Pacific Northwest States. EPA/600/3-86/033, U.S. Environmental Protection Agency Environmental Research Laboratory, Corvallis, OR, July 1986. 
Pruter, A.T. and D.L. Alverson (eds.). 1972. The Columbia River Estuary and Adjacent Ocean Waters: Bioenvironmental Studies. University of Washington Press, Seattle, Washington.

Roegner, C., H.L. Diefenderfer, A.H. Whiting, A.Borde, R.M. Thom, and Dawley. 2006. Monitoring Protocols for Salmon Habitat Restoration Projects in the Lower Columbia River and Estuary. PNNL-15793, Working draft report prepared by PNNL, NMFS, and CREST for the U.S. Army Corps of Engineers, Portland District.

Sherwood, C.R. and J.S. Creager. 1990. Sedimentary Geology of the Columbia River Estuary. Progress in Oceanography 25: 15-79.

Sherwood, C.R., D.A. Jay, R.B. Harvey, P. Hamilton and C.A. Simenstad. 1990. Historical changes in the Columbia River estuary. Progress in Oceanography 25: 299-352.

Simenstad, C.A., C.D. Tanner, R.M. Thom, and L.L. Conquest. 1991. Estuarine Habitat Assessment Protocol. EPA 910/9-91-037. Prepared for U.S. Environmental Protection Agency, Region 10, Office of Puget Sound, Seattle, Washington.

Small, L.F. (ed.). 1990. Columbia River: Estuarine System. Progress in Oceanography, Vol. 25, no. 14.

Steyer, G.D., C.E. Sasser, J.M. Visser, E.M. Swenson, J.A. Nyman, and R.C. Raynie. 2003. A Proposed Coast-Wide Reference Monitoring System for Evaluating Wetland Restoration Trajectories. Journal of Environmental Monitoring and Assessment 81:107-117.

TetraTech. 1996. The Health of the River 1990-1996: Integrated Technical Report. Report TC 0253-01, prepared by Tetra Tech for the Lower Columbia River Bi-State Program, May 20, 1996. Available URL: www.lcrep.org.

Thom, R.M. 1997. System-development matrix for adaptive management of coastal ecosystem restoration projects. Ecological Engineering 8:19-232.

Thom, R.M., G.W. Williams, and H.L. Diefenderfer. 2005. Balancing the need to develop coastal areas with the desire for an ecologically functioning coastal environment: Is net ecosystem improvement possible? Restoration Ecology 13(1): 193-203.

USGS (United States Geological Survey). 1990. Largest Rivers in the United States, in Discharge, Drainage Area, or Length. Open-File Report 87-242, Reston, Virginia.

World Commission on Environment and Development. 1987. Our Common Future. Oxford University Press, New York. 


\title{
2.0 Hydrological Changes to Wetland Restoration Sites after Tidal Reconnection in the Columbia River Estuary
}

\author{
G. Curtis Roegner, ${ }^{\mathrm{a}}$ Allan W. Whiting, ${ }^{\mathrm{b}}$ and Blaine D. Ebberts ${ }^{\mathrm{c}}$
}

\subsection{Introduction}

A common restoration activity in the lower Columbia River and estuary (CRE) is the reconnection of diked and tide gate-controlled former wetlands to ambient hydrological forcing. In the CRE, hydrologic patterns are generated by both seasonal river flows and tidal forcing. Hydrology largely drives wetland evolution, and tidal fluctuations linked to topography strongly determine restoration trajectories (Cornu and Sadro 2002). Tidal forcing affects aerial exposure; circulation patterns in tidal creeks, including the distribution of water properties such as salinity, temperature, and dissolved oxygen; sedimentation/erosion patterns and topographic evolution; and the distribution and abundance of vegetation and fishes. Thus, a key monitoring metric for restoration research is the change in tidal amplitude and period within a restoration project due to hydrological reconnection, which was investigated in 2006. Future analyses will examine the relationship between the areal extent/topography of the newly restored area and hydrology at the outlet.

Organisms have varying tolerances to water properties such as salinity, temperature, and dissolved oxygen. For example, to restore habitat for juvenile salmonids, temperature should be maintained below $19{ }^{\circ} \mathrm{C}$ and oxygen above about $4 \mathrm{mg} \mathrm{L}^{-1}$ during time of residence. Increased circulation due to tidal reconnection is expected to reduce excessive temperature and help maintain suitable dissolved oxygen levels. Salinity also influences fish and vegetation distribution in the CRE. For restoration sites in the estuary section of the CRE, tidal reconnection can lead to increased salinity intrusion, and changes in community structure based on salinity tolerance. Monitoring the variation of water properties during preand post-restoration periods is a necessary measure of habitat change and is important for explaining and predicting floral and faunal community responses to restoration.

Here we report on hydrological variation at two study locations before and after tidal reconnection. The first study location is Kandoll Farm, a tidal freshwater ecosystem located in the Grays River watershed, Washington. Kandoll Farm is a former agricultural pasture that has been reconnected to the ambient hydrologic environment by removing tide gates and establishing a free connection to the river. The second site is Vera Slough, positioned in the brackish (oligohaline) zone of the Columbia River Estuary. Restoration activity at Vera Slough entailed replacing old tide gates with newer models designed to increase circulation and fish passage while maintaining flood protection. This chapter outlines results from this ongoing study to assess the influence of tidal reconnection on water-level changes and water properties.

\footnotetext{
${ }^{\text {a }}$ Pt. Adams Biological Station, National Marine Fisheries Service, Hammond, OR

${ }^{\mathrm{b}}$ Columbia River Estuary Study Taskforce, Astoria, OR

${ }^{\mathrm{c}}$ Portland District, U.S. Army Corps of Engineers, Portland, OR
} 


\subsection{Methods}

Hydrographic stations were established inside and outside restoration sites where conditions before and after tidal reconnection were recorded. At each station, instruments were secured to vertical poles or on bottom weights. The sensor height relative to the NAVD88 vertical datum was measured on site with a Trimble real-time kinematic global positioning system (GPS) using total station or auto-level surveying techniques. Water-level fluctuations are thus referenced to site topography. Measurements were logged at $0.5 \mathrm{~h}$ intervals.

\subsubsection{Grays River System/Kandoll Farm Restoration Site}

Hydrography in the tidal freshwater Grays River system was monitored with pressure/temperature sensors (Hobo). Data logging instrument stations were established at five main sites: two stations were established in the Grays River upstream (GR@Duffys) and downstream (GR@Johnson) of the restoration site; an additional instrument measured hydrography at a reference tidal slough in Seal Slough (SS Ref1); and the final two sensors were placed within the restoration site: one immediately inside of the tide gate removal site (Kandoll Inside) and the other in a relic tidal channel (Kandoll Channel). Additional data loggers were deployed on a short-term basis during flux studies (Chapter 8).

\subsubsection{Vera Slough System}

Vera Slough is within the oligohaline portion of the estuary, and we used various types of pressure/temperature as well as multiparameter probes to monitor water quality (including water-level and temperature, and on occasion salinity and oxygen) before and after tide gate replacement. Stations were established on either side of the tide gates (Vera Inside and Vera Outside) to assess variation in hydrological properties through the gate. A reference station was set up in a tidal slough about $1 \mathrm{~km}$ from the impact site (Reference). A final pressure-temperature logger was established $\sim 1 \mathrm{rkm}$ within Vera Slough, at a location we term Vera Forks, to assess the extent of hydrological reconnection.

\subsubsection{Calculations and Analysis}

Full analysis of the hydrography of these systems awaits recovery of the sensors after the 2007 field season. Here, hydrological change was evaluated with comparisons of key water properties between stations. We used spectral (Fortier) analysis to establish the dominant periods of water-level variability before and after tidal reconnection. Spikes in spectral density at semidiurnal tidal frequencies (12.4 and $24.8 \mathrm{~h}$ ) are evidence of tidal forcing. Future analyses will couple water-level variation with site topography to compute inundation period, which relates to habitat opportunity. Similarly, temperature and salinity time series, linked to established tolerance limits for target species, will be used to predict organism presence and community structure trajectories.

\subsection{Results and Discussion}

\subsubsection{Grays River System}

In the Grays River system, water-level and temperature sensors were deployed in summer 2005 before restoration activity, replaced during spring 2006 (data shown here), and are continuing to log measurements at the date of this writing. The instruments recorded striking changes in hydrology posttide gate removal, as well as interesting weather-induced water-level variation that illustrates one possible cumulative effect of restoration on watershed processes. 


\section{Effect of Tide Gate Removal on Hydrology}

Tide gate removal and dike breaching activity had an immediate effect on water-level fluctuations within the Kandoll Farm site (Figure 2.1). At the Kandoll Inside station, pre-breach fluctuations changed from a weak tidal signal to a fully semidiurnal pattern. Maximum amplitudes increased from $\sim 1.0 \mathrm{~m}$ to $3.0 \mathrm{~m}$. The Kandoll Channel station, which was located at a higher elevation than the Kandoll Inside station, also had $\mathrm{a} \sim 3 \mathrm{x}$ change in mean amplitude albeit at a lower level. Spectral analysis confirms a change in tidal properties (Figure 2.2) as the tidal prism, inundation levels, and flux of water through the system were greatly increased.
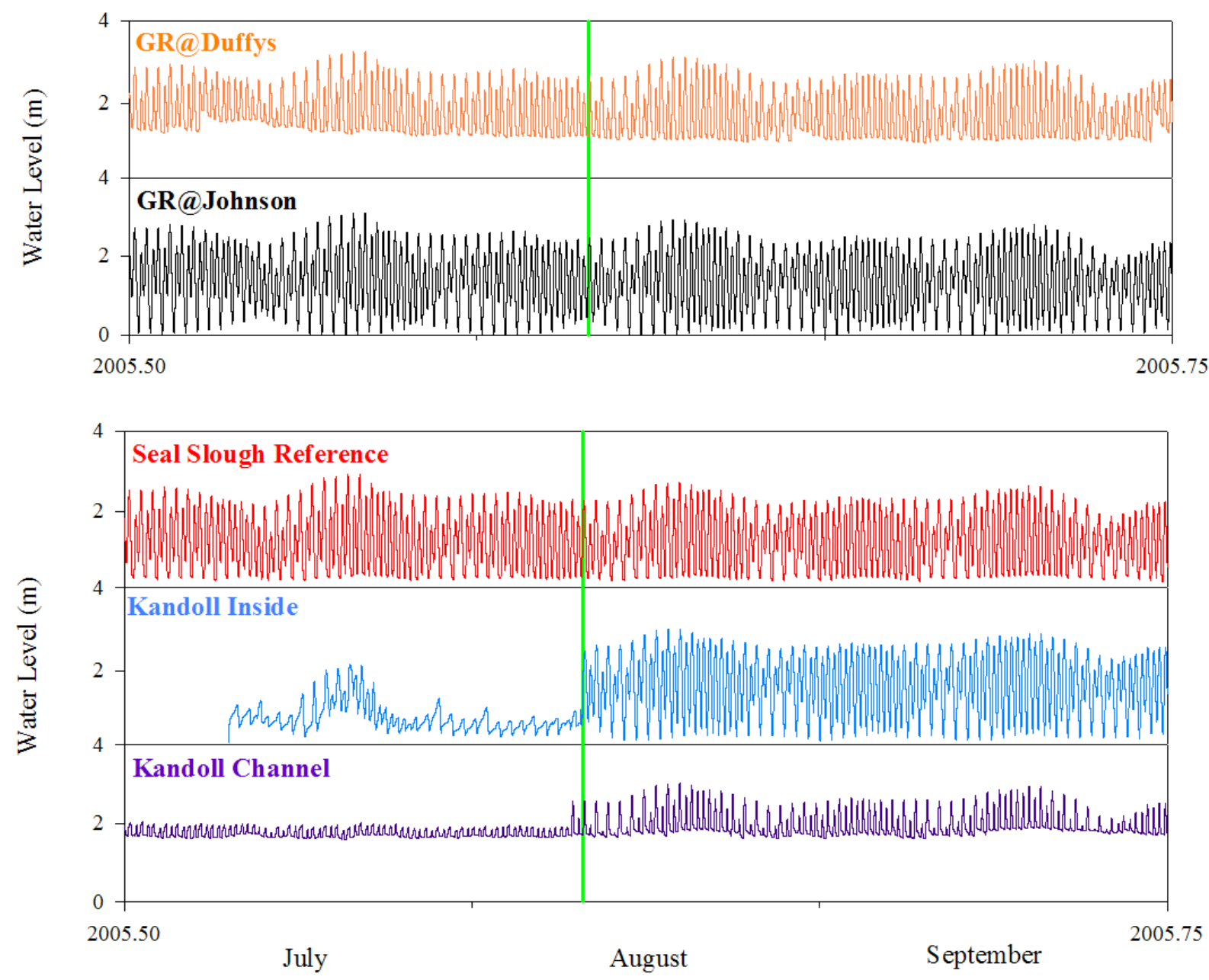

Figure 2.1. Time Series of Water-Level at Hydrographic Stations within the Grays River System before and after the Tide Gate Removal (green vertical line) 

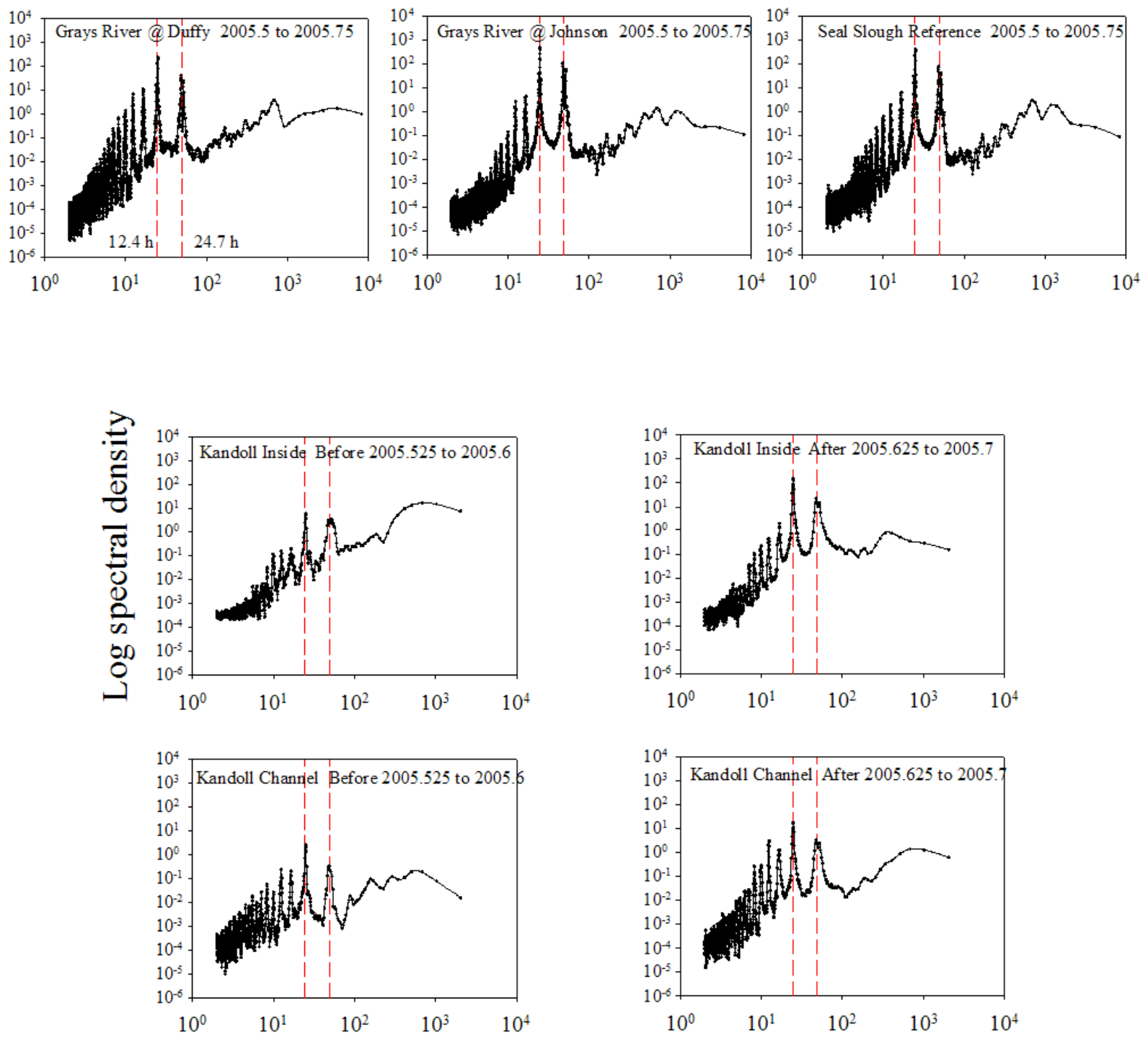

Log period (h)

Figure 2.2. Spectral Density (square of the variance) Plots of Water-Level Data Measured at Hydrographic Stations in the Grays River System. Water-level variance was concentrated at semidiurnal periods at all stations. Top row -- reference stations outside of restoration area. Middle row -- before and after tidal gate removal at the Kandoll Inside station, respectively. Bottom row -- before and after tidal gate removal at the Kandoll Channel station, respectively.

Mean daily temperature (+ standard deviation) was computed to assess changes in habitat quality during restoration, as well as within the larger Grays River system (Figure 2.3). Mean daily temperature values are useful for determining periods where values exceed organism tolerances. Preceding tide gate removal in July, mean daily water temperature at SS Reference and Kandoll Inside were indistinguishable and relatively high, whereas temperature at the Kandoll Channel site was significantly cooler. This is likely due to shading of the Kandoll Channel sensor by dense vegetation. After breaching, temperatures 
sensor, temperatures during the July-August period reached or exceeded the $19{ }^{\circ} \mathrm{C}$ threshold used to delimit conditions for salmonids (Bottom et al. 2005). Most salmonids had probably moved through the system by this date (Roegner et al. 2006). Considering the Grays River stations, mean daily temperatures in summer were as much as $4{ }^{\circ} \mathrm{C}$ cooler in the Grays River at Duffy's compared with Grays River at Johnson, which may be caused by intrusion of Columbia River water to the Johnson site.
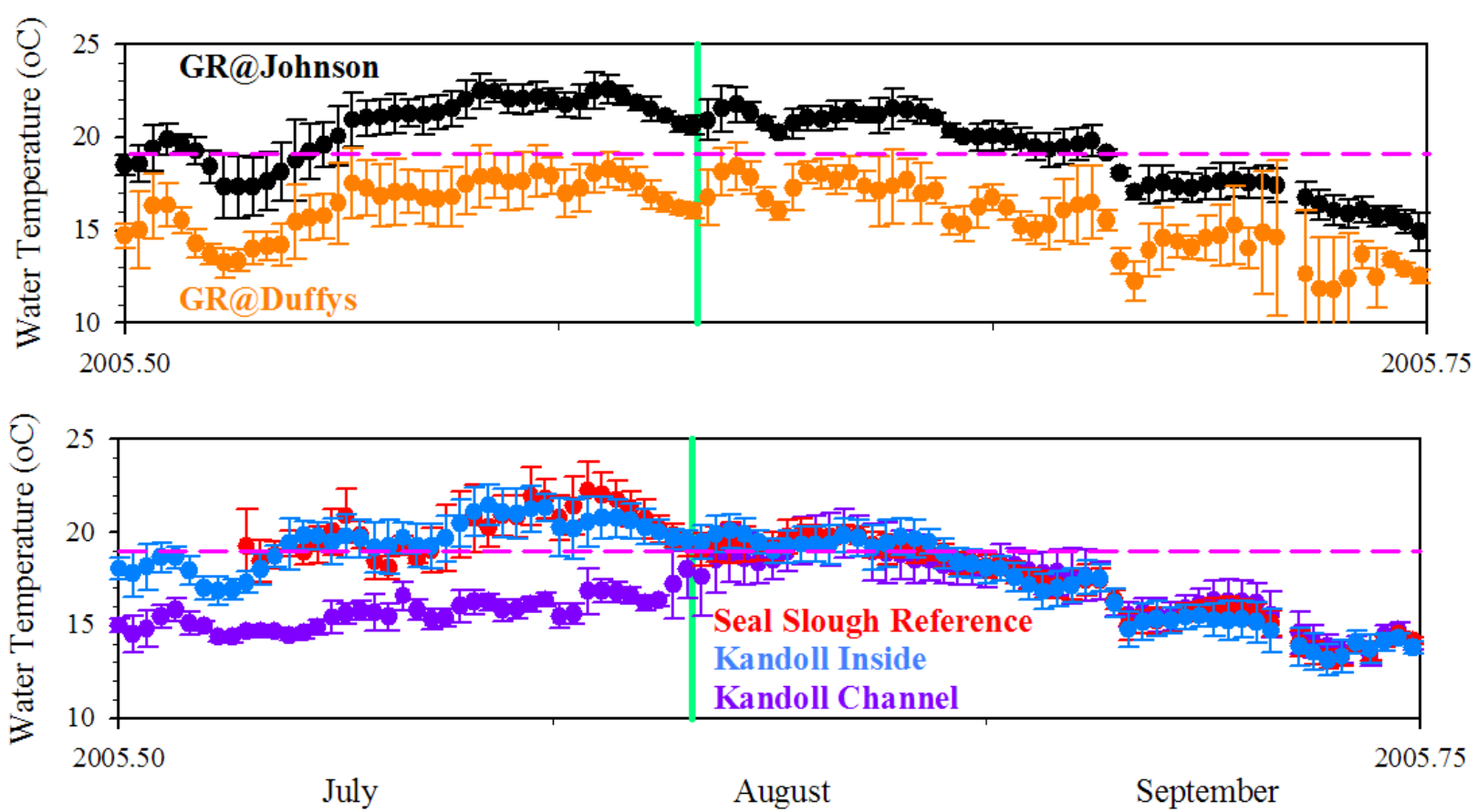

Figure 2.3. Mean Daily Temperature $(+s d)$ at Hydrographic Stations within the Grays River System before and after the tide gate removal (green vertical line)

\section{Effect of Storms}

Long time series of water-level and temperature data are useful for evaluating system-wide impacts, especially episodic events (storms), which can impart lasting structural changes to topography and biota and are a source of uncertainty regarding restoration trajectories (Diefenderfer et al. 2005). The storm events of winter 2005-2006 were clearly recorded in the Grays River system hydrography. The GR@Duffy station measured several flood events that raised water levels $\sim 3 \mathrm{~m}$ above mean high water, with peak levels approaching $7 \mathrm{~m}$ above NAVD88 datum (Figure 2.4). Interestingly, all other instrument stations measured more modest 1-2 $\mathrm{m}$ flood events. It appears the river flow was constrained within dikes at Duffy's causing a rapid surge that was dissipated within the flood plain further downstream. Note the temperature signal of the flood events, a $\sim 9{ }^{\circ} \mathrm{C}$ increase from December 2005 to Feb 2006 (Figure 2.5). 

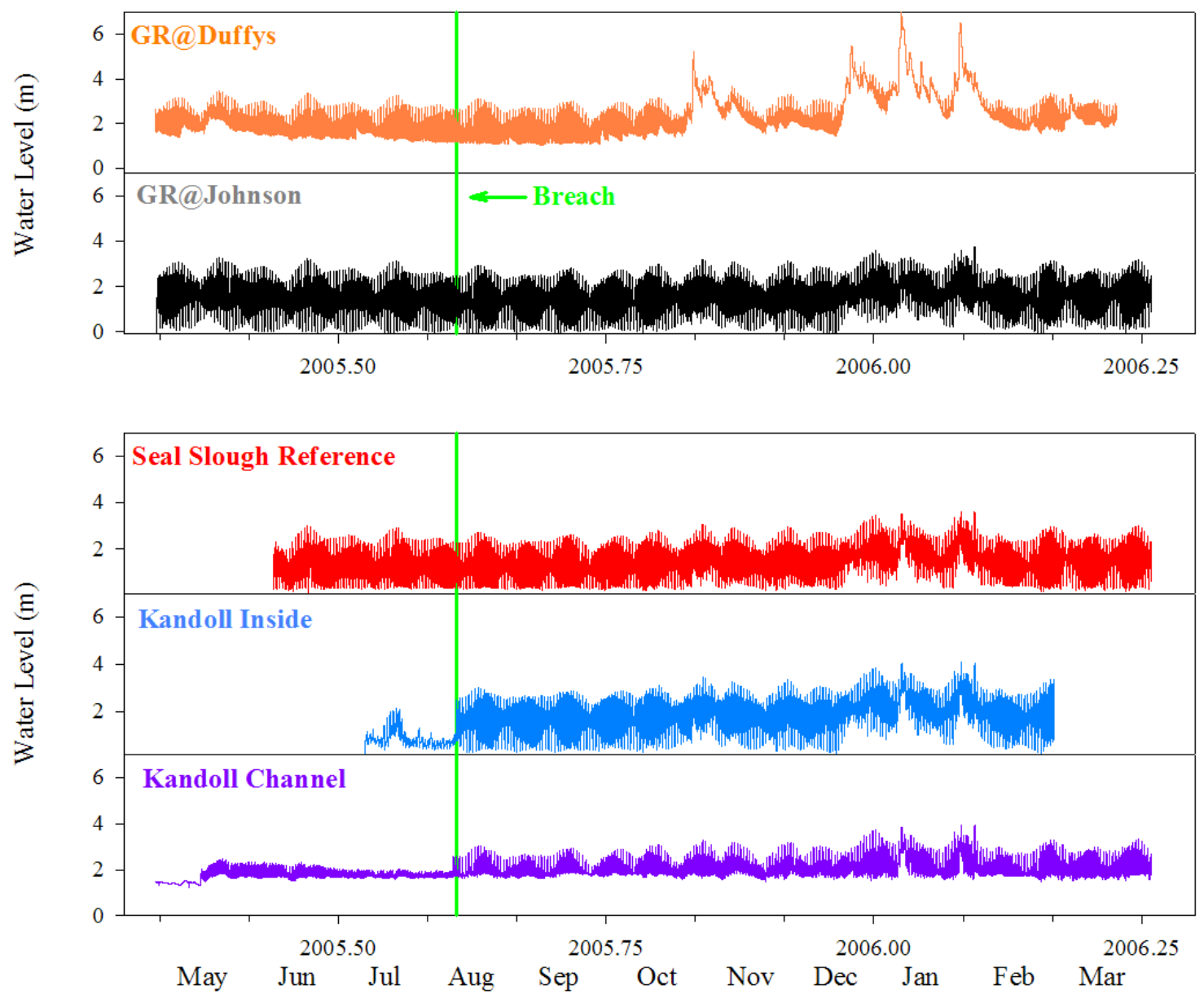

Figure 2.4. Time Series of Water-level at Hydrographic Stations within the Grays River System for the May 2005 through March 2006 period. Note flood conditions in Nov. 2005 and winter 2005-2006. 

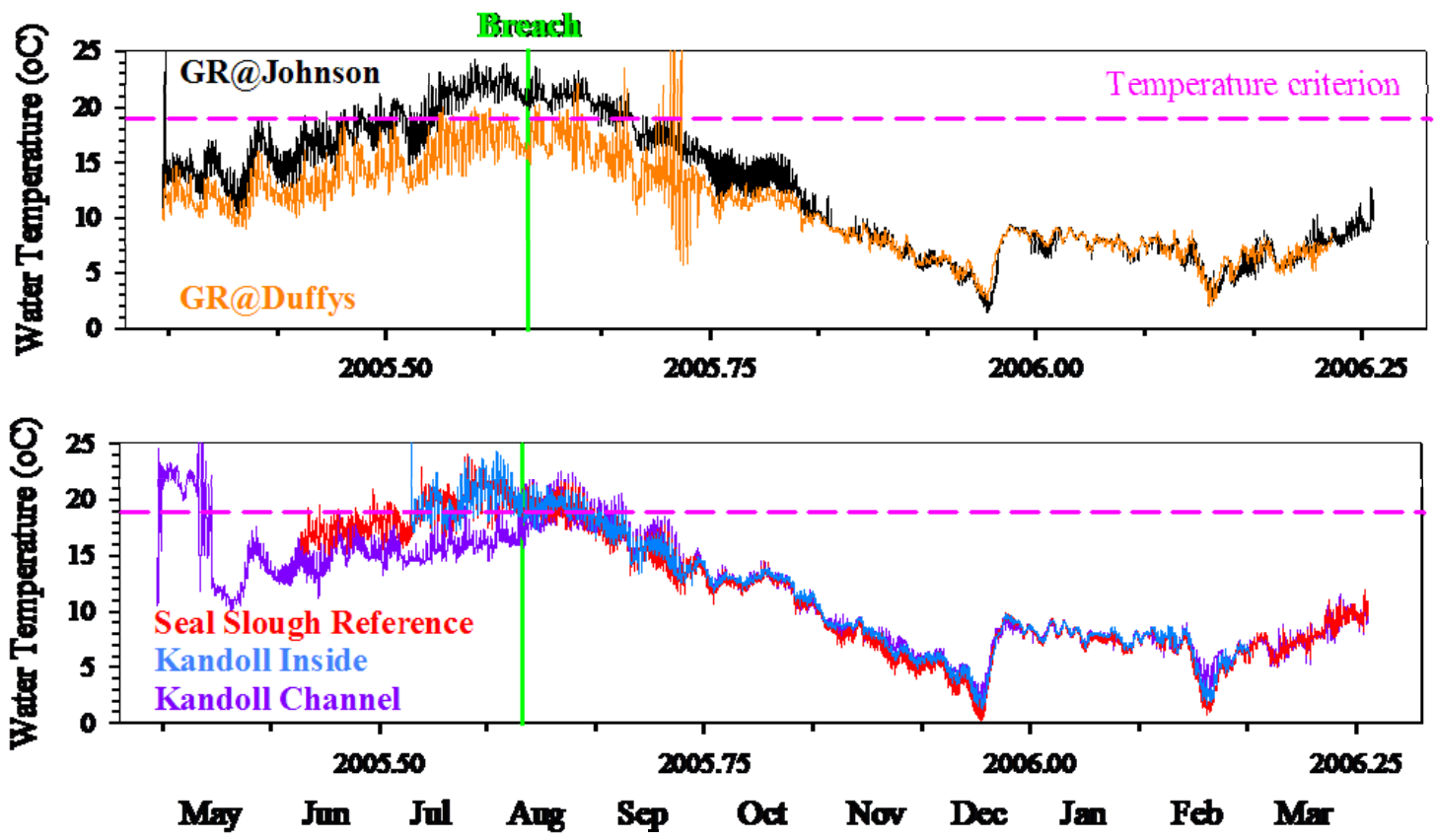

Figure 2.5. Time Series of Temperature at Hydrographic Stations within the Grays River System for the May 2005 through March 2006 Period

\subsubsection{Vera Slough System}

The Vera Slough project was a tide gate replacement designed to increase connectivity and salmonid access with Youngs Bay while maintaining flood protection. Instrument measurements were initiated in May 2005 and are ongoing. The tide gate replacement was initiated on 12 October 2005 (2005.78). Tide gate replacement project experimented with the replacement of two conventional lids with two different designs. These designs entailed one side-hinge door and one top-hinge door, both using lighter materials than the previous gates. In addition, both lids utilized smaller interior doors that could be modified manually to either increase or decrease the amount of tidal intrusion into the slough system. In contrast to the Kandoll restoration where a culvert replaced a tide gate, the new tide gates at Vera Slough continued to restrict hydrologic patterns for the purpose of flood control.

\section{Effect of Tide Gate Replacement on Water Level}

In the pre-replacement condition, tidal fluctuations at the inside station were about $0.10 \mathrm{~m}$, while outside the tide gate and in the reference slough, a full semidiurnal tidal range of amplitude between 1 and $3 \mathrm{~m}$ occurred (Figure 2.6). Tide gate replacement resulted in an increase in tidal amplitude to about $0.5 \mathrm{~m}$ at the Vera Slough Inside station (Figure 2.7), which increased to about $0.75 \mathrm{~m}$ after tide gate adjustment (Figure 2.8). The truncated vertical amplitudes exhibited in both pre- and post-replacement time series indicate the effectiveness of the tide gates at limiting full tidal connection. 

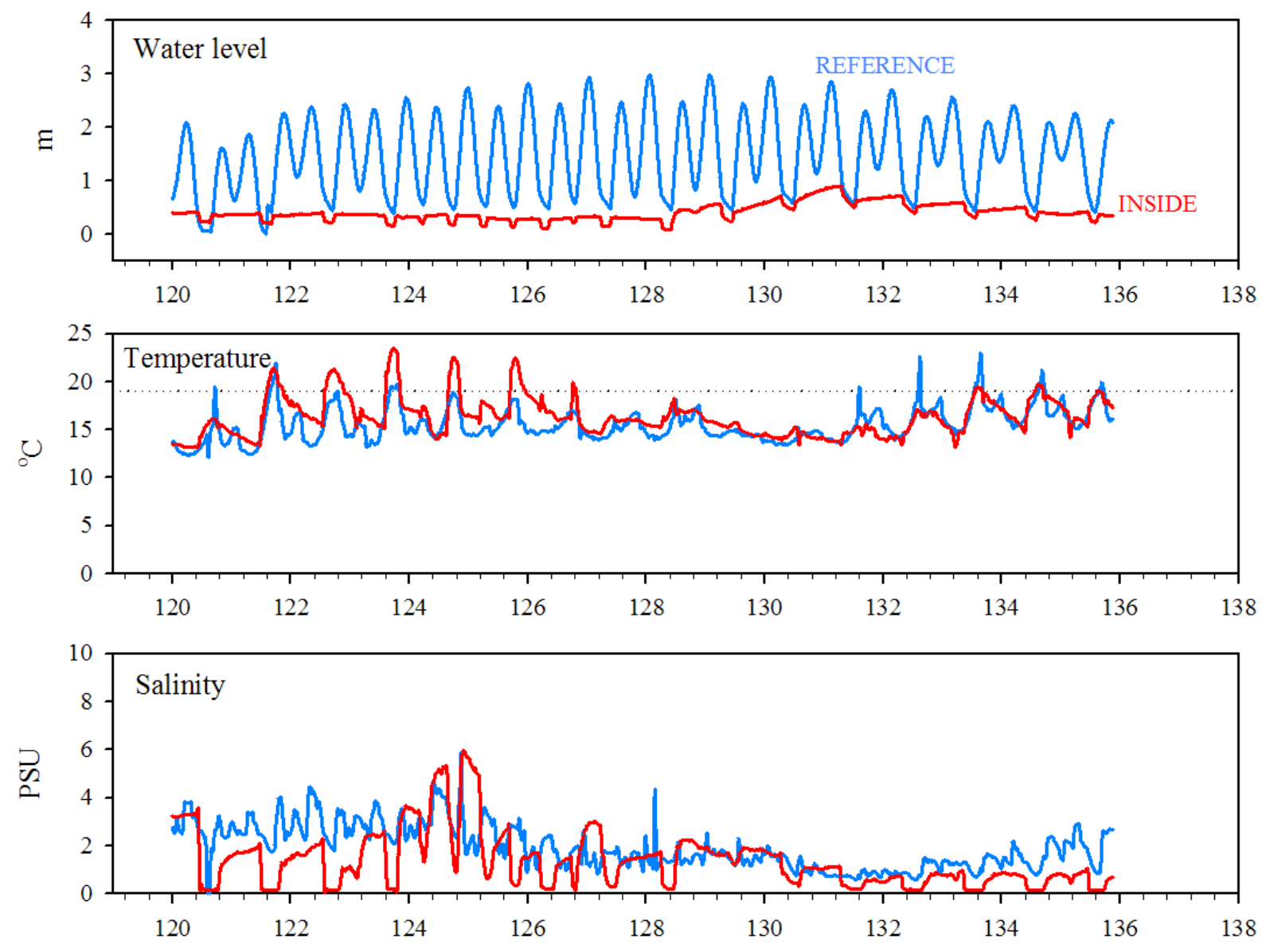

Date in May 2005

Figure 2.6. Vera Slough Pre-Tide Gate Replacement Conditions during May 2005. Time series of water-level, temperature, and salinity at Vera Inside (red) and Vera Reference (blue) hydrographic stations.

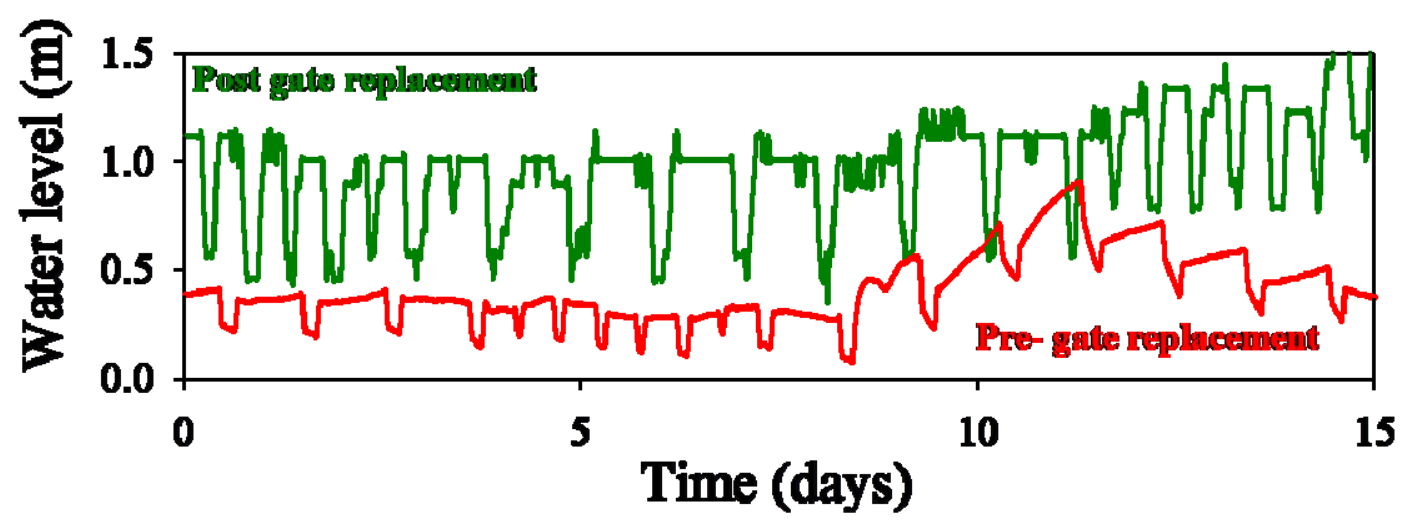

Figure 2.7. Vera Slough Pre- and Post-Tide Gate Replacement Conditions during September 2005. Time series of water-level Vera Inside (red) and Vera Outside (green) hydrographic stations. 

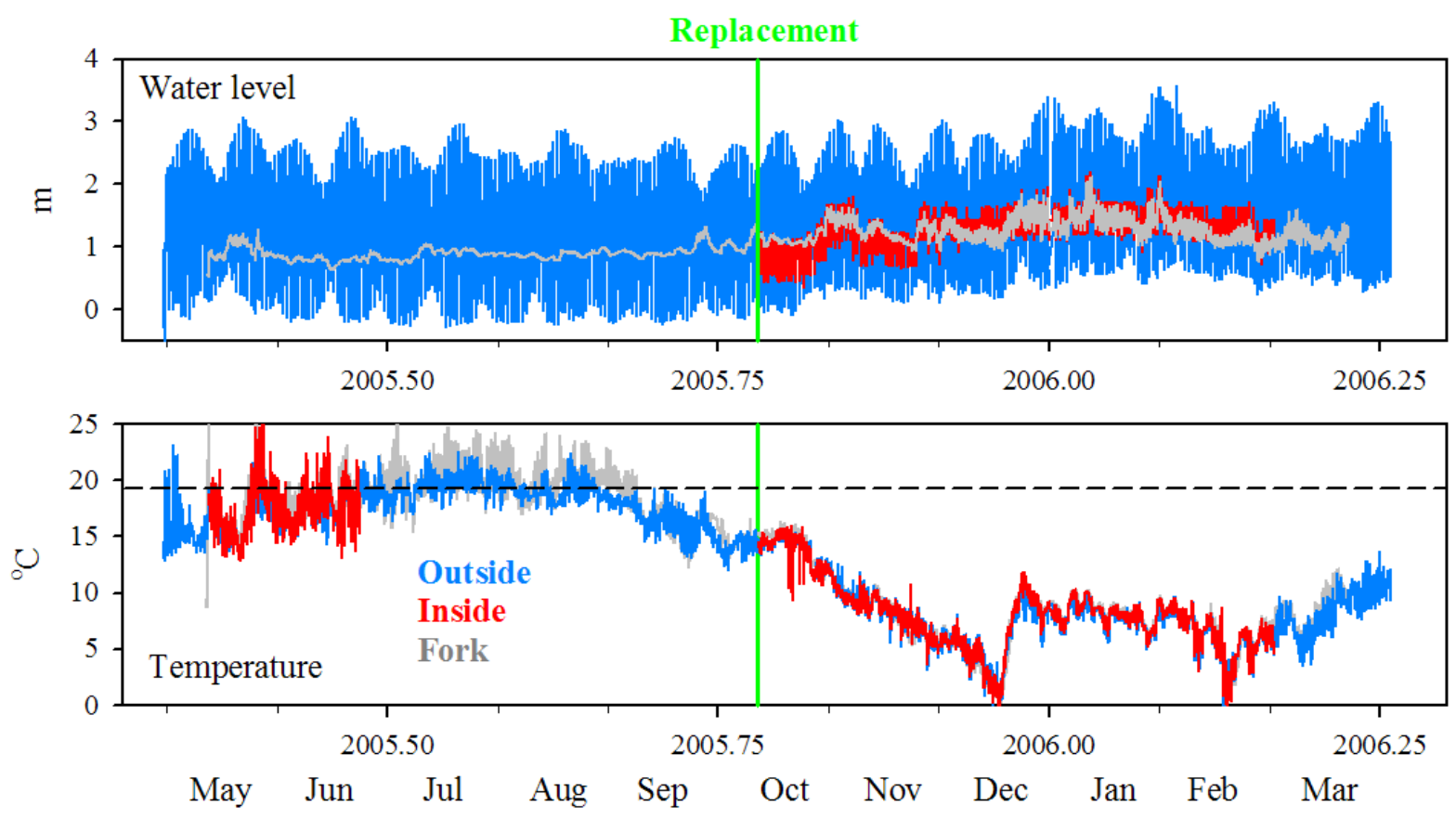

Figure 2.8. Time Series of Water-Level and Temperature at Hydrographic Stations within the Vera Slough System for the May 2005 through September 2006 Period. Vera Outside, blue; Vera Inside, red, Vera Forks, grey. Tide gate replacement, green vertical line. Dashed horizontal line designates $19{ }^{\circ} \mathrm{C}$ temperature threshold.

Analysis of water levels at the Vera Forks station illustrates the effect of increased tidal reconnection on larger spatial and temporal scales (Figure 2.8). During the pre-replacement period of May to October 2005, mean water level at Vera Forks was $0.89+0.11 \mathrm{~m}$, and daily fluctuations were generally $<0.05 \mathrm{~m}$. Spectral analysis of the time series detected a weak semi-diurnal peak but a lack of a diurnal peak in variance (Figure 2.9). In contrast, during the post-replacement period after October, mean water level increased to $1.27+0.20 \mathrm{~m}$, and daily water-level fluctuations increased to a maximum of $0.60 \mathrm{~m}$. Some of this overall increase in water level was likely due to seasonal factors. However, a semidiurnal tidal period was evident in the water-level spectrum post-replacement (Figure 2.9), indicating tidal fluctuations had increased upstream of the tide gate.

The long time series also follows seasonal trends in water level in the CRE. A general increase in water elevation was recorded at all stations from October 2005 through winter 2006 in response to rainfall patterns (Figure 2.8). Note the temperature increase that occurred during the winter 2005-2006 period is identical to that observed in the Grays River system, demonstrating the regional effects of storms on estuarine hydrography. Analysis of sensors still in the field will allow us to determine if restoration has increased the overall mean water level within Vera Slough (as expected). 


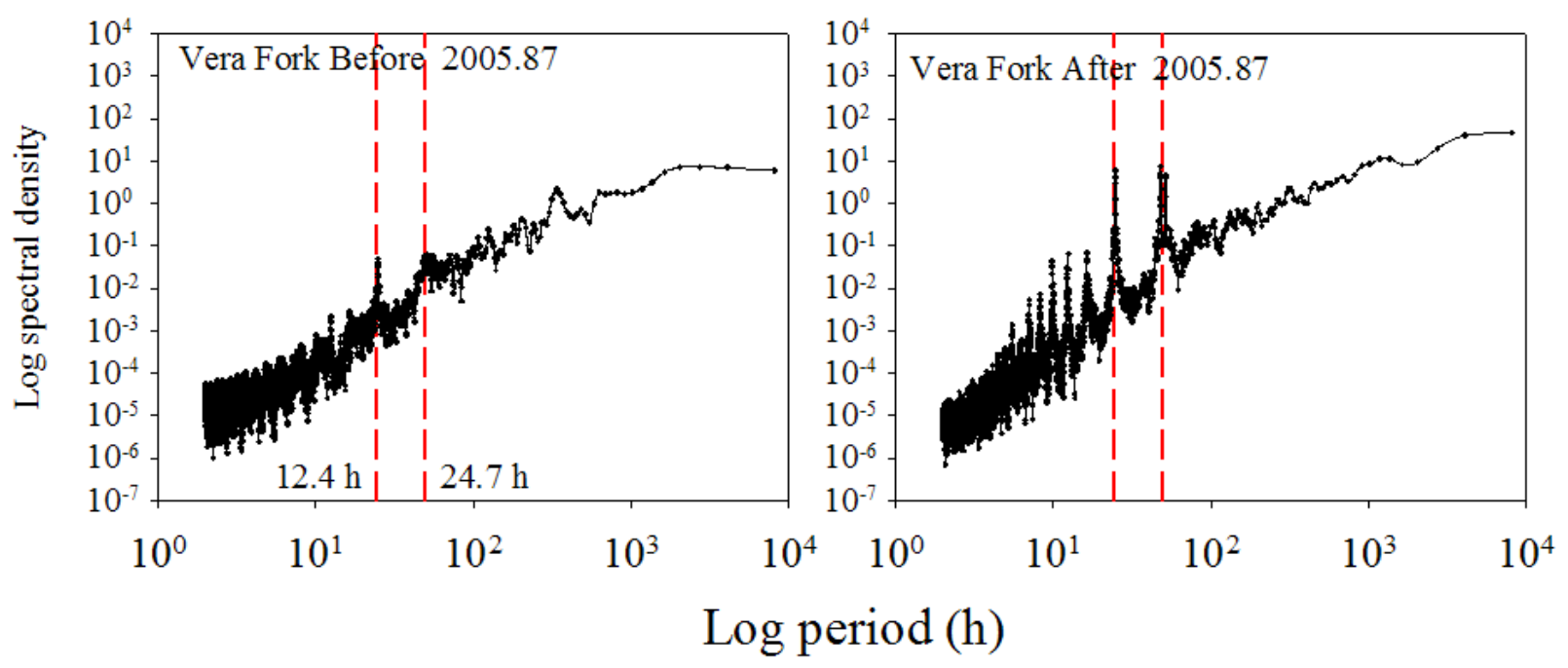

Figure 2.9. Spectral Density (square of the variance) Plots of Water-Level Data Measured at Vera Forks Before and After Tide Gate Replacement. Tidal constituents increased in the postreplacement period.

\section{Effect of Tide Gate Replacement on Water Properties}

Variations in temperature, salinity, and oxygen were measured to evaluate habitat changes within Vera Slough. During the May pre-breach data recordings, water quality properties varied minimally between the Vera Inside and Reference stations (Figure 2.6). Salinity ranged from 0 to 6 practical salinity units (psu), with daily fluctuations of 1 to $4 \mathrm{psu}$. This salinity range is slight compared to stations just outside of the Youngs Bay Bridge ( $\sim 2 \mathrm{~km}$ from Vera Slough), where salinity often ranges $>20$ psu per tide. Daily temperature fluctuations ranged from 0 to $8{ }^{\circ} \mathrm{C}$ at both Inside and Reference stations during the May pre-breach measurement period shown in Figure 2.8. Even in May, maximum temperature at both locations exceeded the $19{ }^{\circ} \mathrm{C}$ threshold for optimum salmon habitat. These data demonstrate that, while the pre-replacement tide gate allowed only minimal tidal exchange within Vera Slough, water properties within the mouth of the slough were similar to those at the reference site. However, mean daily temperature deviations indicate temperatures were generally 0 to $1{ }^{\circ} \mathrm{C}$ warmer Inside and 0 to $3{ }^{\circ} \mathrm{C}$ warmer at Vera Forks than at the Outside during the pre-replacement period (Figure 2.10). Conditions at the tide-gated area were generally unfavorable for salmonids during the April - June monitoring program. Salinity decreased upstream of the tide gate (conductivity, temperature, and depth sensor [CTD] data not shown).

During the post-replacement period, mean daily water temperature deviations between Vera Slough Inside and Outside and Vera Slough Inside and Forks were all generally $<1{ }^{\circ} \mathrm{C}$ (Figure 2.10).

Temperature gradients will be assessed more fully when new data are available. Limited salinity data are shown in Figure 2.11 for the October-September 2006 post-replacement period. Salinity measurements inside ranged from $\sim 5$ to $10 \mathrm{psu}$ and exhibited a spring-neap periodicity. Daily fluctuations were 1 to 4 psu. The data loggers recorded higher overall salinities in the late summer-early fall than had been previously measured (Figure 2.6). Salinities of this range can control floral and faunal distributions. 

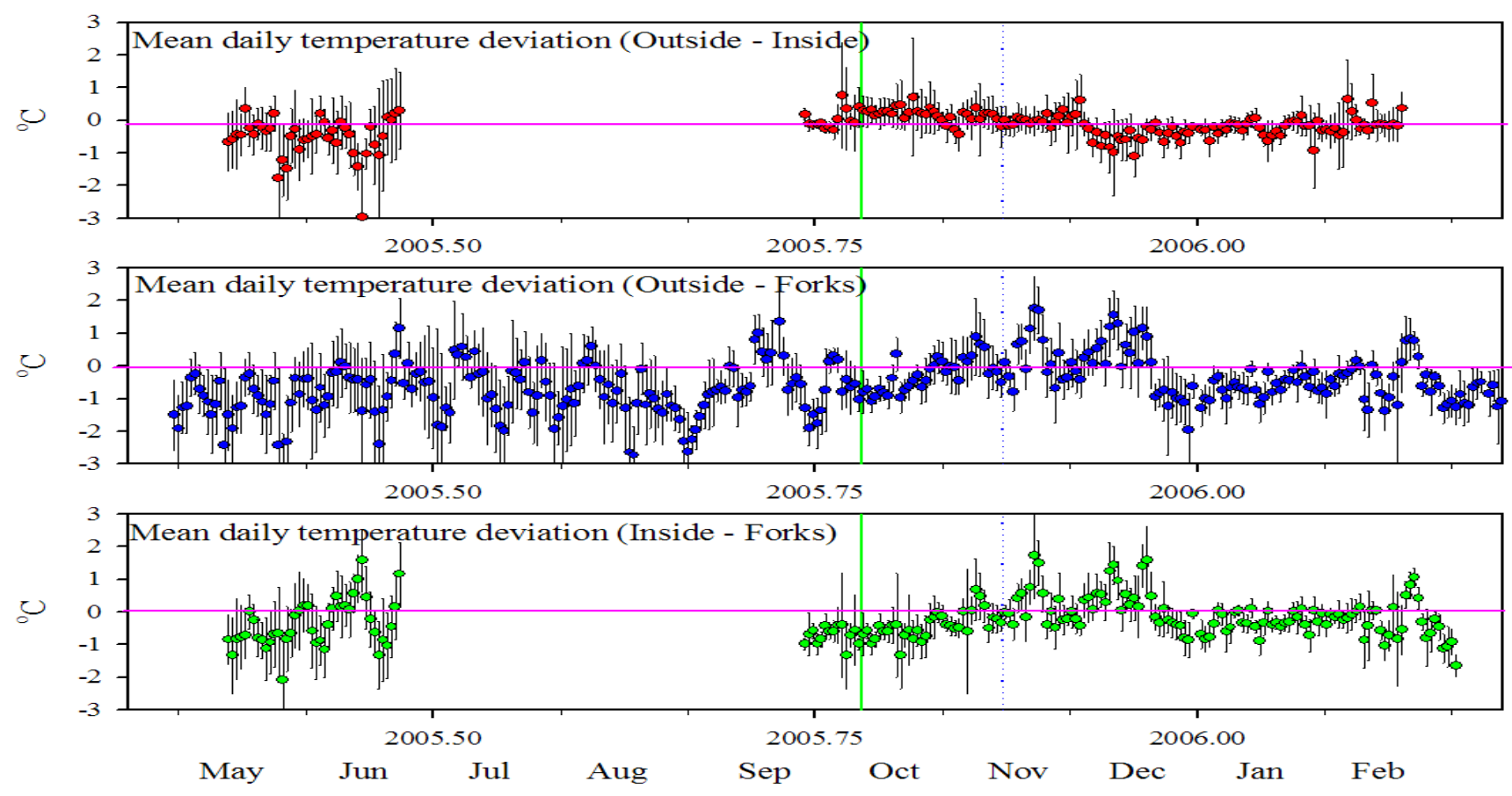

Figure 2.10. Mean Daily Temperature Deviation Time Series for Vera Outside - Vera Forks, Vera OutSide - Vera Inside, and Vera Inside - Vera Forks Tide gate replacement, green vertical line.

\subsection{Conclusions}

Hydrologic data collected demonstrate the range of effects from two distinct restoration treatments. The Kandoll site showed a larger range due to the combination of tide gate removal and dike breach activities. Vera Slough data demonstrated increases in tidal intrusion due to tide gate door manipulations, but amplitudes were "muted" because of tide gate structures. Salinity levels increased at Vera because of the new tide gate design and management treatments of the doors. Temperature variation lessened at both sites between treated areas and reference sites, providing improved habitats for salmonids to occupy and potentially derive benefit. Hydrologic data in particular can help inform the future design, management, and maintenance of these sites overtime. By quantifying the level of tidal intrusion, changes in the management of Vera Slough are better informed. The ability to manipulate tidal volumes and amplitude helps achieve an increased ecological benefit and provide flood control for public and private properties. 

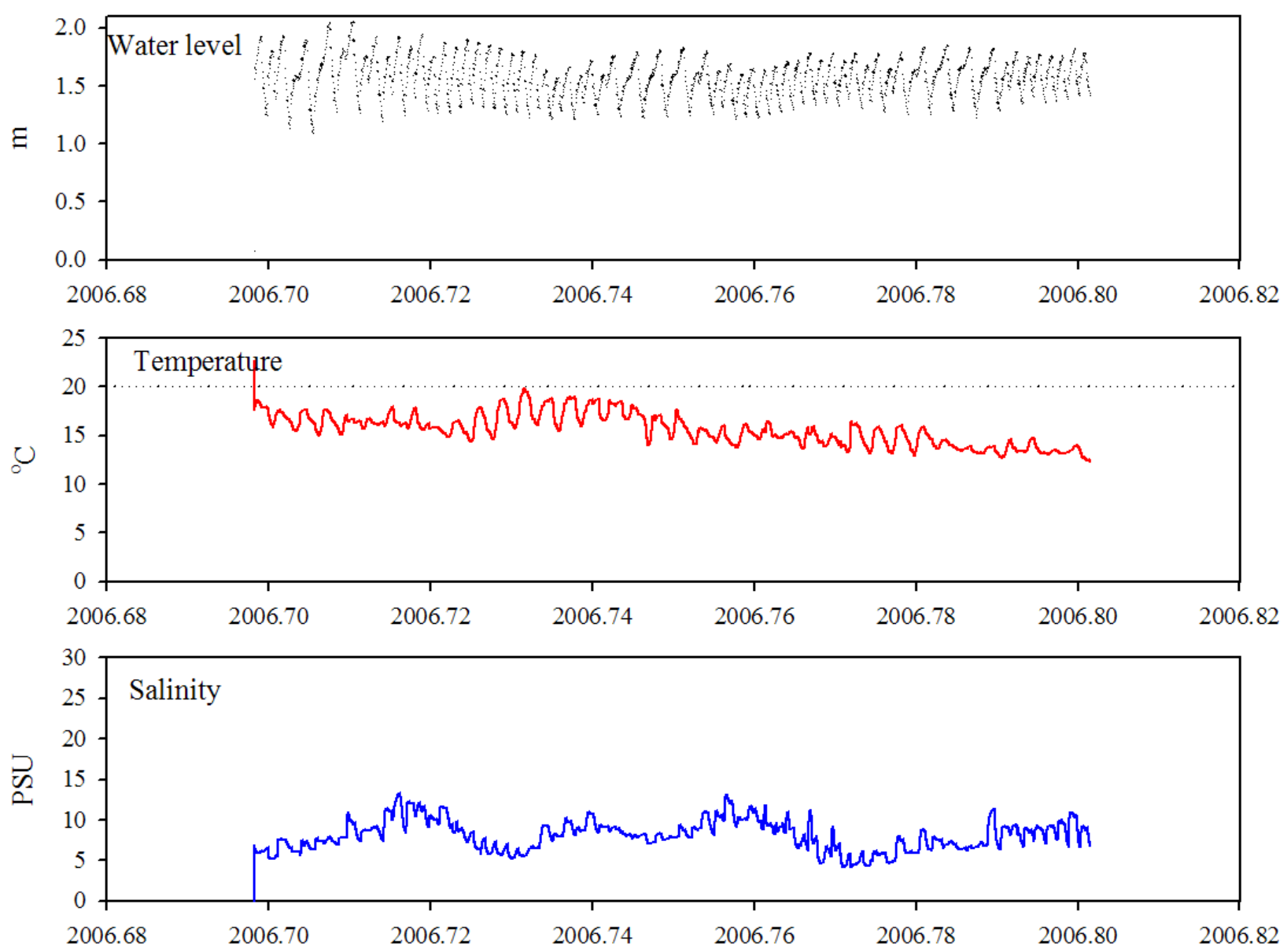

Figure 2.11. Time Series of Water Level, Temperature, and Salinity at Vera Inside during Post-Tide Gate Replacement Conditions in September and October 2006

\subsection{Literature Cited}

Bottom, D.L., C.A. Simenstad, J. Burke, A.M. Baptista, D.A. Jay, K.K. Jones, E. Cassillas, and M.H. Schiewe. 2005. Salmon at River's End: The Role of the Estuary in the Decline and Recovery of Columbia River Salmon. U.S. Dept. Commerce, NOAA Tech. Memo. NMFS-NWFSC-68.

Cornu, C. and S. Sadro. 2002. Physical and functional responses to experimental marsh surface elevation manipulation in Coos Bay's South Slough. Restoration Ecology 10(3):474-486.

Diefenderfer, H.L., R.M. Thom, and K.D. Hofseth. 2005. A Framework for Risk Analysis in Ecological Restoration Projects. In: R.J.F. Bruins and M.T. Heberling (Eds), Economics and Ecological Risk Assessment: Applications to Watershed Management. CRC Press, Boca Raton, Florida.

Roegner, C., H. Diefenderfer, A. Whiting, A. Borde, R. Thom, and E. Dawley. 2006. Monitoring Protocols for Salmon Habitat Restoration Projects in the Lower Columbia River and Estuary. PNNL-15793, Working draft report prepared by CREST, NMFS, and PNNL for the U.S. Army Corps of Engineers, Portland District, Portland Oregon. 


\title{
3.0 Longitudinal Channel Structure, Fallen Trees, and Restoration in Tidal Forested Wetlands of the Columbia River Estuary
}

\author{
Heida L. Diefenderfer ${ }^{\mathrm{a}}$ and David R. Montgomery ${ }^{\mathrm{b}}$
}

\subsection{Introduction}

Ecological restoration requires an understanding of the probable trajectories of ecosystem development, which provides the basis for goals, project designs, and assessment criteria suitable to environmental conditions (Kentula 1992; Thom 1997; 2000; Diefenderfer et al. 2005). To date, however, documentation of channel morphology and the role of wood in Picea sitchensis-dominated tidal wetlands is lacking, complicating efforts to establish goals for the structural characteristics sought by these restoration projects and increasing the need for a survey of this ecosystem. Although log placement is becoming a common, if not wholly successful, treatment in non-tidal streams and rivers worldwide, particularly for fish habitat restoration in North America (Reich et al. 2003), few estuarine restoration projects in the Pacific Northwest have incorporated large wood on the floodplain or in tidal channels (cf. Cornu and Sadro 2002; Cornu, Pers. Comm.; Rot, Pers. Comm.). There is a critical need for information on the effects of large wood in estuaries because coastal restoration programs promote the incorporation of large wood based primarily on data from streams and rivers (Simenstad et al. 2003).

Numerous functions of large wood structures within aquatic and terrestrial ecosystems have been recognized in recent decades (e.g., Swanson and Lienkaemper 1978; Harmon et al. 1986; Sedell et al. 1988; Bilby and Bisson 1998; Gregory et al. 2003; Montgomery and Piégay 2003). The effects of large wood on channel morphology and processes occur at multiple scales. In large floodplain rivers, for example, wood jams can obstruct flow and sediment transport, creating pools and anastomosing channel patterns (Collins and Montgomery 2002; Latterell et al. 2006). In mountain drainage basins, wood structures force the development of pools, bars, and steps (Montgomery and Buffington 1997; 1998). At larger spatial scales, the distribution of wood affects even the development of valley-bottom landforms (Abbe and Montgomery 1996; Collins et al. 2002; Montgomery et al. 2003; Montgomery and Wohl 2004).

Although modifications of channels by wood have been documented in mountain streams and large floodplain rivers, forested tidal channels have received considerably less attention. These channels are subject to influences by oceanic tides and terrestrial watersheds. Thus, large wood from terrestrial sources sometimes forms an obstruction that forces the creation of sloughs by redirecting flow (Collins et al. 2002). Below the elevation of tidal forested wetlands, in the estuarine marshes, drift logs affect the accumulation of organic matter, siltation, and landform development (Eilers 1975; Gonor et al. 1988; Maser and Sedell 1994). Although, historically, large numbers of logs blocked transportation on tidal

\footnotetext{
${ }^{a}$ Marine Sciences Laboratory, Pacific Northwest National Laboratory, Sequim, WA

${ }^{\mathrm{b}}$ University of Washington, Earth and Space Sciences, Seattle, WA
} 
waterways and banks in the western U.S. (Secretary of the Treasury 1859), the structure and functions of wood throughout Pacific Coast estuaries, and in particular at the reach scale in tidal channels, remain largely unknown (Simenstad et al. 2003). In the Sitka spruce (Picea sitchensis) Zone (Franklin and Dyrness 1988) along the Pacific Coast, Hood (2002) showed that floodplain slough size scales with ebb tide surface velocity; however, neither wood transport nor the influence of debris jams on flow or channel morphology were reported.

As large wood affects the physical environment, it also modifies plant succession and habitats for fishes. Fallen trees play significant roles in the succession of estuarine and coastal riparian plant communities on both prograding marshes and river terraces, enabling either the advance or retreat of forest edges (Franklin et al. 1987; Gonor et al. 1988; Maser and Sedell 1994). Specifically, a high percentage of tree reproduction on both alluvial substrates and high marshes occurs on fallen trees, with "nurse logs" providing moisture, salinity, and nutrient levels differing from other substrates (Fonda 1974; Harmon et al. 1986). In contrast, drift logs can batter living trees when re-floated by high tides or storm surges (Eilers 1975; Maser and Sedell 1994). Fallen trees in coastal systems of the Pacific Northwest may also shelter fish, including juvenile salmonids and starry flounder, from predators and provide depressional areas used by juvenile fish once inundation has removed the logs (Eilers 1975; Gonor et al. 1988; Maser and Sedell 1994).

It is reasonable to suppose, given the global declines of both forests and coastal ecosystems, that tidal forested wetlands, and their associated habitat functions, are becoming increasingly rare. In fact, tidal forested wetland plant communities in some regions have been cut over so completely and so long ago that documentation of the characteristics of this ecosystem is virtually nonexistent. One example of a tidal forested wetland is the Picea sitchensis-dominated surge plain wetlands of the Pacific Northwestern U.S. (cf. Peattie 1950; Franklin and Dyrness 1988; Christy and Putera 1992; Kunze 1994). Sitka spruce range from northern California to southeast Alaska (Peterson et. al 1997), with a distribution roughly congruent with the coastal fog belt (Proctor et al. 1980). Peattie (1950) reported that the annual Sitka spruce cut in Oregon and Washington was ten times that of the annual growth rate, due to its high pulp value and strength-to-weight ratio.

On the Columbia River, the largest river system in the Pacific Northwest and second largest in the U.S.A. after the Mississippi basin in terms of discharge, remnant examples of Picea sitchensis-dominated tidal forested wetland provide suitable sites for this study. Below river kilometer 61 on this $235-\mathrm{km}$ drowned-river estuary, settlers reduced the area of tidal forested wetlands by $77 \%$ between 1870 and 1980 (Thomas 1983). Currently, efforts are underway to restore hydrological connections between the Columbia, its tributaries, and diked agricultural lands, in order to recreate tidal forested wetlands and other biotopes (Olenin and Ducrotoy 2006) with tidal channels and floodplain areas used by endangered emigrating juvenile salmon.

Tidally influenced forested wetlands not only occupy a position spatially between terrestrial and oceanic systems, they also exist at the boundaries of scientific disciplines. While this may in part explain the lack of attention that these systems have received previously in the Pacific Northwest, it also provides an opportunity for testing the degree to which it is valid to extend the boundaries of previously tested frameworks: from rivers to tidal channels, forests to wetlands, or brackish aquatic environments to fresh. Accordingly, this paper extends the channel classification system of Montgomery and Buffington (1997; 
1998) down-slope to tidal forested wetland channels and, relative to this classification scheme, examines the influence of large wood, together with dams built by the North American beaver (Castor canadensis), on the morphology of tidal channels in Picea sitchensis-dominated tidal wetlands of the Columbia River estuary.

\subsection{Study Areas and Methods}

Forested portions of three tidal channels in the vicinity of Grays Bay on the Columbia River in Washington State were surveyed in 2006: Secret River (432 m), Seal Slough (273 m), and Crooked Creek (306 m) (Figure 3.1). The three channels are located in tidal forested wetlands of the Picea sitchensis zone (Franklin and Dyrness 1988) approximately $37 \mathrm{~km}$ from the mouth of the Columbia River on the Pacific Ocean (river mile 23). The diurnal range, or difference between mean higher high water and mean lower low water, is $7.7 \mathrm{ft}$ at nearby Harrington Point (NOAA 2006). The widths of the channels at the survey start points were comparable: Secret River was $14.8 \mathrm{~m}$ and the others both measured $15.1 \mathrm{~m}$. Secret River flows directly into Grays Bay and the survey was begun at the edge of the forested area; the other channels both have downstream confluences above Grays Bay and forests surround the mouths of the surveyed channels (Figure 3.1). The Grays River site, on a side channel of Seal Slough, was also compared to adjacent diked pastureland where hydrological processes were controlled by dikes, roadbeds, tide gates, and culverts (Figure 3.1).

The longitudinal channel structure was surveyed from the mouth upwards at each of the three forested sites using a Topcon AT-G2 model auto level to record points along the thalweg and to define obstructions according to the downstream and upstream extent and high point. Log jams and beaver dams were also mapped and photo-documented. Beaver dams were distinguished from log jams solely based on the smaller size and woven arrangement of component wood; not all logs were examined for cause of mortality and some larger logs may have been felled by beaver. Above the end of the survey on Seal Slough, achieving line of sight for survey purposes would have required substantial removal of riparian vegetation; therefore, beaver dams and log jams were simply counted.

Obstructions in upper Seal Slough in the restoration area (Figure 3.1) were photodocumented and mapped in 2005, prior to implementation of restoration actions including culvert replacement and dike breaching the same year. The lengths of channels in the restoration area and above the surveyed portion of the forested Seal Slough reference site (Figure 3.1) were measured from orthophotos using ESRI ArcGIS 9.0. Linear measurement of beaver dam spacing on Seal Slough in the restoration area was precluded by the forked channel; to calculate the average distance between dams, the lengths of mainstem Seal Slough on the farm (149 m), the east channel (453 m) and the west channel (469 m) were summed and divided by $n+1$, where $n=$ number of beaver dams. Channel width was estimated from aerial photos for the restoration area only; for forested wetlands, they were calculated as distance between log jams divided by channel width.

Elevations were determined using real-time kinematic (RTK) global positioning system (GPS) surveys. A base station was placed on a local benchmark and a rover was used to collect point data at one point on each of the three longitudinal surveys. Baseline calculations were performed by the automated Online Positioning User Service (OPUS) provided by the National Geodetic Survey (NGS). Auto-level data from the longitudinal surveys were corrected to these points. 


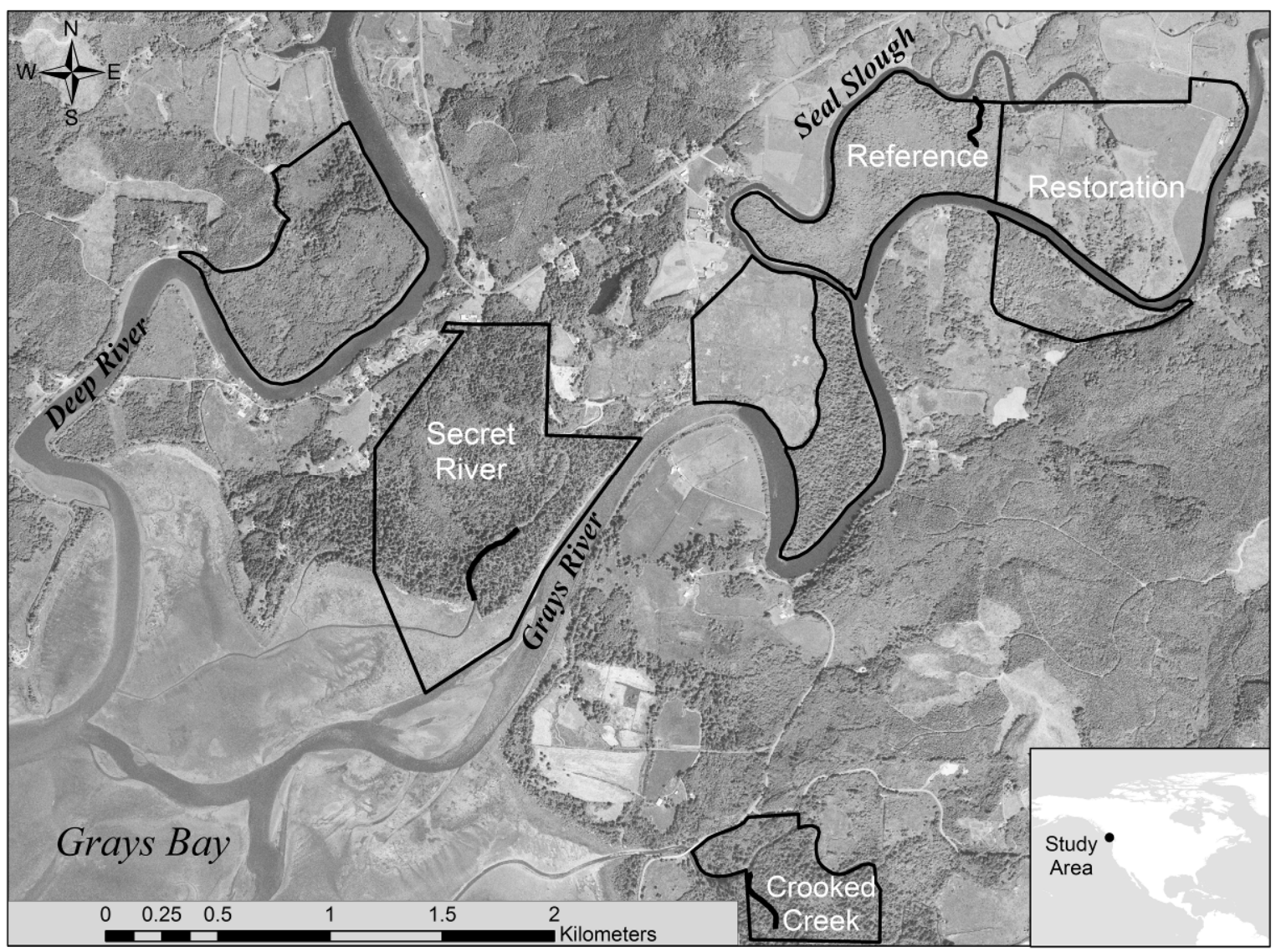

Figure 3.1. Columbia Land Trust Protection and Restoration Properties in the Vicinity of the Deep River (to the west) and Grays River (to the east) on Grays Bay of the Columbia River in Washington State. Channels surveyed for this study were Secret River, a side channel of Seal Slough, and Crooked Creek. Courtesy of the Columbia Land Trust.

\subsection{Results}

The average distance between log jams, or pool length, recorded in longitudinal surveys ranged from $1.9 \pm 1.0$ to $2.5 \pm 1.5$ channel widths in the three tidal forested wetlands (Table 3.1). Within the surveyed areas, two beaver dams were identified on Seal Slough and one at Secret River, all three were upstream of all surveyed log jams. No beaver dams were identified on the Crooked Creek survey. On Seal Slough, five beaver dams and one log were counted in the 130-m stretch above the survey area and below the road bisecting sites E and F (Figure 3.1) (average spacing 1:22 $\mathrm{m}$ or 1.5 channel widths/pool). Channel gradients were low $(0.001-0.005 \mathrm{~m} / \mathrm{m})$ (Table 3.1).

Wood accumulations in the tidal forested wetland channels were dense (Figure 3.2). In contrast, upper Seal Slough within Kandoll Farm (Figure 3.1F), an area of pastureland sparsely forested in places with Picea sitchensis and Alnus rubra, contained no log jams prior to the implementation of restoration actions for hydrological reconnection in 2005. Reconnaissance observations indicated that channel morphology on the farm consisted of featureless planar beds with fine-grained substrate, and only three 
pools, located at the confluence and on each of the two forks, respectively. The 324-m north borrow ditch along Kandoll Road in the farm was also examined; it contained one beaver dam and a burrow on the bank.

Table 3.1. Channel Characteristics

\begin{tabular}{|c|c|c|c|c|c|c|}
\hline & \multicolumn{3}{|c|}{ Tidal Forested Wetlands } & \multicolumn{3}{|c|}{ Restoration Site } \\
\hline & $\begin{array}{l}\text { Crooked } \\
\text { Creek Side } \\
\text { Channel }\end{array}$ & $\begin{array}{l}\text { Secret } \\
\text { River }\end{array}$ & $\begin{array}{l}\text { Seal } \\
\text { Slough } \\
\text { Side } \\
\text { Channel }\end{array}$ & $\begin{array}{l}\text { Seal Slough } \\
\text { Mainstem }\end{array}$ & $\begin{array}{l}\text { Seal Slough } \\
\text { South Fork }\end{array}$ & $\begin{array}{l}\text { Seal Slough } \\
\text { North Fork }\end{array}$ \\
\hline Gradient $(\mathrm{m} / \mathrm{m})$ & 0.005 & 0.001 & 0.004 & ND & $\begin{array}{c}0.004 \\
\text { (includes } \\
\text { mainstem) }\end{array}$ & $\begin{array}{c}0.004 \\
\text { (includes } \\
\text { mainstem) }\end{array}$ \\
\hline $\begin{array}{l}\text { Mean Channel } \\
\text { Width (m) }\end{array}$ & $\begin{array}{l}2007 \text { data } \\
\text { in analysis }\end{array}$ & $\begin{array}{l}2007 \text { data } \\
\text { in } \\
\text { analysis }\end{array}$ & $\begin{array}{l}2007 \text { data } \\
\text { in analysis }\end{array}$ & 31 & 12 & 9 \\
\hline $\begin{array}{l}\text { Distance between } \\
\text { log jams or } \\
\text { beaver dams }(\mathrm{m}) \\
\text { (mean } \pm \text { s.d.) }\end{array}$ & $\begin{array}{c}37.4 \pm \\
22.5\end{array}$ & $\begin{array}{l}34.1 \pm \\
20.3\end{array}$ & $\begin{array}{c}28.9 \pm \\
15.1\end{array}$ & $\begin{array}{c}\text { N/A (no } \\
\text { obstructions) }\end{array}$ & 235 & 227 \\
\hline $\begin{array}{l}\text { Channel } \\
\text { Widths/Pool } \\
\text { (mean } \pm \text { s.d.) }\end{array}$ & $2.5 \pm 1.5$ & $2.3 \pm 1.4$ & $1.9 \pm 1.0$ & 7.9 & 42.7 & 165 \\
\hline $\begin{array}{l}\text { Length Surveyed } \\
\text { (m) }\end{array}$ & 306 & 432 & 273 & 149 & 469 & 453 \\
\hline
\end{tabular}

Typically, in the tidal forested wetland channels, pools were located immediately upstream of each log jam or beaver dam (Figure 3.3). The shallower area or "tail-out" of each pool was usually located upstream of the pool (downstream of the next log jam or beaver dam).

Since culvert replacement at Kandoll in 2005, the developing channel network in the non-forested restoration area has exposed previously buried logs (Figure 3.4). In addition, many of the remaining trees on the restoration site succumbed in the first winter after increased inundation and some remain in or near the channels (Figure 3.4). Anecdotal observations showed that large wood located below the tide gates on Seal Slough moved out of the Seal Slough system following replacement with culverts and increased flow velocities and levels of inundation on the farm. Beaver dams mapped prior to culvert replacement were broken apart by the summer of 2006 . 


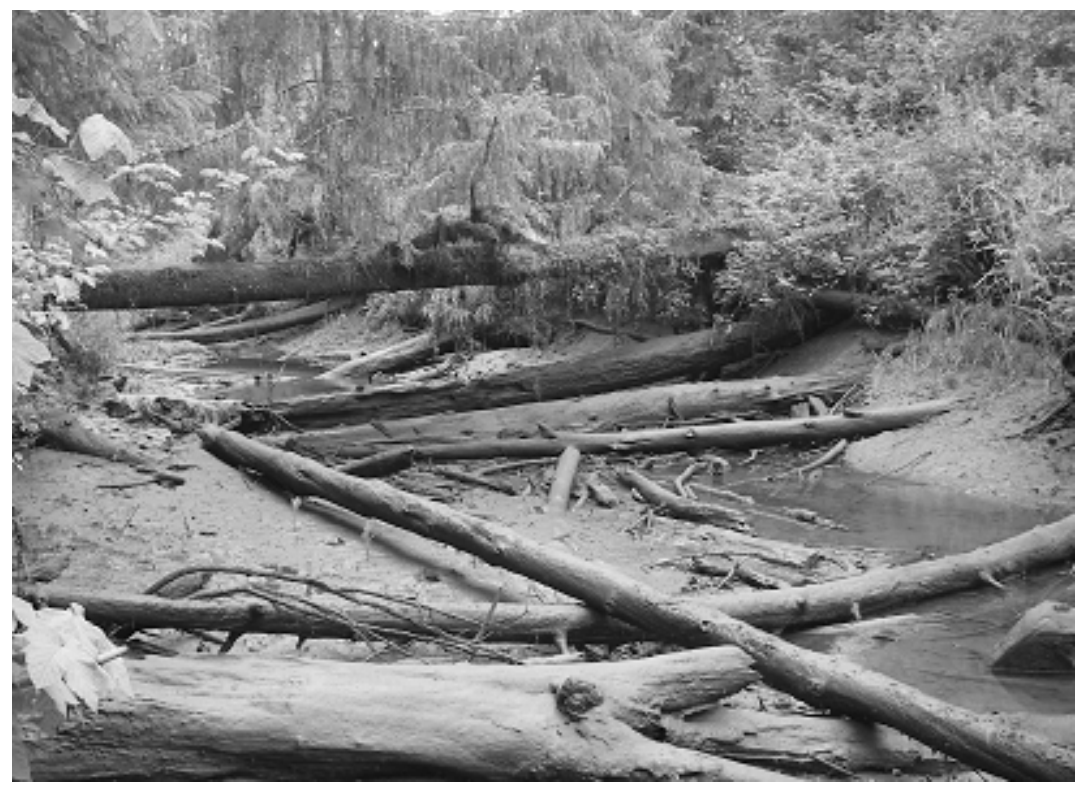

Figure 3.2. Wood in Seal Slough Side Channel. Exposed by a minus tide, looking upstream at the tailout of one pool (right) and the deepest portion of another (left). Elevated nurse log across channel supports Picea sitchensis saplings.

\section{Secret River Longitudinal Survey}

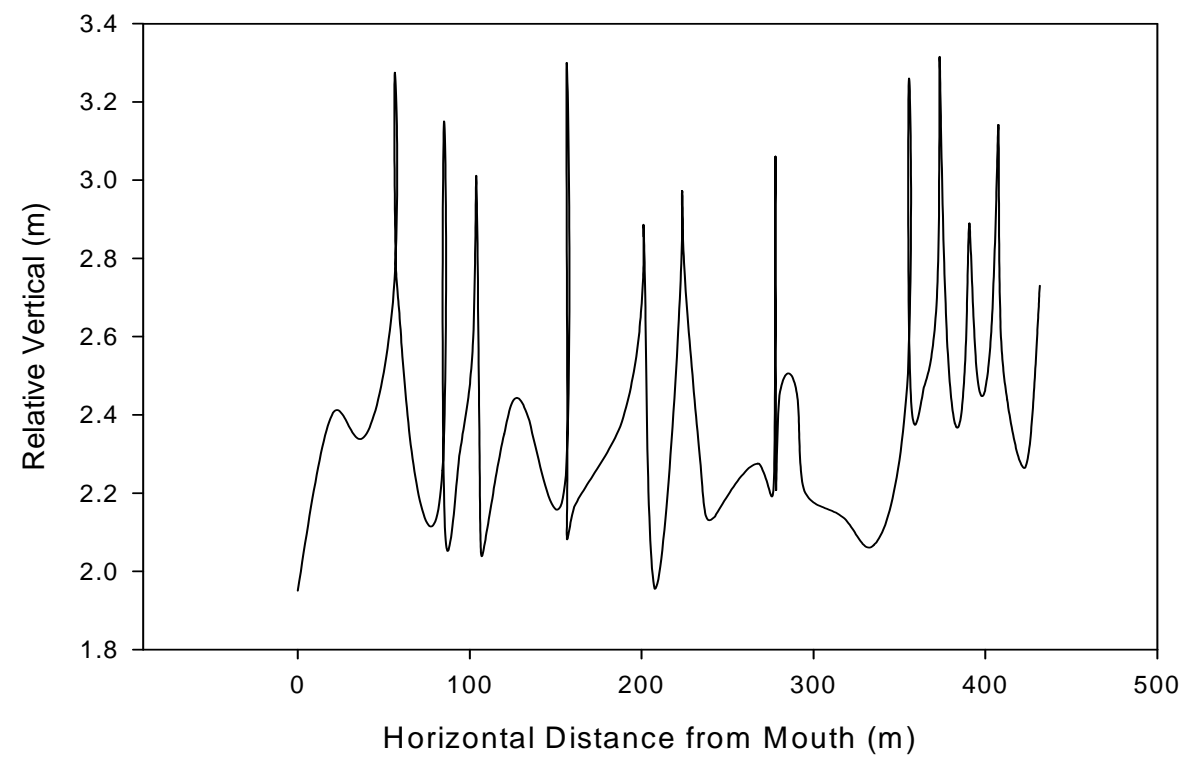

Figure 3.3. Longitudinal Surveys of Forested Wetland Channels in Seal Slough, Secret River, and Crooked Creek. Bold lines represent substrate elevation immediately downstream and upstream of log jams. Peaks are log jams or beaver dams, and troughs are pools. 

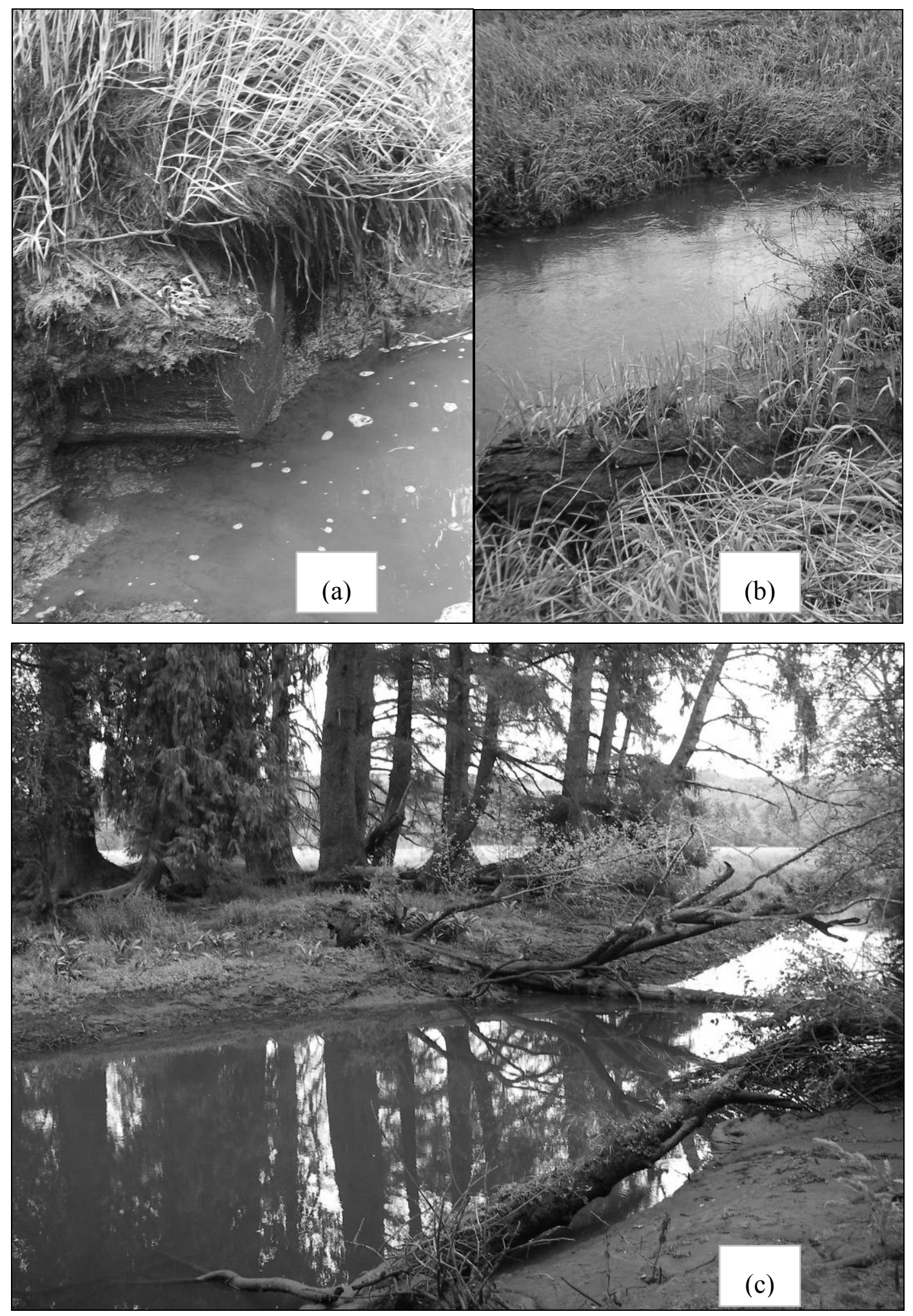

Figure 3.4. Logs Exposed by Channel Network Development following Dike Breaching at two Grays River Restoration Sites: (a) see Figure 3.1, (b) see Figure 3.1, (c) large woody debris (LWD) recruitment following culvert replacement in Seal Slough (see Figure 3.1). 


\subsection{Discussion}

Two features of the tidal channels in Picea sitchensis-dominated wetlands in the vicinity of the Grays River evidence a forced step-pool morphology (Montgomery et al. 1995; Montgomery and Buffington 1998). First, the average number of channel widths per pool (1.7) falls within the characteristic range. Second, the observed sequence of log jams (steps) with pools between them is typical of forced steppools. These tidal channels, however, are different from others to which this classification has previously been applied in that the tidal channels have bidirectional flow and very low gradients whereas the riverine channels typically do not. In fact, the tidal pool structure is reversed from that of typical mountain streams. In the tidal channels, pools most frequently are located immediately upstream of log jams, with tails located upstream of the pool just downstream of the next obstruction. This suggests that the incoming flood tide, in plunging over the log jams and beaver dams once the water-level exceeds their elevation, plays a larger role in structuring channels longitudinally than does the ebb tide.

The average density of large wood jams and beaver dams in the three surveyed forested wetland channels far exceeds that of the diked pasture prior to restoration; in fact, the pasture lacked log jams entirely. Previously buried logs exposed by restoration of tidal channels, and trees felled by inundation following culvert replacement, may be viewed as biological legacies (Franklin et al. 1985; Franklin et al. 1995) of the previously existing forested wetlands. These logs, and others that may be transported onto the restoration site following increased hydrological connection with the Grays and Columbia rivers, have the potential to provide ecological functions analogous to those in the forested wetland channels surveyed in this study. However, the observed abundance on the restoration area remains much lower than that of adjacent forested wetlands, which suggests that the placement of large wood should be evaluated as an option in restoration designs in the vicinity of these surveys (Figure 3.1) and in other tidal forested wetlands.

In evaluating whether to place large wood, several additional elements are important to consider: the anticipated effects on channel structure, the deposition and accumulation of sediments and organic material across the site, and the potential plant communities. Salinity and elevation are the primary determinants of the distribution of plant species and communities in the Columbia River estuary (Fox et al. 1984). If the controlling factor of elevation with associated inundation regimes is not recreated sufficiently within the range of Picea sitchensis, a forested wetland may not result from the hydrological restoration actions (cf. Mahoney and Rood 1998; Rood et al. 2003). If elevations remain lower, with greater inundation, a low or high marsh or shrub-scrub wetland is more likely to replace current conditions, based on the known elevation gradients of these plant communities (Eilers 1975; Proctor et al. 1980; Fox et al. 1984; Small et al. 1990).

In light of the substantial effects of large wood on tidal channel structure, the role of the beaver should also be considered in restoration planning for tidal forested wetlands. Although beaver populations experienced a widespread decline due to the fur trade, they are recovering throughout most of the animal's former range (Maser et al. 1984). Beaver strongly prefer to dam low-gradient streams, and their dams can attenuate flood peaks by slowing velocities and retaining water (Pollock et al. 2003). Despite contentions in early literature to the contrary, no study has shown detrimental effects of beaver dams on salmon at the population level; several studies have documented juvenile salmonids, particularly coho (Oncorhynchus kisutch) and sockeye (Oncorhynchus nerka), using beaver ponds in coastal streams 
for overwintering habitat as well as refuge and rearing throughout the year (Pollock et al. 2003). Seven beaver dams were documented on the forested wetland channel adjacent to the restoration site in this study, and three in farmland channels prior to restoration, suggesting that it may have been safe to predict that beaver would be active throughout the restoration; evidence of this has in fact been observed. Several factors merit further investigation on a larger scale: 1) the potential for modifications to hydraulics and channel structure made by beaver and various restoration actions to interact, positively or detrimentally; and 2) variability in the availability of standing trees and size of beaver populations in restoration areas.

While estuarine channel structure has been correlated with fish species assemblage in some West Coast environments (e.g., Desmond et al. 2000; Williams and Zedler 1999), fish use of pools forced by logs in forested wetlands has not been systematically examined. Unpublished trap net data documented juvenile coho salmon in pools of the forested side channel of Seal Slough surveyed for this study (Columbia Land Trust, 2000-2001); this channel has not been surveyed during the period of juvenile Chinook salmon (Oncorhynchus tshawytscha) or chum salmon (O. keta) emigration. The habitat functions of these pools merit further investigation.

\subsection{Conclusion}

The morphology of forested tidal channels of a tributary to the Columbia River estuary may be viewed as a special case of the forced step-pool class that has previously been defined and documented in higher-gradient forest systems with unidirectional flow (Montgomery et al. 1995; Montgomery and Buffington 1998). However, it must be cautioned that results of these surveys be interpreted in light of the highly regulated condition of the Columbia River, with some 30 major dams in the basin and an altered hydrograph influencing hydrodynamics in the estuary (Kukulka and Jay 2003a). Hydrographic modeling has estimated that the Columbia River peak flow reductions are greater than $40 \%$ (Kukulka and Jay 2003b). In particular, the dampened spring freshet may somewhat limit channel-forming events and flushing of estuary tributary areas such as the Grays River watershed. Nevertheless, dramatic winter floods still occur along the Grays River, and it is clear that the velocities and flows in Seal Slough are sufficient to mobilize and transport logs and remove beaver dams in formerly controlled channels. Channel size in these systems has been shown to scale with the amount of export of allochthonous detritis (Hood 2002).

If surveys of existing tidal forested wetlands are to be used to develop objectives for restoration projects, the relevance of the problem of "shifting baselines" characteristic to rapidly developing coastal and estuarine areas should be explicitly considered (Lotze et al. 2006). Historical evidence (reviewed in Gonor et al. 1988 and Maser and Sedell 1994) shows that very large numbers of pieces of large wood were removed by extensive and sustained labor in Pacific Northwest estuaries including the Columbia, although the numbers and spacing characteristic of reaches in specific biotopes in a pre-disturbance condition cannot be inferred from this record. Likewise, with land cover change in the estuary and changed floodplain dynamics, beaver population sizes and their potential to modify channel structure with logs are likely to have changed. Nevertheless, the Columbia River is likely to remain regulated for the foreseeable future given its importance to agriculture and industry. Therefore, although pre-disturbance 
conditions remain unknown, current conditions in adjacent or ecologically similar tidal forested wetland sites may serve as suitable references for the potential outcomes of restoration trajectories.

\subsection{Literature Cited}

Abbe, T.B. and D.R. Montgomery. 1996. Large woody debris jams, channel hydraulics, and habitat formation in large rivers. Regulated Rivers: Research and Management 12:201-221.

Bilby, R.E. and P.A. Bisson. 1998. Function and distribution of large woody debris. In R.J Naiman and R.E. Bilby, eds. River Ecology and Management: Lessons from the Pacific Coastal Ecoregion, pp.324-346. Springer-Verlag, New York.

Christy, J.A. and J.A. Putera. 1992. Lower Columbia River Natural Area Inventory. Report to The Nature Conservancy, Washington Field Office, Seattle.

Collins, B.D. and D.R. Montgomery. 2002. Forest development, wood jams, and restoration of floodplain rivers in the Puget Lowland, Washington. Restoration Ecology 10(2):237-247.

Collins, B.D., D.R. Montgomery, and A.D. Haas. 2002. Historical changes in the distribution and functions of large wood in Puget Lowland rivers. Canadian Journal of Fisheries and Aquatic Sciences 59:66-76.

Cornu, C. and S. Sadro. 2002. Physical and functional responses to experimental marsh surface elevation manipulation in Coos Bay's South Slough. Restoration Ecology 10(3):474-486.

Desmond, J.S., J.B. Zedler, and G.D. Williams. 2000. Fish use of tidal creek habitats in two southern California salt marshes. Ecological Engineering 14:233-252.

Diefenderfer, H.L., R.M. Thom, and K.D. Hofseth. 2005. A framework for risk analysis in ecological restoration projects. In: R.J.F. Bruins and M.T. Heberling (Eds), Economics and Ecological Risk Assessment: Applications to Watershed Management. CRC Press, Boca Raton, Florida.

Eilers, H.P. 1975. Plants, Plant Communities, Net Production and Tide Levels: the Ecological Biogeography of the Nehalem Salt Marshes, Tillamook County, Oregon. Ph.D. Thesis, Oregon State University, Corvallis, OR. 368p.

Fonda, R.W. 1974. Forest succession in relation to river terrace development in Olympic National Park, Washington. Ecology 55(5):927-942.

Fox, D.S., S. Bell, W. Nehlsen, and J. Damron. 1984. The Columbia River Estuary: Atlas of Physical and Biological Characteristics. Columbia River Estuary Data Development Program, Astoria, Oregon.

Franklin, J.F. and C.T. Dyrness. 1988 (1973). Natural Vegetation of Oregon and Washington. OSU Press. Corvallis, Oregon.

Franklin, J.F., H.H. Shugart, and M.E. Harmon. 1987. Tree death as an ecological process. BioScience 37(8):550-556.

Franklin, J.F., J.A. MacMahon, F. Swanson, J.R. Sedell. 1985. Ecosystem responses to the eruption of Mount St. Helens. National Geographic Research 1(2):198-216.

Franklin, J.F., P.M. Frenzen, and F.J. Swanson. 1995. "Re-creation of ecosystems at Mount St. Helens: contrasts in artificial and natural approaches." In J. Cairns, Jr., ed., Rehabilitating Damaged Ecosystems, pp.287-333. Lewis Publishers, Boca Raton, Fl., U.S.A. 
Gonor, J.J., J.R. Sedell, and P.A. Benner. 1988. What we know about large trees in estuaries, in the sea, and on coastal beaches. In Maser, C., R.F. Tarrant, J.M. Trappe, and J.F. Franklin, eds. From The Forest to the Sea: a Story of Fallen Trees, pp. 83-112. U.S.D.A. Forest Service Gen. Tech. Rep. PNW-GTR-229, Portland, Oregon.

Gregory, S.V., K.L. Boyer, and A.M. Gurnell, eds. 2003. The Ecology and Management of Wood in World Rivers. American Fisheries Society, Symposium 37, Bethesda, Maryland.

Harmon, M.E., J.F. Franklin, F.J. Swanson, P. Sollins, S.V. Gregory, J.D. Lattin, N.H. Anderson, S.P. Cline, N.G. Aumen, J.R. Sedell, G.W. Lienkaemper, K. Cromack, Jr., and K.W. Cummins. 1986. Ecology of coarse woody debris in temperate ecosystems. Advances in Ecological Research 15:133302.

Hood, W.G., 2002. Landscape allometry: from tidal channel hydraulic geometry to benthic ecology. Can. J. Fish. Aquat. Sci. 59: 1418-1427.

Kentula, M.E., R.P. Brooks, S.E. Gwin, C.C. Holland, A.D. Sherman and J.C. Sifneos. 1992. An Approach to Improving Decision Making in Wetland Restoration and Creation. EPA/600/R-92/150, U.S. Environmental Protection Agency Environmental Research Laboratory, Corvallis, Oregon.

Kukulka, T. and D.A. Jay. 2003a. Impacts of Columbia River discharge on salmonid habitat I: a nonstationary fluvial model. Journal of Geophysical Research 108(C9):3293.

Kukulka, T. and D.A. Jay. 2003b. Impacts of Columbia River discharge on salmonids habitat II: changes in shallow-water habitat. Journal of Geophysical Research 108(C9):3294.

Kunze, L.M. 1994. Preliminary Classification of Native, Low Elevation, Freshwater Wetland Vegetation in Western Washington. Washington State Department of Natural Resources, Olympia, Washington.

Latterell, J.J., J.S. Bechtold, T.C. O'Keefe, R. van Pelt and R.J. Naiman. 2006. Dynamic patch mosaics and channel movement in an unconfined river valley of the Olympic Mountains. Freshwater Biology 51:523-544.

Lotze, H.K., H.S. Lenihan, B.J. Bourque, R.H. Bradbury, R.G. Cooke, M.C. Kay, S.M. Kidwell, M.X. Kirby, C.H. Peterson, and J.B.C. Jackson. 2006. Depletion, degradation, and recovery potential of estuaries and coastal seas. Science 312:1806-1809.

Mahoney, J.M. and S.b. Rood. 1998. Streamflow requirements for cottonwood seedling recruitment: An integrative model. Wetlands 18:634-645.

Maser, C. and J.R. Sedell. 1994. From the Forest to the Sea: The Ecology of Wood in Streams, Rivers, Estuaries, and Oceans. St. Lucie Press, Delray Beach, FL.

Maser, C., B.R. Mate, J.F. Franklin, and C.T. Dyrness. 1984 (1981). Natural History of Oregon Coast Mammals. Special Publication of the University of Oregon Museum of Natural History, Eugene, Oregon.

Mongomery, D.R., J.M. Buffington, R.D. Smith, K.M. Schmidt, and G. Pess. 1995. Pool spacing in forest channels. Water Resources Research 31(4):1097-1105.

Montgomery, D.R. and E.E. Wohl, 2004. Rivers and riverine landscapes. Developments in Quaternary Science 1:221-245.

Montgomery, D.R. and H. Piégay, 2003. Wood in rivers: interactions with channel morphology and processes. Geomorphology 51:1-5. 
Montgomery, D.R. and J.M. Buffington. 1997. Channel-reach morphology in mountain drainage basins. GSA Bulletin 109(5):596-611.

Montgomery, D.R. and J.M. Buffington. 1998. Channel processes, classification, and response. In R.J Naiman and R.E. Bilby, eds. River Ecology and Management: Lessons from the Pacific Coastal Ecoregion, pp.13-42. Springer-Verlag, New York.

NOAA (National Oceanic and Atmospheric Administration). 2006. "2006 water-level tidal predictions." http://tidesandcurrents.noaa.gov/

Olenin, S. and J-P Ducrotoy. 2006. The concept of biotope in marine ecology and coastal management. Marine Pollution Bulletin 53:20-29.

Peattie, D.C. 1950. A Natural History of Western Trees. University of Nebraska Press, Lincoln.

Peterson, E.B. N.M. Peterson, G.F. Weetman, and P.J. Martin. 1997. Ecology and Management of Sitka Spruce: Emphasizing its Natural Range in British Columbia. UBC Press, British Columbia, Canada.

Pollock, M.M., M. Heim, and D. Werner. 2003. Hydrologic and geomorphic effects of beaver dams and their influence on fishes. In Gregory, S.V., K.L. Boyer, and A.M. Gurnell, eds. The Ecology and Management of Wood in World Rivers, pp.213-233. American Fisheries Society, Bethesda, MD.

Proctor, C.M., J.C. Garcia, D.V. Galvin, t. Joyner, G.B. Lewis, L.C. Loehr, and A.M. Massa. 1980a. An Ecological Characterization of the Pacific Northwest Coastal Region, Volume One: Conceptual Model. FWS/OBS-79/11, USFWS Office of Biological Services - Region 1, Portland, Oregon.

Reich, M., J.L. Kershner, and R.C. Wildman. 2003. Restoring streams with large wood: a synthesis. In S.V. Gregory, K.L. Boyer, and A.M. Gurnell, eds. The Ecology and Management of Wood in World Rivers, pp. 355-366. American Fisheries Society, Bethesda, MD.

Rood, S.B., C.R. Gourley, E.M. Ammon, L.G. Heki, J.R. Klotz, M.L. Morrison, D. Mosley, G.G. Scoppettone, S. Swanson, and P.L. Wagner. 2003. Flows for floodplain forests: A successful riparian restoration. BioScience 53(7):647-656.

Secretary of the Treasury. 1859. The Report of the Superintendent of the Coast Survey Showing the Progress of the Survey in 1858. In House Executive Documents, No. 33: 2d session, 35th Congress. U.S. Government Printing Office, Washington, D.C.

Sedell, J.R., P.A. Bisson, F.J. Swanson, and S.V. Gregory. 1988. What we know about large trees that fall into streams and rivers. In Maser, C., R.F. Tarrant, J.M. Trappe, and J.F. Franklin, eds. From the Forest to the Sea: a Story of Fallen Trees, pp. 47-81. U.S.D.A. Forest Service Gen. Tech. Rep. PNW-GTR-229, Portland, Oregon.

Simenstad, C.A., A. Wick, S. van de Wetering, and D.L. Bottom. 2003. Dynamics and ecological functions of wood in estuarine and coastal marine ecosystems. In S.V. Gregory, K.L. Boyer, and A.M. Gurnell, eds. The Ecology and Management of Wood in World Rivers, pp. 265-277. American Fisheries Society, Bethesda, MD.

Small, L.F., C.D. McIntire, K.B. MacDonald, J.R. LaraLara, B.E. Frey, M.C. Amspoker, and T. Winfield. 1990. Primary production, plant and detrital biomass, and particle transport in the Columbia River Estuary. In Small, L.F. (ed.). "Columbia River: Estuarine System.” Progress in Oceanography, Vol. 25 , no. $1-4$. 
Swanson, F.J. and G. Lienkaemper. 1978. Physical Consequences of Large Organic Debris in Pacific Northwest Streams. USDA Forest Service General Technical Report PNW-69, Pacific Northwest Forestry and Range Experiment Station, Portland, OR.

Thom, R.M. 2000. "Adaptive management of coastal ecosystem restoration projects.” Ecological Engineering 15:365-372.

Thom, R.M. 1997. "System-development matrix for adaptive management of coastal ecosystem restoration projects." Ecological Engineering 8:19-232.

Thomas, D.W. 1983. Changes in the Columbia River estuary habitat types over the past century. Report of the Columbia River Estuary Data Development Program. Columbia River Estuary Study Taskforce, Astoria, OR.

Williams, G.D. and J.B. Zedler. 1999. Fish assemblage composition in constructed and natural tidal marshes of San Diego bay: relative influence of channel morphology and restoration history. Estuaries 22(3A):702-716. 


\title{
4.0 Early Morphological Response to Dike Breaching and Culvert and Tide Gate Replacement in the Columbia River Estuary
}

\author{
Heida L. Diefenderfer ${ }^{\mathrm{a}}$, Amy B. Borde ${ }^{\mathrm{a}}$, Allan H. Whiting ${ }^{\mathrm{b}}$, and Ian Sinks ${ }^{\mathrm{c}}$
}

\subsection{Introduction}

Methods of habitat restoration for juvenile salmonids rearing in the 235-km Columbia River estuary primarily involve hydrologic reconnection of existing or relict lateral floodplain channels with the mainstem river. "Habitat opportunity" (sensu Simenstad and Cordell 2000), or the ability of fishes to access these tidal channels and adjacent floodplains, was restricted or rendered nonexistent in the 19th and 20th centuries by flow management and the installation of passage barriers having variable permeabilities (e.g., levees and tide gates). Removing these passage barriers - in particular, breaching dikes and removing or replacing culverts and tide gates - is an element of current restoration plans by federal and state agencies, non-governmental organizations, and other entities working in the estuary (Johnson et al. 2003).

The condition of controlling factors at the landscape scale constrains the restoration of aquatic ecosystem structures and processes (National Research Council 1992; Toth 1995). In the case of floodplain channels on the Columbia River, hydrology is the essential altered controlling factor. Since the 1930 s, the river's discharge has been progressively regulated by some 30 major dams and numerous minor dams throughout the basin (Kukulka and Jay 2003a). Historically, unregulated flows were estimated to range from a minimum of $2,237 \mathrm{~m}^{3} / \mathrm{s}(79,000$ cubic feet per second [cfs]) in the fall to maximum flood flows of over $28,317 \mathrm{~m}^{3} / \mathrm{s}$ (1 million cfs) during spring freshets (Sherwood et al. 1990). Today, hydrographic modeling estimates that diking combined with a greater than $40 \%$ reduction in flow during the spring freshet (May-July) has reduced shallow water habitat area used by juvenile salmonids in the Columbia estuary by approximately 62\% (Kukulka and Jay 2003b).

While the removal of barriers to fish passage and flow in the estuarine floodplain does not itself remedy alterations to the mainstem Columbia River hydrograph, it does have the potential to restore access to floodplain habitats for juvenile salmonids and other native biota (cf., Miller and Simenstad 1997; Williams and Zedler 1999; Kukulka and Jay 2003b). Hydrology and elevation are among the factors controlling development of vegetation communities in this very dynamic estuary (Fox et al. 1984); therefore, even limited flow restoration has the potential to affect "habitat capacity" (Simenstad and Cordell 2000), i.e., the ability of the habitat to support juvenile salmonids. For instance, vegetation affects important aquatic habitat characteristics such as shade, organic matter, water velocity, and salmonid prey.

\footnotetext{
${ }^{a}$ Marine Sciences Laboratory, Pacific Northwest National Laboratory, Sequim, WA

${ }^{\mathrm{b}}$ Columbia River Estuary Study Taskforce, Astoria, OR

${ }^{c}$ Columbia Land Trust, Vancouver, WA
} 
The complete removal of dikes and water control structures may permit the fastest changes and the broadest spatial influence of the restoration action when compared to dike breaching (e.g., Simenstad and Feist 1996; Simenstad and Warren 2002; Hood 2004). However, flood control to protect neighboring properties remains the responsibility of property owners undertaking hydrologic restoration on their lands. Therefore, a range of restoration and enhancement measures are currently being tested in situ. Employing larger culverts and tide gates that permit closer replication of natural hydrologic dynamics and fish passage can increase the spatial extent of inundation over existing conditions and change associated plant communities and functions relative to salmonid rearing.

Channels in mature marsh systems exhibit predictable equilibrium morphologies (Williams et al. 2002). For instance, regression relationships documented for cross-sectional area as a function of tidal prism include a study of British salt marshes by Steel and Pye (1997) and a review of San Francisco Bay salt marshes by Williams et al. (2002), respectively. Cross-sectional measurements including top width, area, and thalweg depth have been correlated with marsh area and tidal prism as a surrogate for discharge (Coats et al. 1995; Williams et al. 2002). Changes in tidal channel morphology following hydrologic restoration measures are typically measured through cross-sectional surveys (e.g., Cornu and Sadro 2002, Zedler 2001). In general, however, relationships derived for one regional system cannot be assumed to apply to another because of variations in tidal range, elevation, sediment, and bed and bank friction (Coats et al. 1995; Williams et al. 2002; Hood 2002). Furthermore, equilibrium equations assume stable spatial and temporal homogeneity (Williams et al. 2002). This assumption may be more applicable to emergent marshes in bays than to drowned-river estuaries such as the Columbia, in which geomorphic processes have varying influences on aquatic ecosystems along the river (cf. Montgomery 1999) and tidal channels are subject to extreme inter-annual variability due to combined river flows, tides, and winds.

No surveys documenting equilibrium morphologies or the effects of hydrologic restoration measures on channel morphology have been published for the Columbia River estuary. The Columbia River, with a drainage basin area of $660,480 \mathrm{~km}^{2}$ (Simenstad et al. 1990), has the fourth highest average discharge at mouth and the sixth largest watershed in the United States (U.S. Geological Survey 1990). Semi-diurnal tides occur from Bonneville Dam to the mouth. It is therefore unlikely, based on the unique combination of seasonally extreme flows and high diurnal tidal ranges, that the channel-forming capability of Columbia River hydraulics can be inferred from other systems.

The purpose of this paper is to document the baseline cross-sectional dimensions of tidal channels at restoration sites in the Columbia River estuary prior to dike breaching, culvert replacement, and tide gate replacement, changes in channel dimensions the following year(s), and flows associated with morphological change.

\subsection{Methods}

Data were collected at a tidal marsh mitigation site (Vera Slough) and a tidal forested wetland restoration site (Kandoll Farm) in the Columbia River estuary (Figure 4.1). We surveyed six crosssections at or upstream of four dike breaches; five cross sections above one culvert replacement; and two cross-sections upstream and one downstream of one tide gate replacement (Figure 4.2). In addition, we surveyed four cross-sections on tidal channels at control sites adjacent to the mitigation and restoration sites (Figure 4.2). 


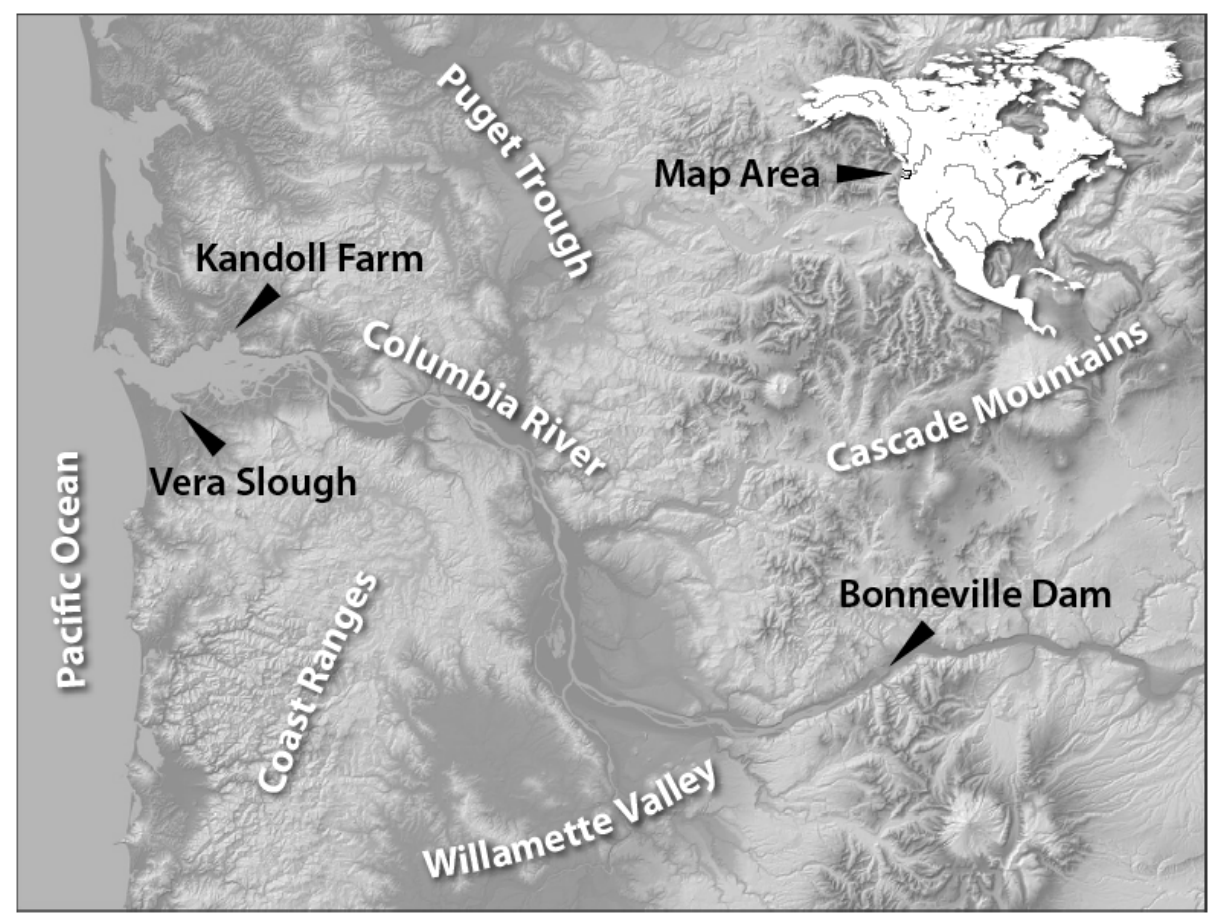

Figure 4.1. Survey Sites on the Columbia River Estuary

Kandoll Farm, Grays River, Washington

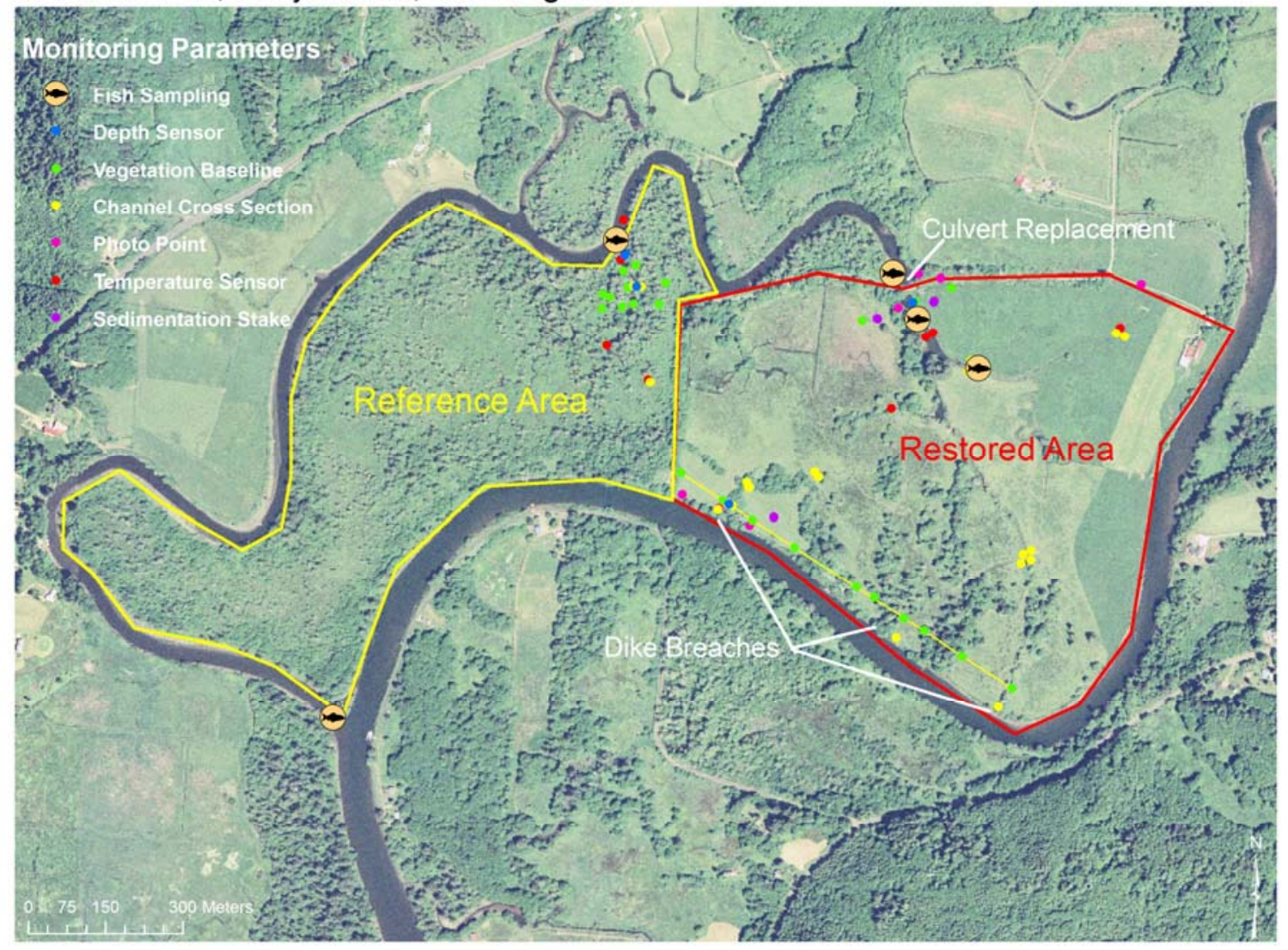

Figure 4.2a. Sampling Schematic for Kandoll 


\section{Vera Slough, Youngs Bay, Oregon}

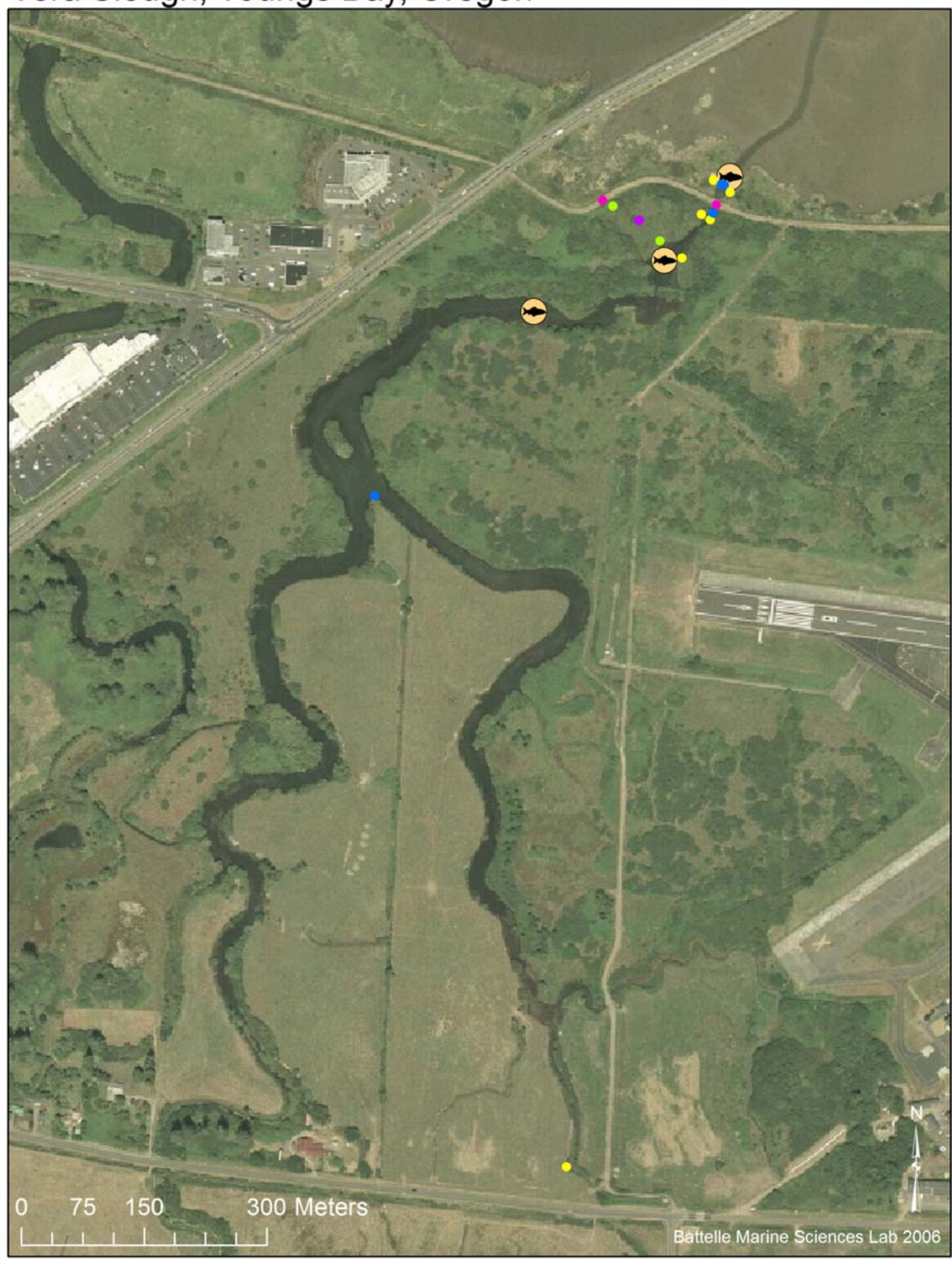

Figure 4.2b. Sampling Schematic for Vera 


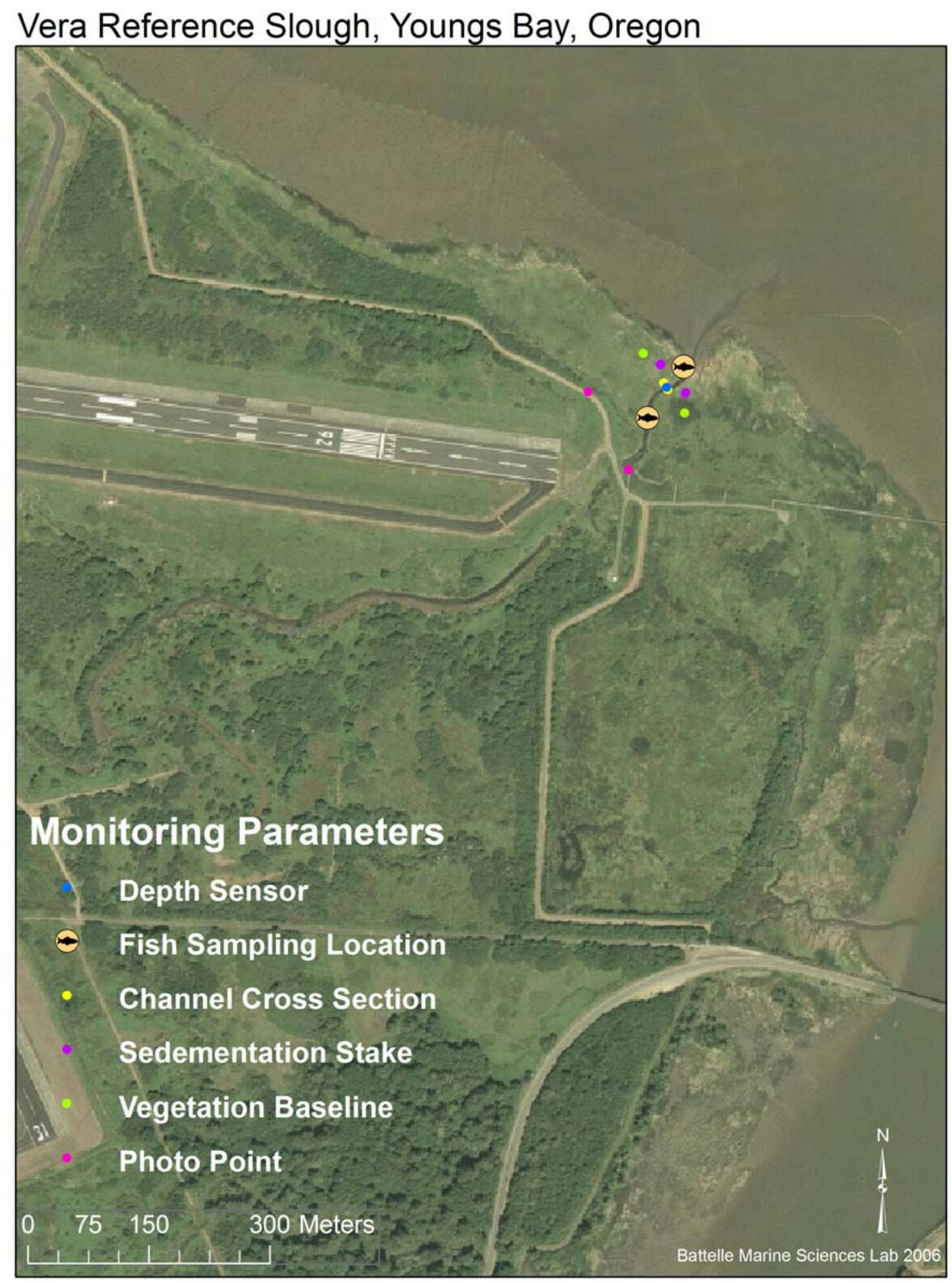

Figure 4.2c. Sampling Schematic for Vera Reference 
Baseline data were collected between June and September of 2005. Post-restoration data were collected between May 2006 and January 2007, after restoration and enhancement measures were implemented in the fall of 2005 (Figure 4.3). To document changes in flows before and after restoration and compare flows between control and restoration areas, HOBO ${ }^{\circledR}$ model U20 water-level logger absolute pressure sensors were installed in both control channels and in channels representing culvert replacement (Figure 4.2a), tide gate replacement (Figure 4.2b), and dike breaching (Figure 4.2c).

Cross sections were surveyed by determining elevations along permanent horizontal transects perpendicular to a channel. To establish transects, endpoints were marked with a permanent marker (PVC pipe) at a distance from the bank to prevent wash out during high flows. The transect endpoint locations were recorded using a GPS with differential correction. If satellite coverage for the GPS was not available due to tree cover, points were established in areas offset from the original location with measurements of distance, azimuth, and elevation difference. With a measuring tape attached to the fixed endpoints, the stadia rod was leveled at each predetermined interval, the interval and horizontal distance were recorded, and the height was measured with a Topcon AT-G2 model auto level or Trimble DR200+ total station. The horizontal interval used was greater (e.g., 1-2 meter) in areas of low slope and smaller (e.g., 0.5 meters) in areas of steeper slope, and the deepest point on the cross section was always surveyed.
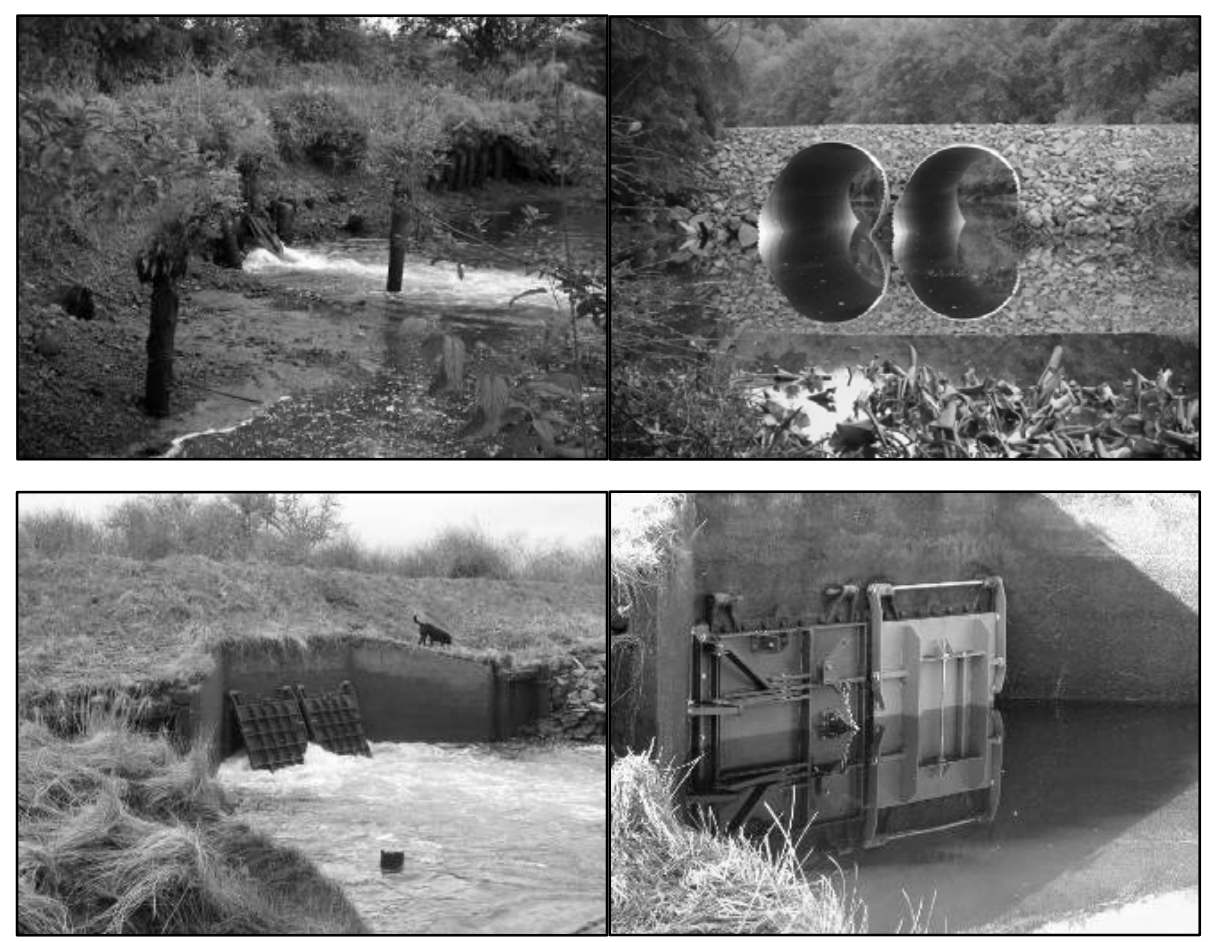

Figure 4.3. Tide Gate with 48-in Culvert on Seal Slough at Kandoll Road (left) Prior to Replacement with Twin, 13-ft Diameter Culverts (right) in 2005 (top) and Tide Gates at Vera Slough before (left) and after (right) Replacement in 2005 (bottom). 


\subsection{Results}

Before and after cross sections at the restoration sites are presented in Figure 4.4, with the crosssections proximal to the restoration actions in the lowest position and the most upstream cross sections in the highest. Reference cross sections are presented in Figure 4.5. The reference channels show little change from before implementation of restoration actions in adjacent areas (Figure 4.5).

Grays River dike breaches (Figure 4.6) were surveyed within the breaches located along the river, and the most downstream is shown in the lowest position. Tide gate replacement deepened and widened the channel immediately inside of the tide gates in the first year (Figure 4.4a). Only $60 \mathrm{~m}$ upstream, however, the only change was a small incision, and immediately outside of the tide gates there was essentially no change (Figure 4.4a). Culvert replacement caused incision of the channel immediately inside by over $1 \mathrm{~m}$ (Figure 4.4b). Cross sections over $580 \mathrm{~m}$ above the culvert replacement on the south fork incised, while on the north fork, a cross section $179 \mathrm{~m}$ above the culvert incised and one cross-section $503 \mathrm{~m}$ above the culvert did not (Figure 4.4b).

While comparison to the as-built surveys inside the dike breaches showed little change over a year later (Figure 4.6), surveys up-channel of one breach showed incision in the most proximal two cross sections (Figure 4.4c). Future reports will include channel geometry and regressions of marsh area/tidal prism against channel width at the mouth/cross-sectional area for reference areas and restoration areas. We will also determine the age of wood in selected channels and perform sediment accretion calculations.

\subsection{Discussion}

As an environmental control, the lack of change in the reference areas indicates stability year to year, such that changes in restoration channels are more likely attributable to the restoration actions. The lack of change also indicates that increased flood volume in adjacent sites did not affect channel structure at the reference sites.

Incision was greatest inside of the culvert, less inside of the tide gate, and even less inside the dike breach. However, these examples are not on exactly comparable channels, and the tide gate is in a different watershed than the culvert and dike breaches.

In future reports we will compare channel size or contributing watershed area. We can examine magnitude of initial incisions and note 40 -year winter events and differences in the system. There will, however, be issues of comparability of tide gate example to culvert and dike breach due to geographic locations. The channel geometry data will allow us to examine if the dike breaches were overbuilt relative to expected channel geometry, i.e., is this why they did not incise? The carbon dating of wood will permit discussion of the relation to subduction earthquake subsidence and implications for rate of sediment accretion qualified by Grays Watershed sediment mass balance issues. 

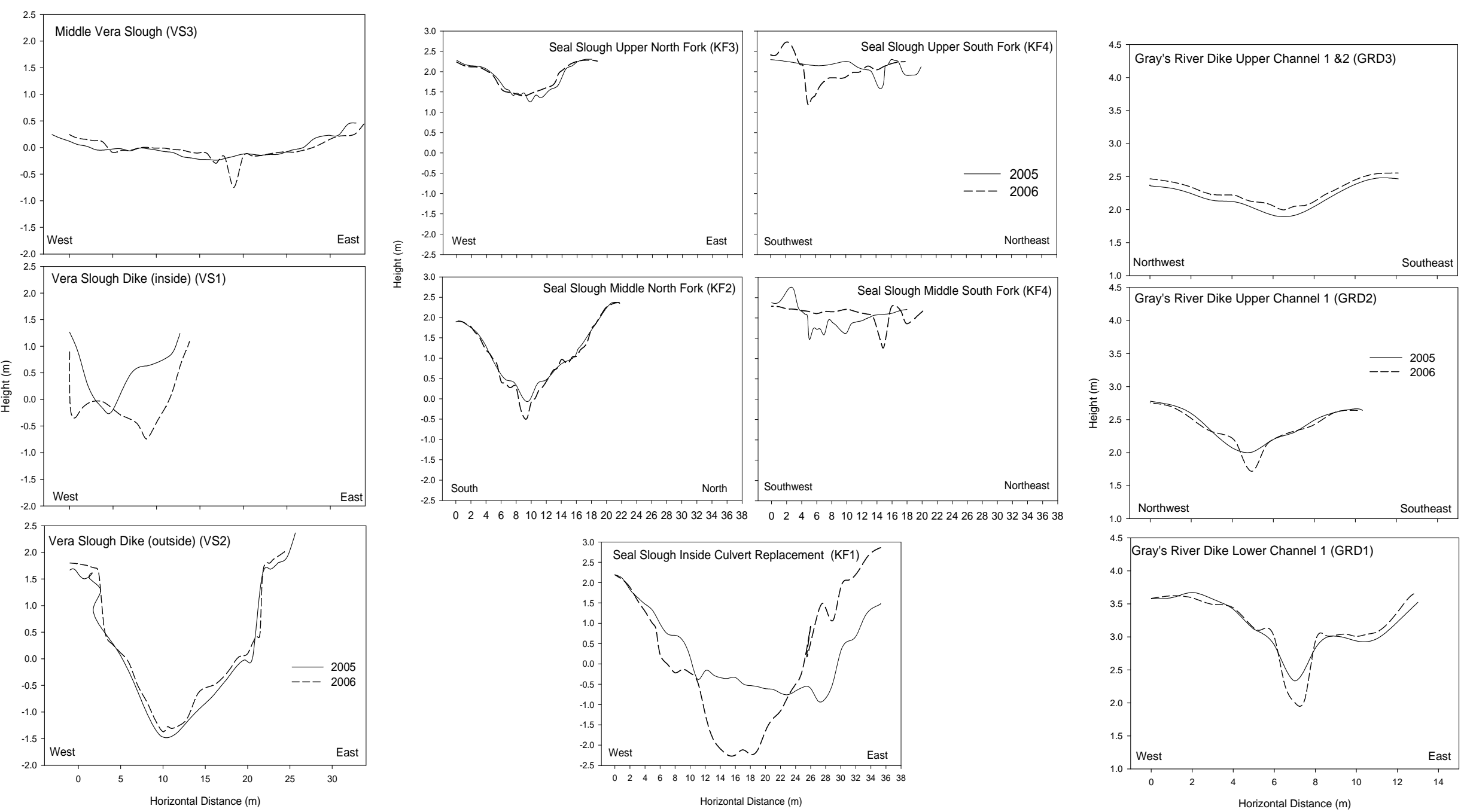

Figure 4.4. Channel Cross Sections before and after (a) Tide Gate Replacement (b) Culvert Replacement and (c) Dike Breaching 

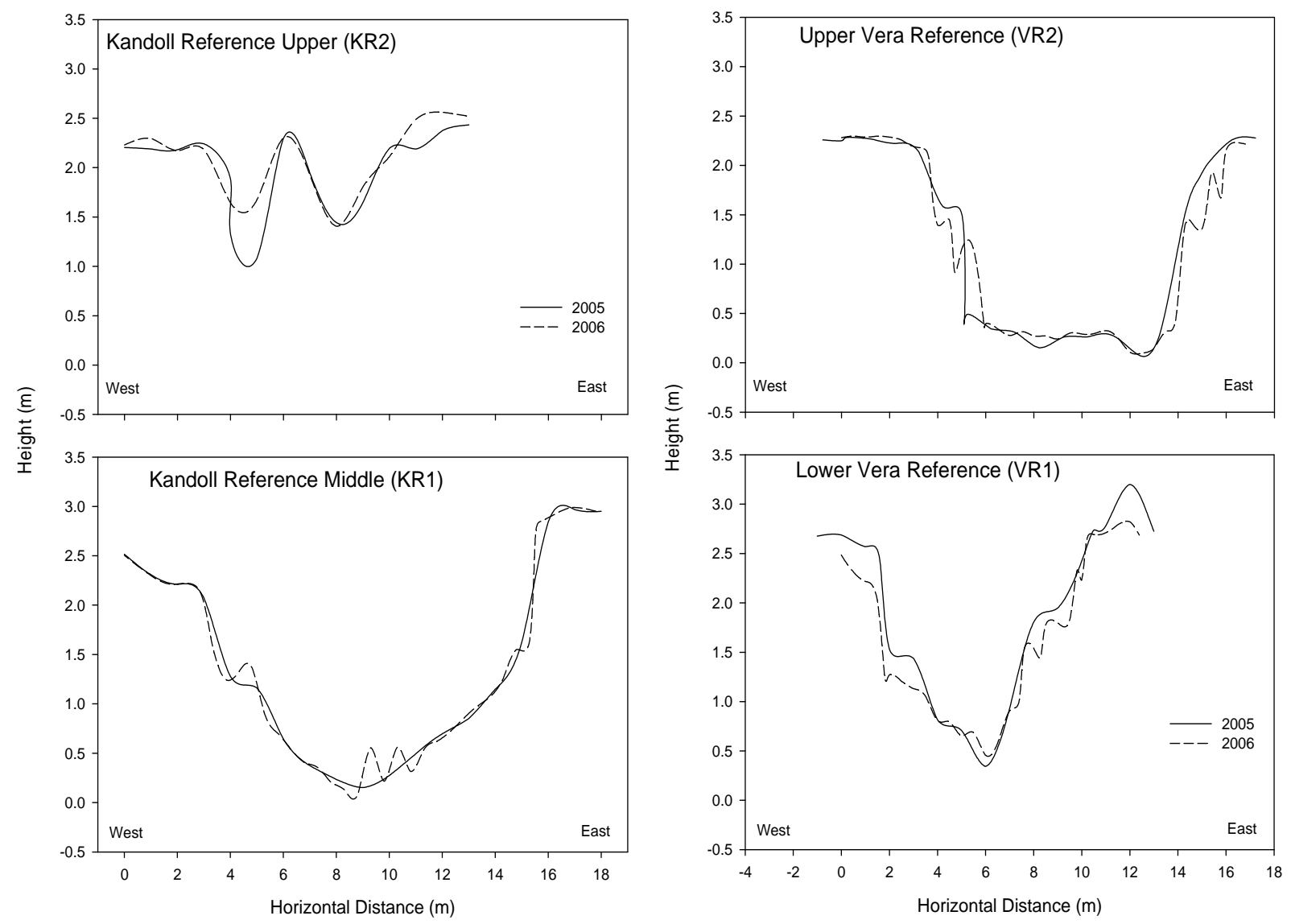

Figure 4.5. Cross Sections at Reference Channels before and after Nearby Restoration and Enhancement Actions 

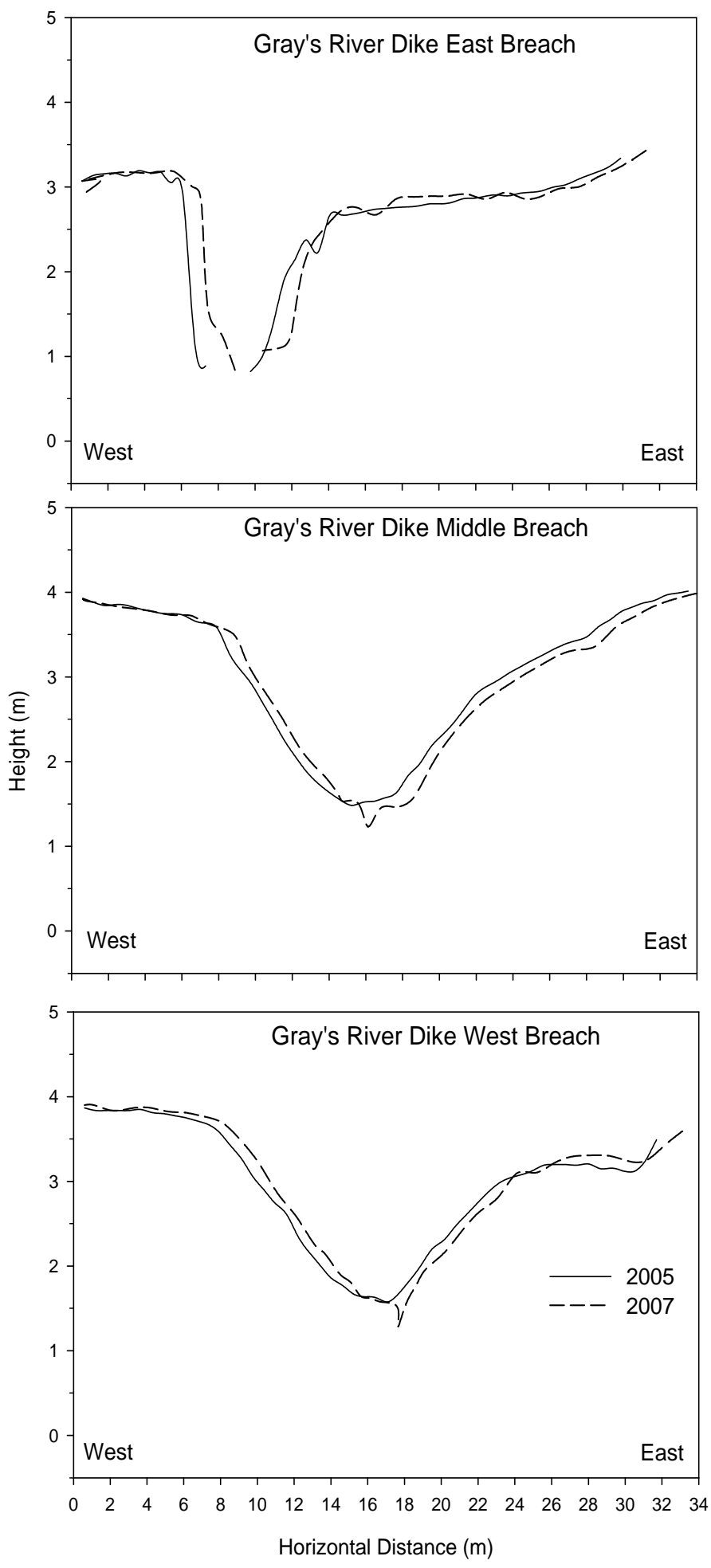

Figure 4.6. Three Dike Breaches on the Grays River: 2005. Data are from as-built surveys after excavation of the breaches. 


\subsection{Literature Cited}

Coats, R.N., P.B. Williams, C.K. Cuffe, J.B. Zedler, D. Reed, S.M. Watry and J.S. Noller. 1995. Design Guidelines for Tidal Channels in Coastal Wetlands. Report prepared for U.S. Army Corps of Engineers Waterways Experiment Station, Catalog. No. TA7W343.D47, Vicksburg, MS.

Cornu, C. and S. Sadro. 2002. Physical and functional responses to experimental marsh surface elevation manipulation in Coos Bay's South Slough. Restoration Ecology 10(3):474-486.

Fox, D.S., S. Bell, W. Nehlsen, and J. Damron. 1984. The Columbia River Estuary: Atlas of Physical and Biological Characteristics. Columbia River Estuary Data Development Program, Astoria, Oregon.

Hood, W.G. 2002. Application of landscape allometry to restoration of tidal channels. Restoration Ecology 10(2):213-222.

Hood, W.G. 2004. Indirect environmental effects of dikes on estuarine tidal channels: Thinking outside of the dike for habitat restoration and monitoring. Estuaries 27(2):273-282.

Johnson, G. and seven co-authors. 2003. An Ecosystem-Based Approach to Habitat Restoration Projects with Emphasis on Salmonids in the Columbia River Estuary. PNNL-14412, Final report prepared by Pacific Northwest National Laboratory for the Bonneville Power Administration, Portland, Oregon. November 2003.

Kukulka, T. and D.A. Jay. 2003a. Impacts of Columbia River Discharge on Salmonid Habitat I: a nonstationary fluvial model. Journal of Geophysical Research 108(C9):3293.

Kukulka, T. and D.A. Jay. 2003b. Impacts of Columbia River discharge on salmonids habitat II: changes in shallow-water habitat. Journal of Geophysical Research 108(C9):3294.

Miller, J.A. and C.A. Simenstad, 1997. A comparative assessment of a natural and created estuarine slough as rearing habitat for juvenile Chinook and Coho salmon. Estuaries 20(4):792-806.

Montgomery, D.R. 1999. Process domains and the river continuum. Journal of the American Water Resources Association 35(2):397-410.

National Research Council (NRC). 1992. Restoration of Aquatic Ecosystems. National Academy Press, Washington, D.C.

Sherwood, C.R., D.A. Jay, R.B. Harvey, P. Hamilton and C.A. Simenstad. 1990. Historical changes in the Columbia River estuary. Progress in Oceanography 25: 299-352.

Simenstad, C.A. and B.E. Feist. 1996. Restoration Potential of Diked Estuarine Wetlands: Inferring Fate and Recovery Rate of Historically Breached Sites. EPA 910/R-96-005, prepared by the University of Washington, School of Fisheries, Wetland Ecosystem Team and U.S. Environmental Protection Agency-Region 10, Seattle, Washington.

Simenstad, C.A. and J.R. Cordell. 2000. Ecological assessment criteria for restoring anadromous salmonid habitat in Pacific Northwest estuaries. Ecological Engineering 15: 283-302.

Simenstad, C.A., L.F. Small, C.D. McIntire, D.A. Jay and C Sherwood. 1990. "Columbia River estuary studies: An introduction to the estuary, a brief history, and prior studies." Progress in Oceanography 25: $1-13$. 
Simenstad, C.A. and R.S. Warren (eds.). 2002. "Special Issue on Dike/Levee Breach Restoration of Coastal Marshes." Restoration Ecology 10(3): 431-605.

Steel, T.J. \& Pye, K. 1997. The Development of Saltmarsh Tidal Creek Networks: Evidence from the UK. Proceedings of the Canadian Coastal Conference 1997, Guelph, Ontario, pp. 267-280.

Toth, L.A. 1995. "Principles and Guidelines for Restoration of River/Floodplain Ecosystems Kissimmee River, Florida.” Pp.49-73 in Cairns, J. Jr. (ed.): Rehabilitating Damaged Ecosystems. Lewis Publishers, Boca Raton, Florida.

USGS (United States Geological Survey). 1990. "Largest rivers in the United States, in discharge, drainage area, or length.” Open-File Report 87-242, Reston, Virginia.

Williams, G.D. and J.B. Zedler, 1999. Fish assemblage composition in constructed and natural tidal marshes of San Diego Bay: Relative influence of channel morphology and restoration history. Estuaries 22:702-716.

Williams, P.B., M.K. Orr and N.J. Garrity. 2002. Hydraulic geometry: a geomorphic design tool for tidal marsh channel evolution in wetland restoration projects. Restoration Ecology 10(3): 577-590.

Zedler, J.B., editor. 2001. Handbook for Restoring Tidal Wetlands. CRC Press, Boca Raton, Florida. 


\subsection{Vegetation Cover, Elevation, and Post-Restoration Change Analysis}

Amy B. Borde ${ }^{\mathrm{a}}$, Heida L. Diefenderfer ${ }^{\mathrm{a}}$, Allan W. Whiting ${ }^{\mathrm{b}}$, and Ron Thom ${ }^{\mathrm{a}}$

\subsection{Introduction}

Large areas of swamps and marshes have been lost in the Columbia River estuary, making them an important target for restoration. These two systems were chosen for this study because the differences, particularly those associated with plant dominants, will likely result in different responses to restoration treatments. For example, tree species are dominant in the swamps whereas herbaceous species are prevalent in marshes. Swamps and marshes provide different habitat characteristics for biota, including salmonids listed under the Endangered Species Act, with respect to plant productivity, detritus, associated invertebrate prey, and refugia characteristics such as coniferous versus deciduous dominants. The objective of this chapter is to characterize the plant communities at tidal swamp and marsh habitats before and after tidal reconnection restoration actions.

\subsection{Methods}

Within each of the plant communities, studies were conducted in one natural reference site and one restoration site. Data from the reference sites were used to help interpret data collected from the restoration sites as per standard procedures for post-restoration monitoring recommended in Diefenderfer et al. (2005). Reference sites corresponding to each restoration site were identified on the basis of a qualitative assessment of geographic proximity, ecological similarity, hydrological similarity, and likelihood that the plant associations at the reference areas would be representative of the endpoint(s) of restoration trajectories at the restored sites.

\subsubsection{Vegetation Sampling}

The sites at Kandoll Farm (West and East of Seal Slough), Vera Slough, and Vera Reference, Crims Island, and Crims Island Reference (Gull Island) were sampled for percent cover with $1-\mathrm{m}^{2}$ quadrats on systematically spaced plots with a random start along transects. Kandoll and Vera were sampled in 2005 and 2006; Crims Island in 2006 only. An example of the vegetation sampling grid at Seal Slough on Kandoll Farm is shown in Figure 5.1. Due to the presence of trees, Kandoll Farm Reference samples were instead collected using $1-\mathrm{m}^{2}$ quadrats for herbaceous vegetation centered on 3-m-diameter circles for shrubs and 10-m-diameter circles for trees (Figure 5.2). Vegetation sampling at the restoration sites was concentrated on transects proximal to expected changes - near the culvert replacement on Seal Slough and the tide gate replacement at Vera Slough. A randomly selected subset of the vegetation plots was also sampled for above-ground and below-ground organic matter. The height and age of a subset of the trees on the Kandoll Reference site were measured using a clinometer and increment borer; if present,

\footnotetext{
${ }^{a}$ Marine Sciences Laboratory, Pacific Northwest National Laboratory, Sequim, WA

${ }^{\mathrm{b}}$ Columbia River Estuary Study Taskforce, Astoria, OR
} 
one Sitka spruce and one red alder from each of the twelve reference plots was measured. Sampling at Kandoll Reference was conducted in 2005 only.

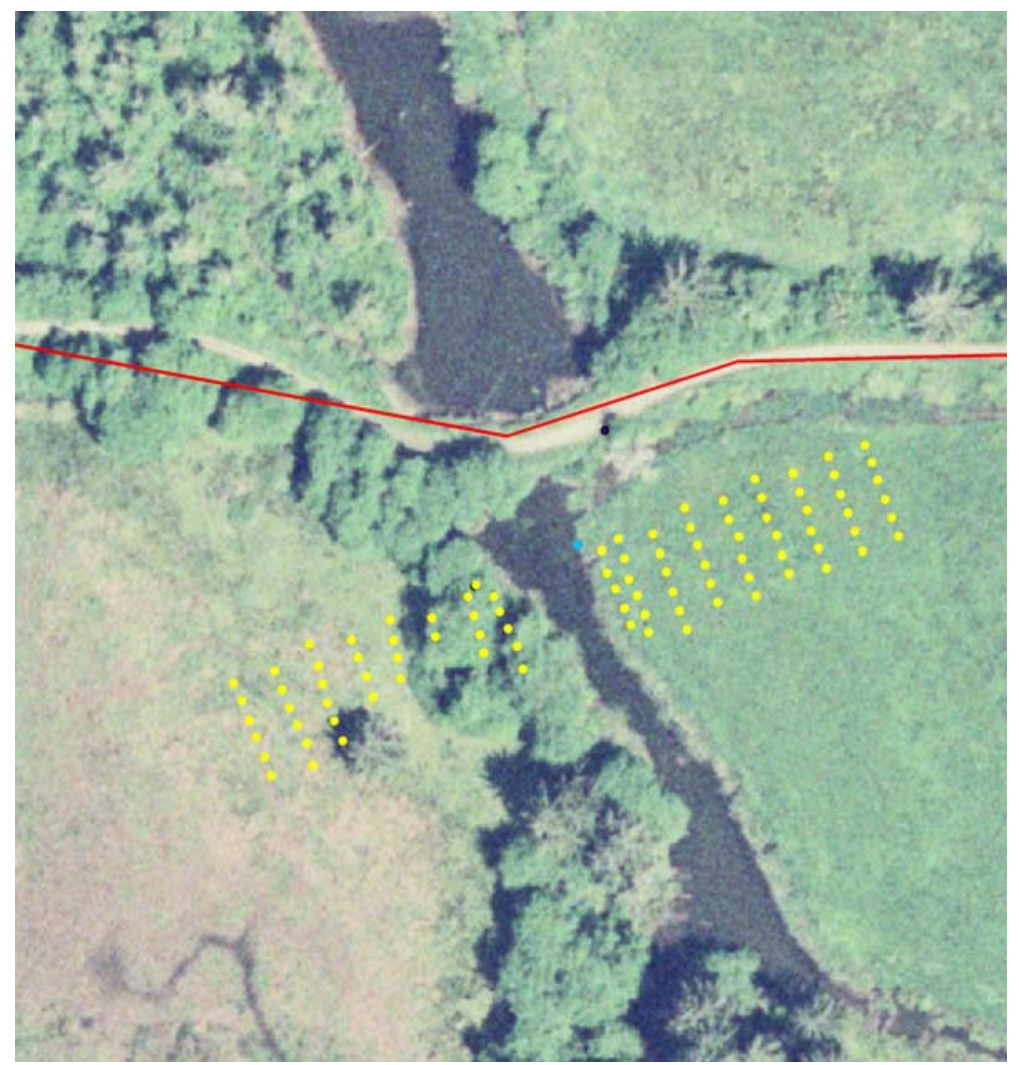

Figure 5.1. Vegetation Sampling Grid at Seal Slough in the Kandoll Farm Restoration Site

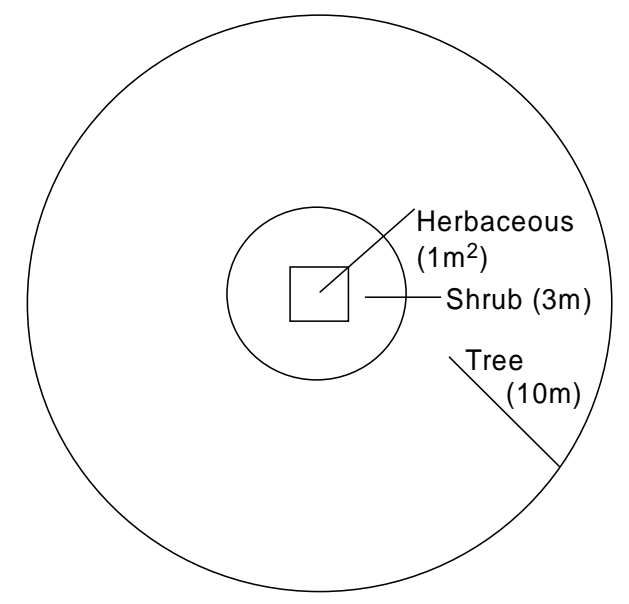

Figure 5.2. Vegetation Plot Design for Forested Wetlands 
In 2005 and 2006, an 800-m transect paralleling the Grays River was also sampled using a lineintercept method with 1-m intervals. Observations had indicated possibly distinctive plant associations between each pair of channels prior to the dike breaching. Testing this hypothesis and tracking postrestoration changes in plant associations relative to dike breaching were the objectives of the lineintercept sampling.

\subsubsection{Elevation}

Elevation was measured in the field using three methods to determine the best monitoring protocol: 1) an auto-level and stadia rod; 2) a Trimble auto-lock total station; and 3) a real-time kinematic (RTK) Geographic Positioning System (GPS). In all cases the "base" was located on a benchmark of known position and elevation and all elevations were referenced to those benchmarks.

\subsubsection{Vegetation Laboratory Analyses}

Below- and above-ground organic matter was iced and shipped to the Battelle Marine Sciences Laboratory in Sequim, Washington, and processed. The entire above-ground organic matter sample was rinsed over a 1- or 2-mm mesh in freshwater to remove sediment and anything other than macrovegetation. The dead (brown and flaccid) and live green plant matter were separated, dried in an oven at $\sim 80-90^{\circ} \mathrm{C}$ and weighed after cooling. Below-ground organic matter samples were homogenized individually then subsampled and dried in a muffle furnace at $500^{\circ} \mathrm{C}$ and the ash-free dry weight was determined after cooling. The percent loss from ignition was then calculated.

\subsubsection{Vegetation Calculations}

General statistics were calculated for the percent cover of each plant species or category in each site. The mean, standard deviation, maximum, and minimum were calculated for each site using all quadrats. Where there was zero percent cover this was included in the calculations. Calculations were also performed on abiotic categories like "open water" and "bare ground/mud" since these are descriptors of the sites. The species richness, or number of species, was calculated for each quadrat and summarized by the statistics described above. Abiotic categories were excluded from this and subsequent calculations.

A similarity index (Czekanowski) was calculated between years and between restoration and reference sites (Bray and Curtis 1957). The index was weighted by including the species and their percent cover using the following equation:

$$
\text { Similarity }=(2 a /[2 a+b+c]) * 100
$$

where, $a$ is the sum of the average percent cover of species in common between the two sites (only the overlapping value), $\mathrm{b}$ is the total percent cover of species exclusive to the first site, and $\mathrm{c}$ is the total percent cover of species exclusive to the second site.

At the Kandoll site, permutational multivariate analysis of variance (PERMANOVA; Anderson 2001; McArdle and Anderson 2001) was used to test for differences in the species compositions of herbaceous layers and their responses to elevation of seven groups as follows: 2005 Restoration West Marsh; 2005 Restoration West Riparian; 2005 Restoration East; 2005 Reference; 2006 Restoration West Marsh; 2006 Restoration West Riparian; and 2006 Restoration East. Selections were Bray-Curtis distance (Legendre and Legendre 1998) and 4,999 permutations, with $n=9$ for all groups (the sample size available at the reference site). 
NMS (nonmetric multidimensional scaling) in PC-ORD (McCune and Grace 2002) was used to visualize the results of the permutational multivariate analysis of variance. The "medium" option was selected, with 50 permutations of real data and 50 additional permutations, and the Bray-Curtis distance. Elevation as a covariate was examined by rotating the first axis to parallel the primary axis of variation detected by the ordination.

The $800-\mathrm{m}$ point-intercept transect data was analyzed by counting the total number of points on which each species was present in each of five areas along the transect. The percent frequency was calculated by dividing the number of points on which a species occurred by the total number of points in that field, and multiplying by 100 .

The swamp overstory was described in Kandoll Reference area by evaluating all the individual trees in the 10-m radius plots. Cross-sectional area was calculated for each individual tree using the equation $\pi \mathrm{r} 2$ and summed by species; basal area was calculated by dividing total cross-sectional area per species by total plot area (calculated as $12 * \pi \mathrm{r} 2$, where $\mathrm{r}=10 \mathrm{~m}$ ). Relative frequency, relative density, and relative dominance were calculated by the same formula: dividing, for example, total frequency of species A by total frequency of all species and multiplying by 100 (McCune and Grace 2002, p.15).

\subsection{Results}

\subsubsection{Percent Cover}

\section{Kandoll}

A total of 49 species were identified within the sample areas in 2005 and 2006. Species richness at the Kandoll restoration site increased at the site from 27 species in 2005 to 41 in 2006 . Six species had an average percent cover greater than $10 \%$ (Table 5.1). Many of the species (51\%) have an average percent cover in the study area of less than $1 \%$ (Table 5.2). The high percentage of species with low cover may in part be due to the transition state of the site caused by the change in hydrologic regime; the number of species may increase temporarily as species adapted to the previous tidal regime persist and new species become established. Six of the nine species present in 2005 and not in 2006 were species more often associated with upland conditions.

Table 5.1. Average Percent Cover of the Dominant Plant Species at the Kandoll Restoration Site Sampling Locations (SSE and SSW)

\begin{tabular}{llcccc}
\hline Scientific Name & Common Name & SSE 2005 & SSE 2006 & SSW 2005 & SSW 2006 \\
\hline Juncus effusus & Soft rush & 0.88 & 1.51 & 14.2 & 3.92 \\
Phalaris arundinacea & Reed canary grass & 27.1 & 57.0 & 33.1 & 56.3 \\
Ranunculus repens & Creeping buttercup & 21.5 & 13.7 & 6.78 & 1.85 \\
Rubus discolor & Himalayan blackberry & 0.00 & 0.00 & 16.8 & 3.42 \\
Trifolium pratense, T. & Red clover, white & 19.4 & 0.28 & 0.00 & 0.00 \\
repens, T. dubium & clover, sm. hopclover & & & & \\
n/a & Mixed Grass & 49.7 & 22.5 & 4.19 & 3.13 \\
\hline
\end{tabular}


Table 5.2. Plant Species Average Percent Cover at Kandoll Restoration (SSE and SSW) and Kandoll Reference (KR) in 2005 and 2006. Species are sorted and colored by Wetland Status codes: OBL = $>99 \%$ probability of occurring in a wetland; FACW $=67 \%-99 \%$; FAC $=34 \%-66 \%$; FACU $=1-33 \%$; UPL $=<1 \%$. Plants with average percent cover greater than $10 \%$ are in bold.

\begin{tabular}{|c|c|c|c|c|c|c|c|c|c|}
\hline & & & & & & & rcent C & & \\
\hline & & & & & ss & & SSI & & KR \\
\hline Code & Scientific Name & Common Name & Status & Category & 2005 & 2006 & 2005 & 2006 & 2005 \\
\hline ALPL & Alisma plantago-aquatica & Broadleaf water plaintain & $\mathrm{OBL}$ & Herb & 0.00 & 0.99 & 0.00 & 0.02 & 0.00 \\
\hline CAHE & Callitriche heterophylla & water starwort & $\mathrm{OBL}$ & Herb & 0.00 & 1.01 & 0.00 & 0.07 & 0.00 \\
\hline CAOB & Carex obnupta & Slough sedge & $\mathrm{OBL}$ & Sedge & 1.02 & 1.49 & 5.83 & 0.52 & 0.50 \\
\hline CIDO & Cicuta douglasii & Western water-hemlock & OBL & Herb & 0.00 & 0.00 & 0.00 & 0.00 & 3.75 \\
\hline ELPA & Eleocharis palustris & common spikerush & $\mathrm{OBL}$ & Sedge & 0.00 & 0.07 & 0.00 & 0.00 & 0.00 \\
\hline ELCA & Elodea canadensis & Canada waterweed & $\mathrm{OBL}$ & Herb & 0.00 & 2.16 & 0.00 & 0.00 & 0.00 \\
\hline JUAC & Juncus acuminatus & tapered rush & $\mathrm{OBL}$ & Rush & 0.00 & 0.15 & 0.00 & 0.00 & 0.00 \\
\hline LYAM & Lysichiton americanum & Skunk cabbage & $\mathrm{OBL}$ & Herb & 0.51 & 0.30 & 4.27 & 4.60 & 7.50 \\
\hline MIGU & Mimulus guttatus & Yellow monkeyflower & OBL & Herb & 0.00 & 0.16 & 0.00 & 0.00 & 0.00 \\
\hline OESA & $\begin{array}{l}\text { Oenanthe sarmentosa } \\
\text { Polygonum hydropiper; } P \text {. }\end{array}$ & $\begin{array}{l}\text { Water parsley } \\
\text { Waterpepper; mild }\end{array}$ & $\mathrm{OBL}$ & Herb & 0.00 & 0.00 & 0.00 & 0.00 & 0.42 \\
\hline $\mathrm{POHY}$ & hydropiperoides & waterpepper & $\mathrm{OBL}$ & Herb & 0.02 & 4.19 & 0.02 & 1.30 & 0.00 \\
\hline SCMI & Scirpus microcarpus & Small-fruited bulrush & $\mathrm{OBL}$ & Sedge & 0.00 & 0.90 & 0.00 & 0.00 & 0.00 \\
\hline SPEM & Sparganium emersum & Narrowleaf burreed & $\mathrm{OBL}$ & Herb & 0.00 & 0.00 & 0.00 & 0.45 & 0.00 \\
\hline CAST & Carex stipata & Sawbeak sedge & FACW & Sedge & 0.02 & 0.00 & 0.23 & 0.00 & 0.00 \\
\hline COST & Cornus stolonifera & Red-osier dogwood & FACW & Shrub & 0.00 & 0.00 & 0.00 & 0.17 & 0.00 \\
\hline GATR & $\begin{array}{l}\text { Galium trifidum } \\
\text { Impatiens capensis, Impatiens noli- }\end{array}$ & $\begin{array}{l}\text { Pacific bedstraw } \\
\text { Spotted touch-me-not, }\end{array}$ & FACW & Herb & 1.29 & 0.00 & 0.75 & 0.00 & 0.00 \\
\hline IMSP & tangere & Common touch-me-not & FACW & Herb & 0.04 & 0.00 & 2.92 & 1.70 & 1.50 \\
\hline JUEF & Juncus effusus & Soft rush & FACW & Rush & 0.88 & 1.51 & 14.2 & 3.92 & 0.00 \\
\hline LYNU & Lysimachia nummularia $L$. & Moneywort; Creeping Jenny & FACW & Herb & 2.15 & 7.46 & 1.65 & 3.62 & 0.00 \\
\hline MYSC & Myosotis scorpioides & Forget-me-not & FACW & Herb & 0.00 & 0.19 & 0.00 & 0.00 & 0.00 \\
\hline PHAR & Phalaris arundinacea & Reed canary grass & FACW & Grass & 27.1 & 57.0 & 33.1 & 56.3 & 5.00 \\
\hline RAFL & Ranunculus flammula & Small creeping buttercup & FACW & Herb & 0.00 & 0.01 & 0.00 & 0.00 & 0.00 \\
\hline RARE & Ranunculus repens & Creeping buttercup & FACW & Herb & 21.5 & 13.7 & 6.78 & 1.85 & 0.00 \\
\hline BICE & Bidens cernua & nodding beggars-ticks & FACW+ & Herb & 0.00 & 0.15 & 0.00 & 0.00 & 0.00 \\
\hline RUMA & Rumex maritimus & Golden dock; seaside dock & FACW+ & Herb & 0.00 & 0.00 & 0.00 & 0.25 & 0.00 \\
\hline ALRU & Alnus rubra & Red alder & FAC & Tree & 0.00 & 0.00 & 0.00 & 0.83 & 0.00 \\
\hline ATFI & Athyrium filix-femina & Lady fern & FAC & Fern & 0.00 & 0.00 & 0.00 & 0.17 & 5.00 \\
\hline LOCO & Lotus corniculatus & Birdsfoot trefoil & FAC & Herb & 1.13 & 0.09 & 0.17 & 0.00 & 0.00 \\
\hline PAVI & Parentucellia viscosa & Yellow parentucellia & FAC- & Herb & 0.07 & 0.00 & 0.00 & 0.00 & 0.00 \\
\hline PLLA & Plantago lanceolata & Rib plantain & FAC & Herb & 8.43 & 2.21 & 0.21 & 0.02 & 0.00 \\
\hline HELA & Heracleum lanatum & Cow-parsnip & $\mathrm{FAC}+$ & Herb & 0.00 & 0.00 & 0.42 & 0.00 & 0.00 \\
\hline LOIN & Lonicera involucrata & Black twinberry & FAC+ & Shrub & 0.00 & 0.00 & 0.00 & 0.75 & 0.00 \\
\hline RUSP & Rubus spectabilis & Salmonberry & FAC+ & Shrub & 0.00 & 0.00 & 1.04 & 3.00 & 2.08 \\
\hline RUCR & Rumex crispus & Curly dock & $\mathrm{FAC}+$ & Herb & 0.00 & 0.37 & 0.00 & 0.08 & 0.00 \\
\hline HYRA & Hypochaeris radicata & Spotted cat's ear & FACU & Herb & 2.82 & 0.00 & 0.00 & 0.00 & 0.00 \\
\hline OECE & Oemleria cerasiformis & Indian-plum & FACU & Shrub & 0.00 & 0.00 & 0.00 & 0.17 & 0.00 \\
\hline POGL & Polypodium glycyrrhiza & Licorice fern & FACU & Fern & 0.00 & 0.00 & 0.00 & 0.00 & 0.08 \\
\hline POMU & Polystichum munitum & Sword fern & FACU & Fern & 0.00 & 0.00 & 1.04 & 0.00 & 0.00 \\
\hline PTAQ & Pteridium aquilinum & Bracken fern & FACU & Fern & 0.00 & 0.00 & 0.00 & 0.17 & 0.33 \\
\hline RUDI & Rubus discolor & Himalayan blackberry & FACU & Shrub & 0.00 & 0.00 & 16.8 & 3.42 & 0.00 \\
\hline RUUR & Rubus ursinus & Trailing blackberry & FACU & Shrub & 0.00 & 0.00 & 0.42 & 1.25 & 0.00 \\
\hline SARA & Sambucus racemosa & Red elderberry & FACU & Shrub & 0.00 & 0.00 & 5.10 & 0.33 & 0.00 \\
\hline TAOF & Taraxacum officinale & Common dandelion & FACU & Herb & 0.00 & 0.03 & 0.00 & 0.00 & 0.00 \\
\hline CIAR & Cirsium arvense & Canada thistle & FACU+ & Herb & 0.30 & 0.15 & 1.15 & 0.00 & 0.00 \\
\hline GLHE & Glecoma hederacea & Creeping Charlie & FACU+ & Herb & 0.00 & 0.00 & 1.34 & 0.08 & 0.00 \\
\hline PRVU & Prunella vulgaris & Self heal & FACU+ & Herb & 0.18 & 0.00 & 0.00 & 0.00 & 0.00 \\
\hline RULA & Rubus laciniatus & Evergreen blackberry & FACU+ & Shrub & 0.00 & 0.00 & 3.02 & 4.75 & 0.00 \\
\hline TEGR & Tellima grandiflora & Fringe cup & $\begin{array}{l}\text { UPL } \\
\text { FACW, }\end{array}$ & Herb & 0.00 & 0.00 & 0.63 & 0.00 & 0.00 \\
\hline JUSP & Juncus spp. & & $\begin{array}{l}\text { OBL } \\
\text { FACU, }\end{array}$ & Rush & 0.00 & 0.00 & 0.00 & 0.02 & 0.00 \\
\hline TRSP & $\begin{array}{l}\text { Trifolium pratense, T. repens, } T \text {. } \\
\text { dubium }\end{array}$ & $\begin{array}{l}\text { Red clover, white clover, } \\
\text { small hop-clover }\end{array}$ & $\begin{array}{l}\text { FAC, } \\
\text { UPL } \\
\text { FACW, }\end{array}$ & Herb & 19.4 & 0.28 & 0.00 & 0.00 & 0.00 \\
\hline MYSP & Mysotis spp. & Forget-me-not & OBL & & 0.00 & 0.22 & 0.00 & 0.00 & 0.00 \\
\hline MG & & Mixed Grass & Mixed & Grass & 49.7 & 22.5 & 4.19 & 3.13 & 1.67 \\
\hline
\end{tabular}


The two sample areas (SSE and SSW) are somewhat different in their composition and subsequent changes from pre- to post-restoration. The differences can be attributed primarily to the topography. SSW has a natural levee adjacent to Seal Slough ranging in elevation from $2.0 \mathrm{~m}$ to $2.5 \mathrm{~m}$, with some lower channels, and the marsh plain beyond the levee is about $1.5 \mathrm{~m}$. Species such as red elderberry (Sambucus racemosa) and Himalayan blackberry (Rubus discolor) were associated with the higher elevation of the levee, while on the marsh plain of SSW, the vegetation had a high average percent cover of soft rush (Juncus effusus), a species associated with wetter pastures. All three of these species declined significantly post-restoration (Table 5.2). In contrast, SSE is lower along the bank of Seal Slough, at 0.6 $\mathrm{m}$ to $1.7 \mathrm{~m}$, while the marsh plain is higher around $2 \mathrm{~m}$ with some lower channels. As a result, the vegetation on SSE was composed of high percentages of pasture-related species such as grasses and clover (Trifolium spp.) prior to restoration. Both of these species groups declined significantly (55\% and $99 \%$, respectively) post-restoration (Table 5.2).

The number of obligate wetland species (OBL in Table 5.2) increased $70 \%$ and $50 \%$ in SSE and SSW, respectively. Reed canary grass (Phalaris arundinacae), an invasive species, increased 52\% and $41 \%$ at both SSE and SSW, respectively. This species has a broad inundation tolerance and was observed from elevations of $0.9 \mathrm{~m}$ to $2.2 \mathrm{~m}$ at the site. Creeping buttercup (Ranunculus repens) decreased in both areas, perhaps due to a lower inundation tolerance. Vegetation data for Vera Slough and Crims Island remain to be analyzed.

\subsubsection{Similarity Indices}

The assemblage of plants at SSE was $72.6 \%$ similar to the assemblage at SSW in 2005, although these plots represent the east and west sides of Seal Slough, both in the Kandoll restoration area (Table 5.3). The sites became more similar (86.3\%) post-restoration. The very low similarities between these restoration plots and the Kandoll reference site reflect the major differences between these areas. However, SSW became more similar to the reference site post-restoration. The Vera Slough and Vera reference assemblages were only $24.5 \%$ similar using a weighted similarity coefficient in 2005 (Table 5.3). This indicates a major difference, both in species composition and in species abundances, prior to tide gate replacement.

Table 5.3. Weighted Similarity Index for 2005 and 2006 between Kandoll Restored (SSE and SSW) and Kandoll Reference (KR) and between Vera Restored (VS) and Vera Reference (VR).

\begin{tabular}{cccccc}
\hline & SSE & SSW & SSE & SSW & KR \\
& 2005 & 2005 & 2006 & 2006 & \\
\hline SSE 2005 & & 72.6 & 92.8 & - & 23.4 \\
SSW 2005 & & & - & 94.0 & 30.6 \\
SSE 2006 & & & & 86.3 & 23.4 \\
SSW 2006 & & & & & 53.2 \\
\hline & VS & VR & VS & VR & \\
& 2005 & 2005 & 2006 & 2006 & \\
VS 2005 & & 24.5 & tbd & tbd & \\
VR 2005 & & & tbd & tbd & \\
VS 2006 & & & & tbd & \\
\hline
\end{tabular}




\subsubsection{Permutational Multivariate Analysis (PERMANOVA)}

The permutational multivariate analysis of variance showed that the treatment (site) and covariable (elevation) both had significant effects on herbaceous species composition at the Kandoll restoration and reference sites (in all cases, $\mathrm{p}=0.0002$ ). An analysis including 2006 data showed that Seal Slough West (beneath Red alder) is the closest to the reference site in 2006; Seal Slough East changed substantially from 2005 to 2006 ( $p=0.0002$ ). Elevation was also a significant covariate in $2006(\mathrm{p}=0.0002)$.

\subsubsection{Nonmetric Multidimensional Scaling (NMS)}

Initial results of nonmetric multidimensional scaling showed that those sites under forest cover in the restoration area grouped separately from other restoration area plots and closer to the reference site. The results of nonmetric multidimensional scaling, with covariate elevation rotated to be parallel to axis 1 show clear distances between the three sites in multidimensional space, with some exceptions. On this basis, plots on the restoration site were divided into three categories instead of two, and PERMANOVA and NMS analyses were run again on randomly selected subsets of the data. Final stress was 13.8 and 12.9 on these runs, and instability in both cases was 0.00001 , indicating satisfactory results (McCune and Grace 2002). The reference site shows a wide variability on both primary axes of the NMS and is located at the highest elevations (Figure 5.3).

\subsubsection{Point-Intercept Transect (Kandoll Restoration)}

The most frequent species in each field in 2005, prior to restoration, were not all the same (Table 5.4). For example, while fields A, B, and C all had greater than $75 \%$ cover in mixed grasses, field D was dominated by Ranunculus repens (buttercup, 85\% frequency), and field $\mathrm{E}$ had a substantial component of Phalaris arundinacea (reed canarygrass, $38 \%$ frequency) in addition to $68 \%$ frequency of mixed grasses. Field B also had a 17\% frequency of Cirsium arvense (Canada thistle), which was not present on any other field. Reed canarygrass was present on only the three easternmost fields and experienced some increase on all three in 2006. The three easternmost fields also experienced substantial declines of mixed grass cover following breaching: $75 \%, 24 \%$, and 55\% frequency, respectively. Buttercup increased by $35 \%$ in field $\mathrm{C}$ following dike breaching. Lysimachia nummularia (creeping jenny) virtually disappeared from the easternmost two fields, was never present in the middle field (C), and remained constant or increased slightly in the westernmost fields.

\subsubsection{Tree Morphometrics (Kandoll Reference)}

Three tree species dominate the forested wetland, with one standing out above the others; Picea sitchensis (Sitka spruce) has the highest density, frequency, and basal area of any tree on the site (Table 5.5). Thuja plicata (Western redcedar) is next with four times lower relative dominance than the Sitka spruce. Although Western redcedar has lower frequency and density than the third tree, Alnus rubra (red alder), it makes up for this with greater basal area; red alder is the second most frequent and dense tree species in the forested wetland. 


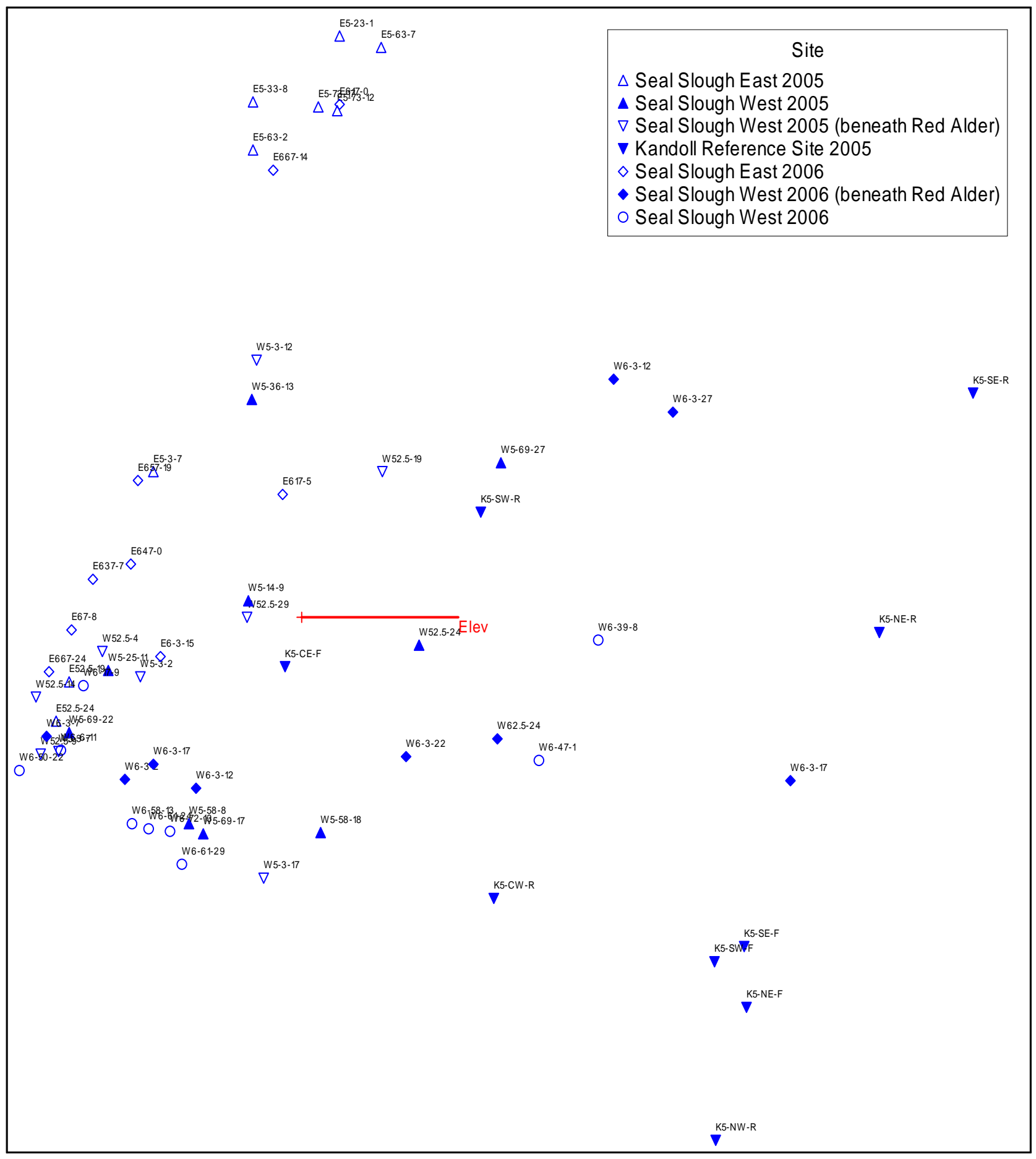

Figure 5.3. Non-Metric Multidimensional Scaling of 2005 and 2006 Species Composition Data 
Table 5.4. Species Composition of Fields between Channels, before and after Dike Preaching

\begin{tabular}{|c|c|c|c|c|c|c|c|c|c|c|c|c|c|c|c|c|c|c|c|c|c|c|}
\hline & & & & UID & CAH & & & ELP & EQF & GAT & GLH & & HYD & LYA & LYN & PHA & & RAR & & RUS & SCM & TRS \\
\hline & & & MG & Rush & E & CAOB & CIAR $A$ & & $\mathrm{~L}$ & $\mathrm{R}$ & $\mathrm{E}$ & GNMI & & M & U & $\mathrm{R}$ & PLLA & $\mathrm{E}$ & RUDI & & A & $\mathrm{P}$ \\
\hline \multirow{4}{*}{$\begin{array}{l}\text { Field A - } \\
97 \text { points }\end{array}$} & & No. & 96 & 0 & 0 & 0 & 0 & 0 & 0 & 0 & 2 & 0 & 0 & 0 & 19 & 0 & 11 & 4 & 2 & 0 & 0 & 1 \\
\hline & 2005 & Freq.\% & 98 & 0 & 0 & 0 & 0 & 0 & 0 & 0 & 2 & 0 & 0 & 0 & 19 & 0 & 11 & 4 & 2 & 0 & 0 & 1 \\
\hline & & No. & 92 & 0 & 1 & 0 & 0 & 1 & 0 & 0 & 0 & 0 & 0 & 0 & 6 & 0 & 0 & 8 & 0 & 0 & 0 & 0 \\
\hline & 2006 & Freq.\% & 95 & 0 & 1 & 0 & 0 & 1 & 0 & 0 & 0 & 0 & 0 & 0 & 6 & 0 & 0 & 8 & 0 & 0 & 0 & 0 \\
\hline \multirow{4}{*}{$\begin{array}{l}\text { Field B - } \\
99 \text { points }\end{array}$} & & No. & 75 & 0 & 0 & 0 & 17 & 0 & 0 & 0 & 3 & 0 & 0 & 2 & 1 & 0 & 1 & 1 & 1 & 0 & 0 & 0 \\
\hline & 2005 & Freq.\% & 76 & 0 & 0 & 0 & 17 & 0 & 0 & 0 & 3 & 0 & 0 & 2 & 1 & 0 & 1 & 1 & 1 & 0 & 0 & 0 \\
\hline & & No. & 82 & 0 & 0 & 0 & 6 & 0 & 0 & 0 & 0 & 0 & 0 & 1 & 6 & 0 & 0 & 8 & 11 & 1 & 0 & 0 \\
\hline & 2006 & Freq.\% & 83 & 0 & 0 & 0 & 6 & 0 & 0 & 0 & 0 & 0 & 0 & 1 & 6 & 0 & 0 & 8 & 11 & 1 & 0 & 0 \\
\hline \multirow{4}{*}{$\begin{array}{l}\text { Field C - } \\
40 \text { points }\end{array}$} & & No. & 39 & 0 & 0 & 0 & 0 & 0 & 0 & 0 & 0 & 0 & 0 & 0 & 0 & 8 & 0 & 23 & 1 & 0 & 0 & 2 \\
\hline & 2005 & Freq.\% & 98 & 0 & 0 & 0 & 0 & 0 & 0 & 0 & 0 & 0 & 0 & 0 & 0 & 20 & 0 & 58 & 3 & 0 & 0 & 5 \\
\hline & & No. & 9 & 0 & 0 & 0 & 0 & 0 & 0 & 0 & 0 & 0 & 0 & 0 & 0 & 15 & 0 & 37 & 0 & 0 & 0 & 0 \\
\hline & 2006 & Freq.\% & 23 & 0 & 0 & 0 & 0 & 0 & 0 & 0 & 0 & 0 & 0 & 0 & 0 & 38 & 0 & 93 & 0 & 0 & 0 & 0 \\
\hline \multirow{4}{*}{$\begin{array}{l}\text { Field D - } \\
46 \text { points }\end{array}$} & & No. & 15 & 0 & 0 & 1 & 0 & 0 & 0 & 1 & 1 & 0 & 0 & 3 & 11 & 6 & 0 & 39 & 2 & 0 & 0 & 0 \\
\hline & 2005 & Freq.\% & 33 & 0 & 0 & 2 & 0 & 0 & 0 & 2 & 2 & 0 & 0 & 7 & 24 & 13 & 0 & 85 & 4 & 0 & 0 & 0 \\
\hline & & No. & 4 & 0 & 0 & 2 & 0 & 0 & 0 & 0 & 0 & 0 & 0 & 3 & 1 & 10 & 0 & 35 & 0 & 0 & 0 & 0 \\
\hline & 2006 & Freq.\% & 9 & 0 & 0 & 4 & 0 & 0 & 0 & 0 & 0 & 0 & 0 & 7 & 2 & 22 & 0 & 76 & 0 & 0 & 0 & 0 \\
\hline \multirow{4}{*}{$\begin{array}{c}\text { Field E - } \\
150 \\
\text { points }\end{array}$} & & No. & 103 & 0 & 0 & 0 & 0 & 0 & 0 & 0 & 1 & 0 & 0 & 8 & 16 & 57 & 0 & 25 & 0 & 0 & 0 & 2 \\
\hline & 2005 & Freq.\% & 68 & 0 & 0 & 0 & 0 & 0 & 0 & 0 & 1 & 0 & 0 & 5 & 11 & 38 & 0 & 17 & 0 & 0 & 0 & 1 \\
\hline & & No. & 20 & 4 & 0 & 0 & 0 & 1 & 1 & 1 & 0 & 1 & 8 & 3 & 0 & 95 & 0 & 22 & 0 & 0 & 8 & 0 \\
\hline & 2006 & Freq.\% & 13 & 3 & 0 & 0 & 0 & 1 & 1 & 1 & 0 & 1 & 5 & 2 & 0 & 63 & 0 & 15 & 0 & 0 & 5 & 0 \\
\hline
\end{tabular}

Table 5.5. Description of Reference Site Based on Individual Tree Data from Fixed-Area Plots. Species follow: Acer circinatum, Alnus rubra, Fraxinus latifolia, Malus fusca, Picea sitchensis, Prunus emarginata, Rhamnus purshiana, Salix spp., Thuja plicata, Tsuga heterophylla.

\begin{tabular}{cccccccccc}
\hline & $\begin{array}{c}\text { No. } \\
\text { Trees }\end{array}$ & Freq & $\begin{array}{c}\text { Basal } \\
\text { Area } \\
\mathrm{dm}^{\wedge} 2\end{array}$ & $\begin{array}{c}\text { Beq } \% \\
\text { Frensity } \\
\text { (Trees/ha) }\end{array}$ & $\begin{array}{c}\text { BA } \\
\left(\mathrm{dm}^{\wedge} 2\right) / \text { ha } \\
(\text { dominance) }\end{array}$ & $\begin{array}{c}\text { Relative } \\
\text { Frequency }\end{array}$ & $\begin{array}{c}\text { Relative } \\
\text { Density }\end{array}$ & $\begin{array}{c}\text { Relative } \\
\text { Dominance }\end{array}$ \\
\hline ACCI & 3 & 2 & 2 & 17 & 8 & 6 & 5 & 3 & 0 \\
ALRU & 23 & 8 & 117 & 67 & 61 & 310 & 19 & 25 & 12 \\
FRLA & 7 & 1 & 2 & 8 & 19 & 6 & 2 & 8 & 0 \\
MAFU & 3 & 3 & 2 & 25 & 8 & 5 & 7 & 3 & 0 \\
PISI & 27 & 11 & 695 & 92 & 72 & 1843 & 26 & 30 & 69 \\
PREM & 1 & 1 & 1 & 8 & 3 & 2 & 2 & 1 & 0 \\
RHPU & 10 & 7 & 13 & 58 & 27 & 33 & 17 & 11 & 1 \\
SASP & 1 & 1 & 1 & 8 & 3 & 2 & 2 & 1 & 0 \\
THPL & 10 & 4 & 159 & 33 & 27 & 422 & 10 & 11 & 16 \\
TSHE & 6 & 4 & 21 & 33 & 16 & 56 & 10 & 7 & 2 \\
TOTAL & 91 & 42 & 1012 & 350 & 241 & 2685 & 100 & 100 & 100 \\
\hline
\end{tabular}




\subsubsection{Organic Matter}

Above-ground standing live and dead macrophytic vegetation biomass was sampled along with below-ground organic matter. Above-ground biomass (AGOM) averaged nearly $500 \mathrm{~g} / \mathrm{m}^{2}$ at all sites except Kandoll reference (Figure 5.4). This tidal forested wetland site had a very low standing biomass of herbaceous plant species. Above-ground biomass showed high variance at all sites. Kandoll reference site had the highest ratio of dead to live biomass (Figure 5.5). Below-ground organic matter (BGOM) at Kandoll reference site was between $5 \%$ and $35 \%$ of soils (Figure 5.6 ). There appears to be no correspondence between below-ground organic matter and above-ground biomass. Vera Slough and Reference sites had similar AGOM levels, whereas BGOM was much greater in Vera Slough. This may reflect the restricted flushing of this site.
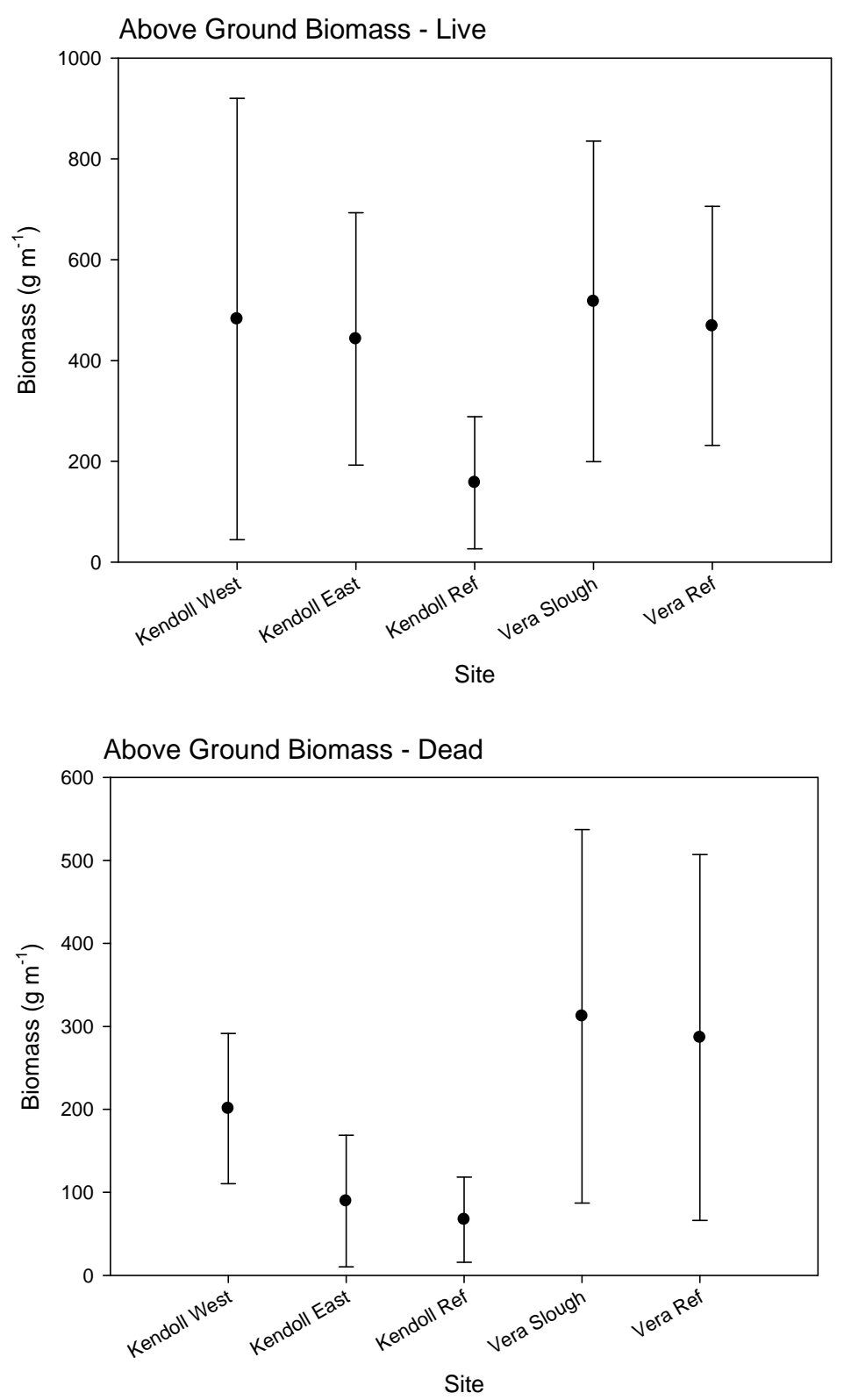

Figure 5.4. Amounts of Above-Ground Biomass, Live and Dead, Measured at Each Site 


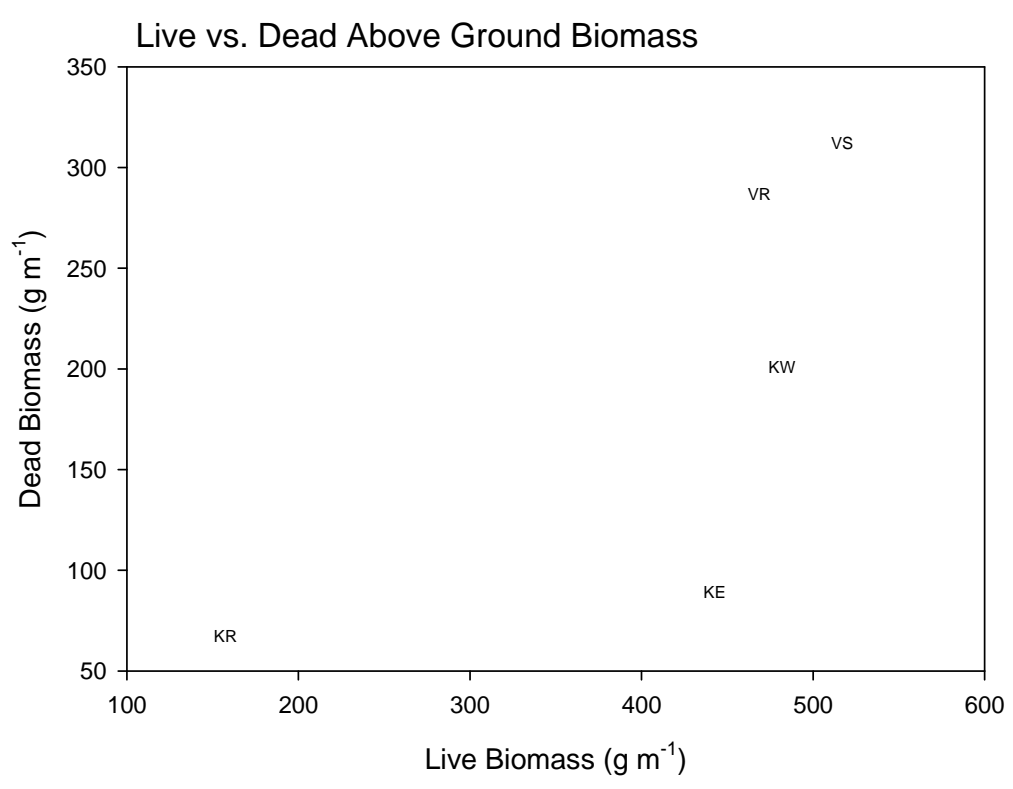

Figure 5.5. Comparison of Live to Dead Biomass at each Site

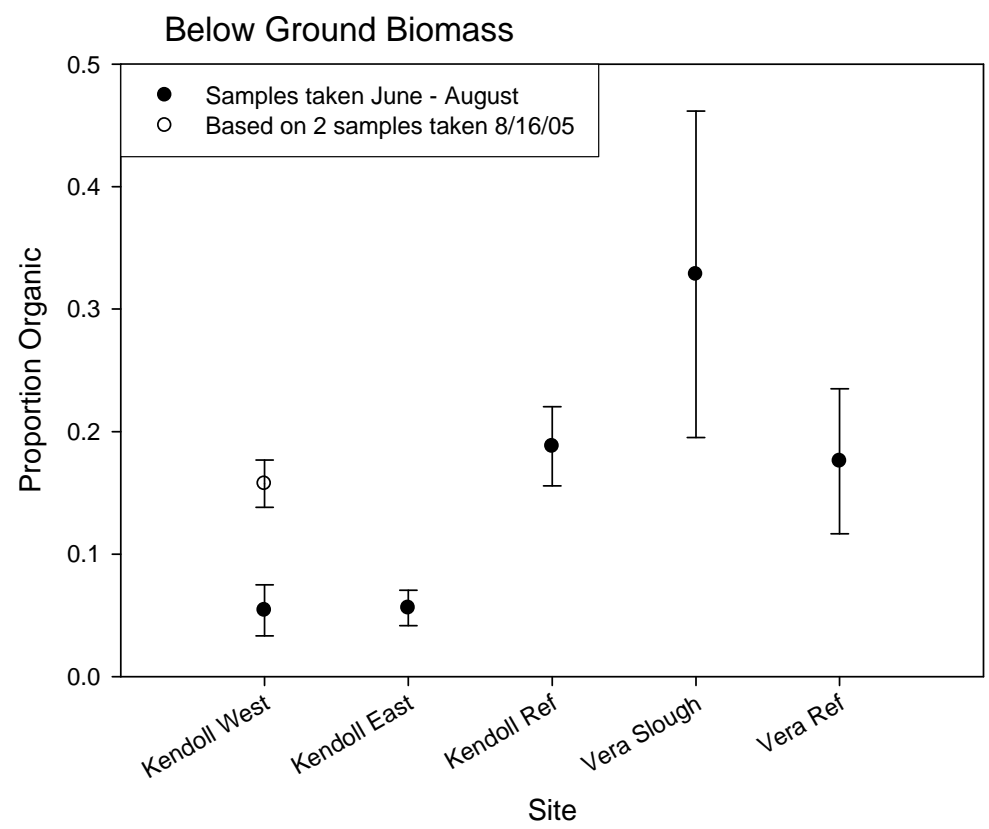

Figure 5.6. Amounts of Below-Ground Organic Matter Measured at each Site

\subsection{Discussion}

The narrow elevation ranges of plant species in the estuary indicate that small differences in elevation result in large changes in vegetation community. Further, hydrology controlled by river flows, tides, and 
topography is affecting vegetation distribution on a site-specific basis. Based on the large elevation differences between restored and reference sites, lengthy restoration trajectories are expected.

The sample plots at Kandoll Farm included a broad range of species with varying degrees of wetlandadapted characteristics. This is likely due to the range in elevations found at the site, with a low of $0.6 \mathrm{~m}$ and high of $2.3 \mathrm{~m}$ (relative to NAVD88). These elevation differences result in differences in the depth, frequency, and duration of hydrologic inundation, which in turn affects growing conditions for plant species. Additionally, the hydrologic regime changed considerably from 2005 to 2006 due to the increase in tidal flow as a result of the restoration action. In response to these changes, plant species composition is shifting from more upland and wet pasture species to those adapted to wetter conditions, including many obligate wetland species.

The forested swamp at Kandoll Reference represents the remnants of what was likely a much more widely distributed assemblage in the area prior to settlement, forestry, and agriculture. We are beginning to acquire quantitative information about these types of systems; however, additional measurements are needed. Qualitative observations indicate a diverse microtopography exists within these swamps, with the tree species typically growing on more elevated hummocks. Additional information on elevation and the associated vegetation in the area would help define the elevations required for establishing swamp species for restoration.

\subsection{Literature Cited}

Anderson, M.J. 2001. A new method for non-parametric multivariate analysis of variance. Austral Ecology 26:32-46.

Bray and Curtis 1957. An ordination of the upland forest community of southern Wisconsin. Ecological Monographs 27:325:349.

Diefenderfer, H.L., G.C. Roegner, R.M. Thom, E.M. Dawley, A.H. Whiting, G.E. Johnson, K.L. Sobocinski, M.G. Anderson, and B.D. Ebberts. 2005. Evaluating Cumulative Ecosystem Response to Restoration Projects in the Columbia River Estuary, Annual Report 2004. PNNL-15102 prepared by Pacific Northwest National Laboratory for the U.S. Army Corps of Engineers, Portland District.

Legendre, P. and L. Legendre. 1998. Numerical Ecology. Elsevier, Amsterdam, The Netherlands.

McArdle, B.H. and M.J. Anderson. 2001. Fitting multivariate models to community data: a comment on distance-based redundancy analysis. Ecology 82:290-297.

McCune, B. and J.B. Grace. 2002. Analysis of Ecological Communities. MjM Software Design, Gleneden Beach, Oregon, U.S.A. 


\title{
6.0 Selected Salmon Habitat Characteristics of Picea sitchensis-Dominated Tidal Forested Wetlands on the Columbia River Estuary, U.S.A.
}

\author{
Heida L. Diefenderfer ${ }^{\mathrm{a}}$ and Kathryn L. Sobocinski ${ }^{\mathrm{a}}$
}

\subsection{Introduction}

This chapter addresses habitat characteristics, such as temperature, velocity, and prey resources, within tidal forested spruce swamps in the Gray's River watershed in southwestern Washington. This characterization is made in the context of the support that spruce swamps could provide to salmonid production and helps to provide a basis for analyzing restoration trajectories.

Sitka spruce (Picea sitchensis) forests were once common in the Pacific Northwest, ranging from Southeast Alaska to northern California (Peterson et. al 1997). The range of Picea sitchensis is broadly congruent with the coastal fog belt, but also includes river valleys in the Tsuga heterophylla zone (Proctor et al. 1980). Considerable ethnobotanical uses of these forests by native peoples included tying salmon spears with Sitka spruce roots gathered from the exposed banks of eroding tidal channels (Smith 1929; Gunther 1945). With the highest strength-to-weight ratio of any wood in the world, Sitka spruce makes highly valuable timber, and the forests were heavily logged, particularly for airplane construction during the world wars (Peattie 1950).

Despite their once widespread occurrence and importance, little documentation on the tidal forested wetlands or "swamps" of the coastal portion of the $235-\mathrm{km}$ Columbia River estuary exists. No mention of these systems is made in national syntheses of wetlands (Mitsch and Gosselink 2000) or forested wetlands (Trettin et al. 1997; Messina and Conner 1998). Nor are they considered at a global scale among the world's coastally restricted forests (Laderman 1998) or forested wetlands (Lugo et al. 1990). Franklin and Dyrness (1988) make only a brief description of forested tideland plant communities of the Columbia River estuary islands and floodplain; they term Sitka spruce (Picea sitchensis) "tideland spruce" and state that it borders tideland flats and channels throughout the Pacific Northwest coast while disappearing east of the city of Cathlamet, Washington, at river mile 40 on the Columbia River. Christy and Putera (1992) noted that Sitka spruce forest was one of seven regionally or globally rare plant communities in the Columbia River, adding that the largest remaining stands of spruce swamp in Oregon and Washington (about 1500 acres) are on the Oregon shore of the Columbia River. Bensen et al. (2001) have documented the disturbance history of tidal forests on the West Coast relative to subsidence of coastal lands caused by earthquakes.

The Columbia River Estuary Data Development Program (CREDDP) sampled low and high marshes of the estuary but did not extensively sample forested wetlands (Small et al. 1990). CREDDP found forested wetlands (swamps) only in freshwater areas of the estuary, whereas scrub-shrub swamps also

\footnotetext{
${ }^{a}$ Marine Sciences Laboratory, Pacific Northwest National Laboratory, Sequim, WA
} 
occurred in brackish water (Fox et al. 1984). These forested wetlands were characterized by Picea sitchensis dominance and a hummock-hollow topography in "well-developed" areas, supporting upland forest species at higher elevations and wetland plant species at lower elevations (Fox et al. 1984). In contrast, forested swamps of the Picea sitchensis zone, in particular those of the Puget Sound and Olympic Peninsula regions, often are dominated by western redcedar (Thuja plicata) and red alder (Alnus rubra) (Franklin and Dyrness 1988).

After the 1700 Cascadia subduction earthquake, spruce forests were widely reestablished by the early 1800s (Benson et al. 2001). However, one arm of the CREDDP study showed that below Puget Island (RM 38) in the Columbia River, the area of tidal swamps was reduced by $77 \%$ between 1870 and 1980 (Thomas 1983). Spruce is believed to be one of the species harvested for cordwood on the Columbia River beginning in the mid-1800s (Christy and Putera 1992). Peattie (1950) also reported an annual Sitka spruce cut in the states of Oregon and Washington of 240 million board feet (MBF), over ten times the annual growth in the region (21 MBF). This large-scale land-cover change may in part explain the dearth of current information regarding this plant community and its habitat functions.

Statewide and regional studies have attempted to classify the Picea sitchensis-dominated forested swamps based on systems of succession or plant associations. A study in western Washington categorized "Picea sitchensis-Alnus rubra/Rubus spectabilis/Carex obnupta" among the community types of the category "surge plain wetlands" (Kunze 1994). As described by Kunze (1994), the surge plain encompasses topographic relief in many forms - including slough channels, natural levees, shallow basins, large woody debris, and mounded areas - and the Picea sitchensis community is typically found on natural levees or terraces with good surface drainage and soils composed of silt, clay, and organic matter with large woody debris. Surge plain wetlands are typically flooded by fresh water $(<0.5 \mathrm{ppt}$ salt $)$ during incoming tides, and drain during low tides (Kunze 1994). Other communities within the surge plain wetlands are, for example, dominated by ferns (Athyrium filix-femina), cattails (Typha latifolia), willows (Salix spp.), sedges (Carex lyngbyei), Lilaeopsis occidentalis (in the sloughs), and alder (Alnus rubra) (Kunze 1994). In their treatment of the Columbia River, Christy and Putera (1992) referred to "freshwater tidelands" and described the ecosystem as being "of low relief, typically flooded or subirrigated at high tide, and permeated by conspicuous, dendritic and meandering tidal streams and sloughs. Cut banks, when present, show mucky soils with high organic content."

Little attention has been given to tidal forested wetlands as salmon habitat throughout the Pacific Northwest, though in the past, it is likely that salmon (Oncorhynchus sp.) used forested wetlands as part of the matrix of available habitats in the estuary. Miller and Simenstad (1997) used a tidal forested wetland to assess characteristics of salmon habitat. Lott (2004) included a forested Sitka spruce wetland as one site in a comparative study of salmonid use and prey resource availability at several sites in the Columbia River estuary; other sites included emergent marshes and scrub-shrub wetlands. While Lott's study found Chinook salmon (Oncorhynchus tshawytscha) utilizing all sites, including the forested wetland, diet studies indicated fuller stomachs from fish collected in emergent marshes. She suggests forested wetlands may offer an additional point of refuge, especially given the physical structure provided by large amounts of woody debris in these systems, while still offering prey resources, even if in lesser densities than nearby emergent marshes (Lott 2004). 
Burke (2004) and Bottom et al. (2005) give considerable discussion to the maintenance of a diversity of life history patterns in the recovery of salmonid populations, suggesting that in the past salmon utilized a wide range of strategies in response to various stresses. One component of life history diversity was the varied reliance on estuarine habitats for rearing. Several researchers on the Pacific Coast have shown benefits to salmon from estuarine rearing (e.g., Reimers 1973; Healey 1980; Healey 1982; Levy and Northcote 1982; Levings et al. 1986; Levings et al. 1991; Levings 1994; Magnussen and Hilborn 2003), though the explicit advantages of specific estuarine habitat types (e.g., emergent marsh, shallow flat, forested wetland) have not been well described, possibly because the complexity of estuarine habitats has been much reduced by human disturbance. Given the prevalence of forested swamp habitat in Pacific Northwest estuaries and in the Columbia River estuary in particular, prior to development, it is likely that these ecosystems once served as critical rearing habitats for salmon.

In addition to rearing habitat suitability in terms of prey availability and physical refuge, of concern for salmonid habitat capacity in the Columbia River estuary are velocity, depth, and temperature, which may limit salmon growth in the estuary, and thus survival upon exiting to the ocean (Bottom et al. 2005). Thermal regimes affect all aspects of salmon life history, with metabolic rate being a function of temperature in juvenile and adult fish (Weatherly and Gill 1995). Several researchers have shown that at elevated temperatures, growth slows and ultimately ceases, as metabolic processes consume an excess of energy (Brett 1952; Wang and Overgaard 2007).

Studies of fish bioenergetics have shown optimal growth to occur in water temperatures between $5{ }^{\circ} \mathrm{C}$ and $17{ }^{\circ} \mathrm{C}$, with some evidence of completely inhibited growth at temperatures above $24{ }^{\circ} \mathrm{C}$ for Chinook salmon (Brett 1971, as cited in Sullivan et al. 2000). During juvenile life stages, growth is critical to future survival and sublethal temperature stress could inhibit growth, although this stress has not been well documented in estuaries. Recently, researchers have suggested that a maximum water temperature limit of $19{ }^{\circ} \mathrm{C}$ or $20^{\circ} \mathrm{C}$ is thought to regulate salmonid smolt/fry usage of estuarine wetlands in the Pacific Northwest (Bottom et al. 2005). However, prevailing temperatures of spruce forested wetlands in floodplain areas lateral to the mainstem Columbia River during both periods of seasonally high air temperatures or key salmonid migration remain unreported. It has been suggested that, due to overstory cover, such biotopes may provide temporary "refugia" from the seasonally high temperatures in other estuarine habitats such as emergent marshes and shallow non-vegetated areas.

Similarly, it is hypothesized that forested wetlands provide refuge in the form of shallow water with low velocity. Several researchers have shown subyearling salmonids to use shallow water extensively for rearing before moving into deeper water at larger size classes (Groot and Margolis 1991; McCabe et al. 1986; Simenstad and Salo 1982). Additionally, because of the high volume of woody debris in forested wetlands, it is plausible that some species, such as coho, utilize tidal forested wetlands in a manner similar to other shallow, low-velocity off-channel areas (Bisson et al. 1982). Several researchers have documented non-natal tributary rearing (e.g., Murray and Rosenau 1989) by Chinook and coho salmon.

Recently, in their calculation of estuarine rearing habitat loss in the Columbia River, Bottom et al. (2005) used a velocity criterion of $30 \mathrm{~cm} / \mathrm{s}$, based upon literature values for Chinook salmon swimming speeds. This threshold has not been evaluated in the field; however, we will use it in comparison to our velocity findings as an approximate limit, recognizing that fish swimming performance is related to fish size and water properties (such as temperature and dissolved oxygen), as well as burst duration. 
While the channel structure of these biotopes has been described as a forced step-pool type (Diefenderfer and Montgomery 2007), the characteristics of these pools with respect to salmonid habitat parameters, such as velocity, temperature, and general suitability for salmonid rearing remain largely unreported. In this paper we report measurements of temperature, velocity, and prey resources within tidal forested spruce swamps in the Gray's River watershed in southwestern Washington.

\subsection{Study Area}

Our primary study area is a small, unnamed slough that drains to Seal Slough in the Grays River watershed in southwest Washington. Additional measurements were taken at Crooked Creek and Secret River in the vicinity of Grays Bay. The sites are approximately $37 \mathrm{~km}$ from the mouth of the Columbia River on the Pacific Ocean, in tidal forested wetlands of the Picea sitchensis zone (cf. Franklin and Dyrness 1988). Approximately $92 \mathrm{~km}^{2}$ of the $322 \mathrm{~km}^{2}$ Grays River watershed are tidally influenced. Erosion and channel instability in the upper Grays River watershed (with a maximum elevation of $820 \mathrm{~m}$ in the Willapa Hills) have been caused by extensive logging over the course of 150 years since non-native settlement.

Our unnamed slough site contains one major meandering slough measuring $15.1 \mathrm{~m}$ across at the mouth, with several smaller sloughs and no perennial streams draining into it. The slough has a soft bottom comprised of mixed fines; woody debris is abundant. The slough banks are unvegetated and steep, rising to a bench 2.5-3 m above NAVD88.

\subsection{Methods}

\subsubsection{Temperature}

Data-logging temperature sensors manufactured by Onset Computer Corporation HOBO ${ }^{\circledR}$ (pendant sensors at Crooked Creek and Secret River or H8 sensors at unnamed slough) were deployed between the upper portions of each channel and the mouth beginning on June 27, 2006. These sensors were set to $\log$ at 1-hour intervals, and the pendant sensors also logged light intensity. Within the channels, the locations of these sensors were selected for their potential as salmon thermal refugia; i.e., close to the substrate in the deepest pools. Two sensors in each channel were positioned as a sun/shade pair in the same pool to evaluate effects of available light on temperature. In addition, a HOBO® Water Level Logger datalogging temperature and pressure sensor recording at $1 / 2$-hour intervals was placed in one pool of our unnamed slough site.

\subsubsection{Velocity}

We measured velocities at the mouth of our unnamed forested tidal channel in 2005 and 2006, using a Marsh-McBirney Flow-Mate. ${ }^{\text {TM }}$ Velocities were measured each month from April to July of 2005 and from April to June of 2006, at approximately one-hour intervals over an ebb and a flood tide for up to 12 hours on each sampling date. Depth was measured at the outset of each measurement period and velocity measurements were recorded at 1/10th total depth (bottom), $1 / 2$ total depth (middle), and at $10 \mathrm{~cm}$ below the surface (surface). Data were recorded to a data sheet and entered into a spreadsheet in the lab. 


\subsubsection{Prey Resources}

Terrestrial Insects. Fallout traps have been found to effectively sample terrestrial invertebrates, particularly insects, which would be available to salmonids foraging in the wetland channel (Gray et al. 2002; Lott 2004). We deployed insect fallout traps to collect terrestrial insects originating in forested wetland vegetation. Six insect fallout traps were set out for 48 hours prior to collection, coinciding with fish sampling at the research sites. The traps consisted of $30-\mathrm{cm} \times 20-\mathrm{cm} \times 15-\mathrm{cm}$ plastic tubs filled with 3 to $5 \mathrm{~cm}$ of soapy water (sieved prior to being poured), which were placed on the bank of the slough, higher than the extent of tide. After 48 hours, the traps were collected. The water and collected insects were sieved through a $106-\mu \mathrm{m}$ sieve and the insects were flushed into a sample jar. The samples were preserved in $\approx 50 \%$ ethanol and held at room temperature until processed. In the laboratory, samples were examined under a dissecting microscope, and taxa were identified and counted to the highest taxonomic level possible, based on the sample condition and taxonomic keys available. Data are presented as counts per $0.25 \mathrm{~m}^{2}$

Benthos. Core samples for benthic infauna were collected monthly (from April until June) at five haphazardly selected points at the site. The corer used was a schedule $40 \mathrm{PVC}$ pipe with inside diameter $5.2 \mathrm{~cm}$ and outside diameter $6 \mathrm{~cm}$, with a sample area of $21.2 \mathrm{~cm}^{2}$. The cores were collected to a depth of $10 \mathrm{~cm}$. The samples were field sieved through a $0.5-\mathrm{mm}$ sieve and fixed with $\approx 10 \%$ buffered formalin and shaken to assure all animals were preserved. These samples were stored at ambient temperature until processing. In the laboratory, samples were examined under a dissecting microscope and taxa were identified and counted to variable taxonomic levels, based on keys available, and the importance of the taxa to salmonid diets.

Neuston. Small neuston samples were collected in the unnamed slough channel over the course of a tidal cycle to capture incoming and outgoing neuston. Typically five samples were taken, two on the ebb, two on the flood, and one at slack tide (high slack or low slack noted). The net was deployed in the center of the channel and was towed 10-m on the channel bank by field staff using an extended boat-hook to maintain position on the surface and in the thalweg. The net used was 16 " x 8 " x 36 " with a PVC frame and cod-end with mesh-size of $130 \mu \mathrm{m}$. This net has successfully sampled neuston in other emergent marsh systems. Once the neuston net was retrieved, the mesh was washed externally to flush any detritus into the cod end. The cod end was removed and the neuston and detritus emptied into a 500- $\mu \mathrm{m}$ sieve. Macrodetritus was rinsed, weighed, and removed. All other contents were placed into a jar and preserved in ethanol $(\sim 70 \%)$ or formalin $(\sim 10 \%)$ depending upon the composition of the sample.

In the laboratory, neuston samples were simultaneously sieved at $6.7 \mathrm{~mm}$ and $333 \mu \mathrm{m}$ in order to separate the macrodetritus from the rest of the sample. The macrodetritus portion of the sample was weighed to the nearest $0.01 \mathrm{~g}$, and then combined with the remainder of the sample for processing. The sample was examined under a dissection microscope, and taxa were identified and counted to the highest taxonomic level possible, based on the sample condition and taxonomic keys available.

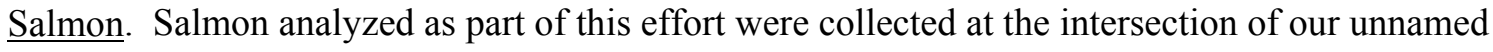
slough and Seal Slough using a beach seine set by boat. The seine was deployed parallel to the shoreline and set out more than half the channel width, then pulled into shore where fish were bagged in the net center and dip netted into holding containers. Salmon were anesthetized with a $50 \mathrm{mg} / \mathrm{l}$ solution of 
tricaine methane sulfonate (MS-222), identified to species, counted, weighed, and measured (fork length). Additionally, stomach contents were taken by gastric lavage on a sub-sample of salmon (up to 10 per species per size class). All fish were allowed to recover in a bucket of fresh river water and were released to the local area.

\subsection{Results}

\subsubsection{Temperature}

Temperature data were not available at the time of this report; they will be reported from three forested wetland study sites after the data are downloaded in spring 2007.

\subsubsection{Velocity}

We made 22 velocity measurements over three days (4/10, 5/23 and 6/1) during the spring of 2006 . The channel measured $15.1-\mathrm{m}$ at the mouth, with a very mild longitudinal gradient of $0.004-\mathrm{m} / \mathrm{m}$, typical of other forested wetland channels measured in this estuary (Diefenderfer and Montgomery 2007). There was no significant difference between measurements at the surface, middle, and bottom of the water column (typically less than $2 \mathrm{~cm} / \mathrm{s}$ variation, ANOVA, $\mathrm{p}=0.69$ ); as such we will present average velocities from the three stations in the water column.

The minimum velocity measured was $0 \mathrm{~cm} / \mathrm{s}$ and the maximum was $8 \mathrm{~cm} / \mathrm{s}$ (Table 6.1 ). There were 10 measurements each made on the ebb and flood tides and 1 each on high slack and low slack. There was no statistical difference in velocity between ebb and flood tides (t-test, $\mathrm{p}=0.79$ ).

Table 6.1. Velocities in a Tidal Forested Wetland Channel

\begin{tabular}{lcccc}
\hline & Minimum $(\mathrm{cm} / \mathrm{s})$ & Maximum $(\mathrm{cm} / \mathrm{s})$ & Mean & Median \\
\hline 2005 & Tbd & Tbd & Tbd & tbd \\
2006 & 0 & 8 & 3.05 & 3.00 \\
Combined & Tbd & Tbd & Tbd & Tbd \\
\hline
\end{tabular}

\subsubsection{Fish Abundance}

Previous sampling in 2001 and 2003 using trap nets in our sampling site and other small tributary sloughs feeding Seal Slough documented subyearling coho $(42-62 \mathrm{~mm}$ ) in May of both years (Baker and Sinks, unpubl. data). In future reports, we will add data from the 2006 sampling efforts outside of the unnamed channel.

\subsubsection{Fish Diets}

A total of 9 Chinook, 1 chum and 15 coho salmon stomachs were collected over the course of three sampling days $(4 / 10,5 / 23$, and 6/1) in 2006. At the Kandoll restored and reference sites, Chinook salmon were eating Chironomidae (Figure 6.1). At Seal, two of the Chinook salmon were eating Corophium (Figure 6.1). Chum and coho diets included Chiromonidae, Heteroptera, and other insects (Figure 6.2). 


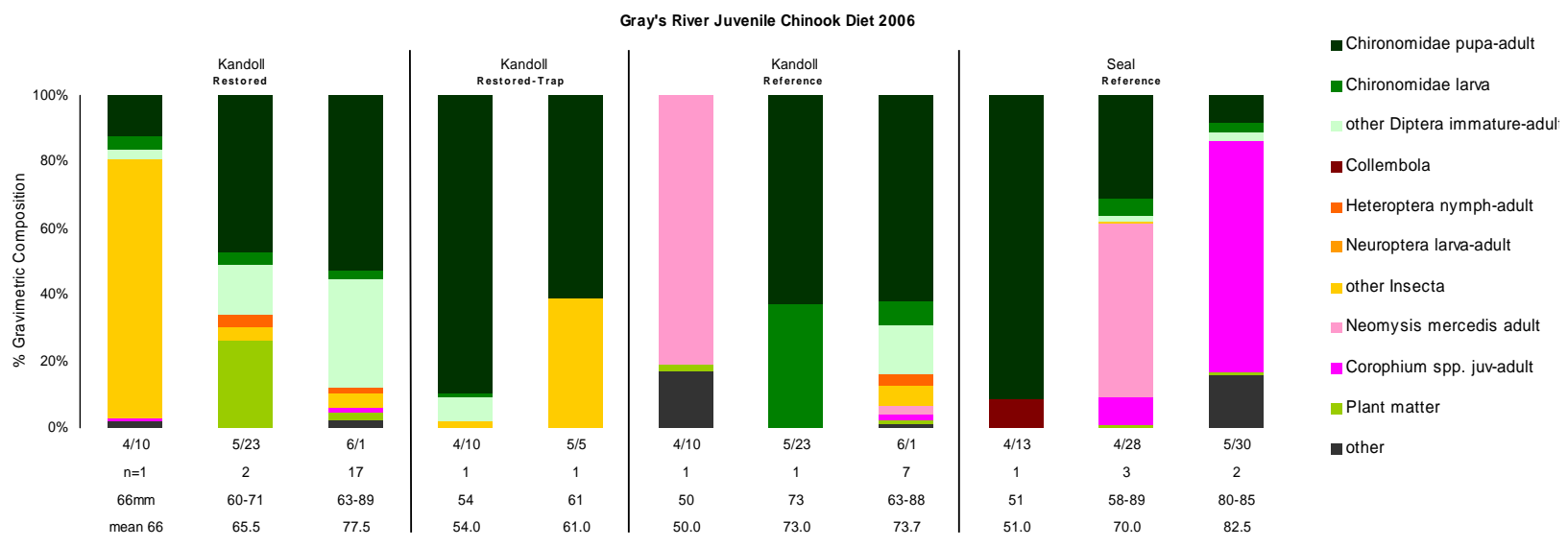

Figure 6.1. Juvenile Chinook Salmon Diets at Restoration and Reference Sites on Seven Sampling Days April-June, 2006

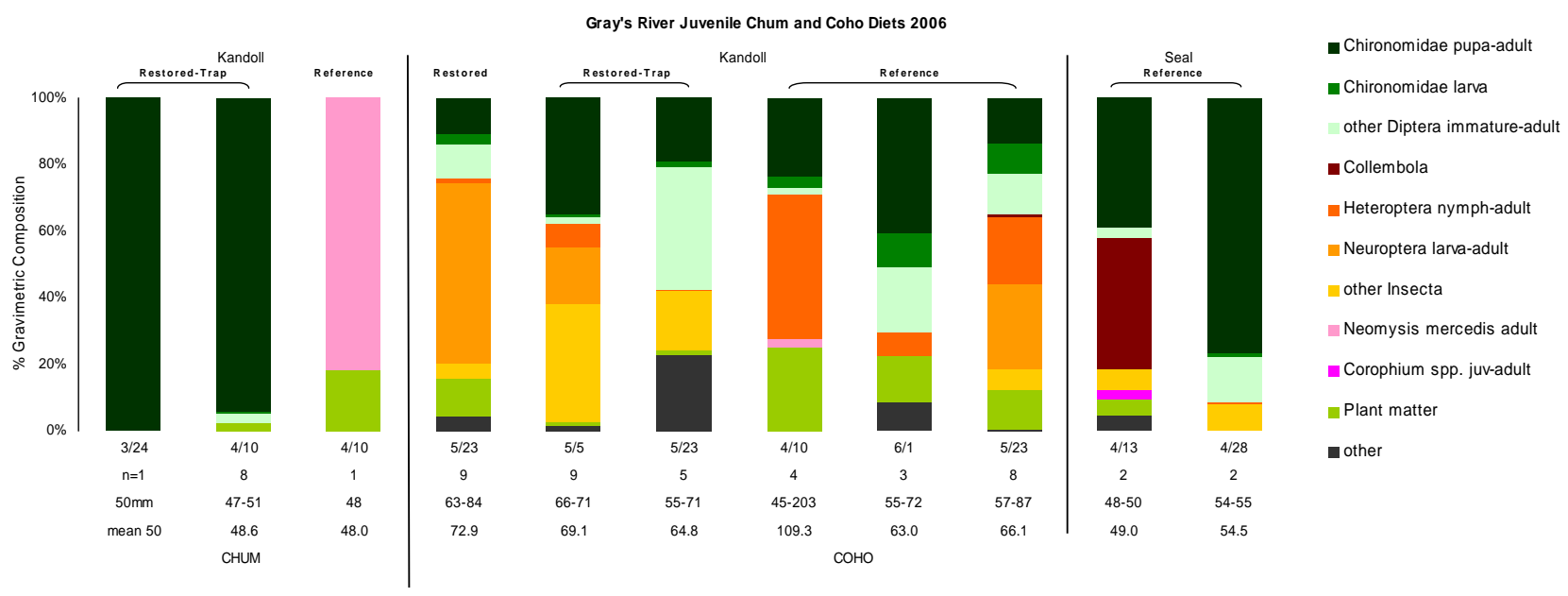

Figure 6.2. Juvenile Chum and Coho Salmon Diets at Restoration and Reference Sites on Seven Sampling Days April-June, 2006

\subsubsection{Insect Fallout Traps and Neuston Tows}

In a future report, the major taxa identified in Chinook, chum, and coho salmon stomachs will be compared to species composition in the fallout traps and neuston tows.

\subsubsection{Benthic Cores}

Benthic core data remain to be analyzed.

\subsection{Discussion}

The diversity and abundance of salmonid populations in the Columbia River basin have declined through the past 150 years in association with increased harvest and alterations to the environment, 
especially degradation and loss of spawning and rearing areas, changes in river flows, and impediments to juvenile and adult migration (Fulton 1968; Mullan et al. 1992; Weitkamp 1994). Physical modifications of the estuary such as filling, diking, timber harvest, and dredging have resulted in the loss of shallow water habitat including most tidal swamps and marshes (Thomas 1983; Kukulka and Jay 2003a,b). Changes in the timing and magnitude of river flow by dam construction have affected water depth and velocity, sedimentation rates and locations, and salinity intrusion (Sherwood et al. 1984; Kukulka and Jay 2003a,b). Mitigation, including hatchery supplementation of stocks and corrective measures to recover from the many anthropogenic impacts, was attempted throughout the 20th century; however, even together with fisheries harvest management actions, it has been insufficient to maintain fish stocks at high abundances (Mighetto and Ebel 1995; Lichatowich 1999; ISG 2000).

There remains a need for specific research projects designed to evaluate habitat use in restored and natural areas of the CRE. Such research has been conducted in other Pacific Coastal estuaries such as the Chehalis, Coos, Fraser, and Salmon, and in Puget Sound (e.g., Levings et al. 1991; Miller and Simenstad 1997; Cornu and Sadro 2002; Gray et al. 2002); however, the applicability of conclusions from these unique systems to the CRE cannot be assumed. Research and monitoring are required to document and assess the long-term and cumulative effects of habitat restoration on the CRE and specifically on the recovery of salmonid stocks.

\subsection{Literature Cited}

Bensen, B.B., B.F. Atwater, D.K. Yamaguchi, L.J. Amidon, S.L. Brown, and R.C. Lewis. 2001. Renewal of tidal forests in Washington State after a subduction earthquake in A.D. 1700. Quaternary Research 56:139-147.

Bisson, P.A., Nielson, R.A., Palmason, R.A., and Gore, L.E. 1982. A system of naming habitat types in small streams with examples of habitat utilization by salmonids during low stream flow. In Acquisition and Utilization of Aquatic Habitat Information. Edited by N.A. Armatrout. American Fisheries Society, Bethesda, Md. pp. 62-73.

Bottom, D.L., C.A. Simenstad, J. Burke, A.M. Baptista, D.A. Jay, K.K. Jones, E. Casillas, and M. Schiewe. 2005. Salmon at River's End: The role of the estuary in the decline and recovery of Columbia River salmon. U.S. Department of Commerce, NOAA Technical Memorandum, NMFS-NWFSC-68.

Brett, J.R. 1952. Temperature tolerance in young Pacific salmon, Genus Oncorhynchus. Journal of the Fisheries Research Board of Canada 9(6):265-323.

Burke, J.L. 2004. Life histories of juvenile Chinook salmon in Columbia River Estuary, 1916 to the present. Master Thesis, Oregon State University. August, 2004. 88p.

Christy, J.A. and J.A. Putera. 1992. Lower Columbia River Natural Area Inventory. Report to The Nature Conservancy, Washington Field Office, Seattle.

Cornu, C. and S. Sadro. 2002. Physical and functional responses to experimental marsh surface elevation manipulation in Coos Bay's South Slough. Restoration Ecology 10(3):474-486.

Diefenderfer HL, and DR Montgomery. 2007. "Pool spacing, channel morphology, and the restoration of tidal forested wetlands of the Columbia River, U.S.A." PNNL-SA-55592, submitted to Restoration Ecology. Pacific Northwest National Laboratory, Richland, WA. 
Fox, D.S., S. Bell, W. Nehlsen, and J. Damron. 1984. The Columbia River Estuary: Atlas of Physical and Biological Characteristics. Columbia River Estuary Data Development Program, Astoria, Oregon.

Franklin, J.F. and C.T. Dyrness. 1988. Natural Vegetation of Oregon and Washington. OSU Press. Corvallis, Oregon.

Fulton, L. A. 1968. Spawning areas and abundance of Chinook salmon (Oncorhynchus tshawytscha) in the Columbia River basin - past and present. U.S. Fish and Wildlife Service, Special Scientific Report. Fisheries No. 571, 26 pp.

Gray, A., C.A. Simenstad, D.L. Bottom, and T.J. Cornwell, 2002. Contrasting functional performance of juvenile salmon habitat in recovering wetlands of the Salmon River estuary, Oregon, U.S.A. Restoration Ecology 10(3):514-526.

Groot, C., and L. Margolis. 1991. Pacific salmon life histories. University of British Columbia Press, Vancouver, Canada.

Gunther, E. 1945. Ethnobotany of Western Washington: The Knowledge and Use of Indigenous Plants by Native Americans. University of Washington Press, Seattle.

Healey, M.C. 1980. Utilization of the Nanaimo River estuary by juvenile Chinook salmon, Oncorhynchus tshawytscha), Fishery Bulletin.

Healey, M.C. 1982. Juvenile Pacific salmon in estuaries: the life support system. In V. S. Kennedy, (editor), Estuarine Comparisons, p. 315-341. Academic Press, New York.

ISG (Independent Scientific Group). 2000. Return to the river: restoration of salmonid fishes in the Columbia River ecosystem. Northwest Power Planning Council Document 2000-12. Northwest Power Planning Council, Portland. 538 p. (Available URL: www.nwppc.org/return_toc.htm)

Kukulka, T. and D.A. Jay, 2003b. Impacts of Columbia River discharge on salmonid habitat: 2. changes in shallow-water habitat. Journal of Geophysical Research 108(C9):3294.

Kukulka, T. and D.A. Jay. 2003a. Impacts of Columbia River discharge on salmonid habitat: 1. a nonstationary fluvial tide model. Journal of Geophysical Research 108(C9):3293.

Kunze, L.M. 1994. Preliminary classification of native, low elevation, freshwater wetland vegetation in Western Washington. Washington State Department of Natural Resources, Olympia, Washington.

Laderman, A.D. (ed.). 1998. Coastally Restricted Forests. Oxford University Press, New York.

Levings, C.D. 1994. Feeding behavior of juvenile salmon and significance of habitat during estuary and early sea phase. Nordic Journal of Freshwater Research 69:7-16.

Levings, C.D., C.D. McAllister, and B.D. Chang. 1986. Differential use of the Campbell River estuary, British Columbia, by wild and hatchery-reared juvenile chinook salmon (Oncorhynchus tshawytscha). Canadian Journal of Fisheries and Aquatic Sciences 43(7):1386-1397.

Levings, C.D., K. Conlin and B. Raymond. 1991. Intertidal habitats used by juvenile Chinook salmon (Oncorhynchus tshawytscha) rearing in the North Arm of the Fraser River Estuary. Marine Pollution Bulletin 22(1):20-26.

Levy, D.A. and T.G. Northcote. 1982. Juvenile salmon residency in a marsh area of the Fraser River Estuary. Canadian Journal of Fisheries and Aquatic Sciences 39:270-276.

Lichatowich, J. 1999. Salmon without Rivers: a History of the Pacific Salmon Crisis. Island Press, Chicago. 
Lott, M. A. 2004. Habitat-Specific Feeding Ecology of Ocean-Type Juvenile Chinook Salmon in the Lower Columbia River Estuary. MS Thesis, University of Washington, Seattle.

Lower Columbia Fish Recovery Board (LCFRB). 2004. Grays River Sub-Basin Plan. Prepared for Bonneville Power Administration (BPA), Northwest Power Planning Council (NWPPC).

Lugo, A.E., M. Brinson, and S. Brown (eds.). 1990. Ecosystems of the World, "15: Forested Wetlands." Elsevier, Amsterdam.

Magnusson, A., and R. Hilborn. 2003. Estuarine Influence on survival rates of coho (Oncorhynchus kisutch) and Chinook salmon (Oncorhynchus tshawytscha) released from hatcheries on the U.S. Pacific Coast. Estuaries 26(4B):1094-1103.

McCabe, G.T., R.L. Emmett, W.D. Muir, and T.H. Blahm. 1986. Utilization of the Columbia River estuary by subyearling Chinook salmon. Northwest Science 60:113-124.

Messina, M.G. and W.H. Conner, eds. 1998. Southern Forested Wetlands: Ecology and Management. Lewis Publishers, Boca Raton, Florida, U.S.A.

Mighetto, L. and W.J. Ebel. 1995. Saving the Salmon: A History of the U.S. Army Corps of Engineers' Efforts to Protect Anadromous Fish on the Columbia and Snake Rivers. Prepared for U.S. Army Corps of Engineers, North Pacific Division, Portland and Walla Walla Districts, 262 p. (Available from USACE, North Pacific Division, P.O. Box Custom House, Portland 97208)

Miller, J.A. and C.A. Simenstad, 1997. A comparative assessment of a natural and created estuarine slough as rearing habitat for juvenile Chinook and Coho salmon. Estuaries 20(4):792-806.

Mitsch, W.J. and J.G. Gosselink. 2000. Wetlands. 3rd ed. John Wiley \& Sons, Inc., New York.

Mullan, J.W., K.R. Williams, G. Rhodus, T.W. Hillman, and J.D. McIntyre. 1992. Production and habitat of salmonids in Mid-Columbia River tributary streams. U.S. Fish and Wildlife Service, Monograph I. 489 pp.

Olenin, S. and J-P Ducrotoy. 2006. The concept of biotope in marine ecology and coastal management. Marine Pollution Bulletin 53:20-29.

Peattie, D.C. 1950. A Natural History of Western Trees. University of Nebraska Press, Lincoln.

Peterson, E.B. N.M. Peterson, G.F. Weetman, and P.J. Martin. 1997. Ecology and Management of Sitka Spruce: Emphasizing its Natural Range in British Columbia. UBC Press, British Columbia, Canada.

Proctor, C.M. , J.C. Garcia, D.V. Galvin, G.C. Lewis, L.C. Loehr, and A.M. Massa. . 1980. An ecological characterization of the Pacific Northwest coastal region Volume Two:

Characterization Atlas - Regional synopsis. FWS/OBS-79/12. USFWS Office of Biological Services - Region 1, Portland, Oregon.

Reimers, P.E. 1973. The Length of Residence of Juvenile Fall Chinook Salmon in Sixes River, Oregon. Oregon Fish Comm. Res. Rep. 4, 43 p.

Sherwood, C.R., J.S. Creager, E.H. Roy, G.A Gelfenbaum, and T. Dempsey. 1984. Sedimentary processes and environments in the Columbia River estuary. Columbia River Estuary Study Taskforce. Astoria, OR.

Simenstad, C. A., and E. O. Salo. 1982. Foraging success as a determinant of estuarine and nearshore carrying capacity of juvenile chum salmon (Oncorhynchus keta) in Hood Canal, Washington. In B. R. Melteff and R. A. Neve (eds.), Proceedings of the North Pacific Aquaculture Symposium, 18-27 August 1980, p. 21-37. Alaska Sea Grant Program, Univ. Alaska, Fairbanks. 
Simenstad, C.A. and J.R. Cordell. 2000. Ecological assessment criteria for restoring anadromous salmonid habitat in Pacific Northwest estuaries. Ecological Engineering 15: 283-302.

Small, L.F., C.D. McIntire, K.B. MacDonald, J.R. LaraLara, B.E. Frey, M.C. Amspoker, and T. Winfield. 1990. Primary production, plant and detrital biomass, and particle transport in the Columbia River Estuary. In Small, L.F. (ed.). "Columbia River: Estuarine System.” Progress in Oceanography, Vol. 25, no. 1-4.

Smith, H.I. 1929. Materia Medica of the Bella Coola and Neighboring Tribes of British Columbia. Annual Report of 1927. Department of Mines, National Museum of Canada, Bulletin 56. Ottawa.

Sullivan, K., D.J. Martin, R.D. Cardwell, J. E. Toll, and S. Duke. 2000. An Analysis of the Effects of Temperature on Salmonids of the Pacific Northwest with Implications for Selecting Temperature Criteria. Sustainable Ecosystems Institute, Portland Oregon.

Thomas, D.W. 1983. Changes in the Columbia River estuary habitat types over the past century. Columbia River Estuary Data Development Program. 51 (Available from Columbia River Estuary Study Taskforce. P.O. Box 175, Astoria, OR 97103).

Trettin, C.C., M.F. Jurgensen, D.F. Grigal, M.R. Gale, and J.K. Jeglum. 1997. Northern Forested Wetlands: Ecology and Management. Lewis Publishers, Boca Raton, Florida, U.S.A.

Wang, T. and J. Overgaard. 2007. The heartbreak of adapting to global warming. Science 315: 49-50.

Washington State Conservation Commission (WCC). 2002. Water Resource Inventory Area (WRIA) 25 Salmon and Steelhead Habitat Limiting Factors Analysis. Olympia, Washington.

Weatherly, A.H. and H.S. Gill. 1995. Growth. Pages 101-158 In: [ed] C. Groot, L. Margolis, and W.C. Clarke. Physiological Ecology of Pacific Salmon. UBC Press, Vancouver, B.C. Canada.

Weitkamp, Laurie A. 1994. Effect of Dams on Columbia River Estuarine Environment with Special Reference to Salmonids. National Marine Fisheries Service, Seattle, WA. 


\title{
7.0 Monitoring Juvenile Salmon Use and Fish Community Structure in Restored Wetland Habitat
}

\author{
G. Curtis Roegner ${ }^{\mathrm{a}}$, Earl M. Dawley ${ }^{\mathrm{b}}$, Allan W. Whiting ${ }^{\mathrm{c}}$, and Blaine D. Ebberts ${ }^{\mathrm{d}}$
}

\subsection{Introduction}

Wetland habitats were historically important for juvenile salmon, both ocean- and stream-type life histories, providing prey resources and protection from predation (Bottom et al. 2005). One goal for the restoration of wetland habitats in the CRE is to increase opportunity, connectivity, and capacity functions for juvenile salmonids. Tidal reconnection of degraded habitat should benefit growth, fitness, and survival of emigrating juvenile salmon. The restoration actions will also benefit the entire ecosystem. This section describes salmonid presence and fish community structure in two restoration sites undergoing tidal reconnection.

At both the Vera Slough and Kandoll Farm restoration sites, tidal hydrology has been substantially increased, allowing fish access to tidal channel networks and wetland habitats (Chapter 2). The two sites differ in scale, hydrography, type of tidal reconnection, and proximity to sources of juvenile salmonids. The data presented here represent fish presence/absence pre-restoration and post-restoration during the first reproductive season following tidal reconnection. The study is ongoing to better evaluate fish population changes as the sites evolve and approach equilibrium. This section explains the methods used, initial findings, and a brief discussion of results.

\subsection{Methods}

Fish communities were sampled before and after tide gate removal (Kandoll) or replacement (Vera). In addition, fish populations were sampled at stations inside the tide gate (Inside), immediately outside the tide gate (Outside), and at one or more reference sites not directly affected by the restoration activity (Reference). Since determining the presence/absence of salmonids was a goal, fishing effort was concentrated in the spring and early summer.

For the 2005 pre-restoration (Before) fish community determination, sampling in Vera Slough and Kandoll Farm was conducted in May and June, before tide gate modification. Sampling was conducted inside and outside of the pre-restoration tide gates as well as at reference sites separate from the restoration sites (Figures 1.2 and 1.4). Sampling within the pre-restoration Kandoll Farm site was limited to one date, as fish habitat conditions there were found to be marginal. For post-restoration (After) sampling in 2006, reference and restoration sites were sampled at approximately biweekly intervals at

\footnotetext{
${ }^{a}$ Pt. Adams Biological Station, National Marine Fisheries Service, Hammond, OR

${ }^{\mathrm{b}}$ Retired NMFS Biologist, Clatskanie, OR

${ }^{c}$ Columbia River Estuary Study Taskforce, Astoria, OR

${ }^{\mathrm{d}}$ Portland District, U.S. Army Corps of Engineers, Portland, OR
} 
Vera Slough from 3 April through 3 June (which includes sampling during the Flux Study outlined in Chapter 8). At Kandoll, biweekly sampling with a trap net inside the restoration site (24 March - 19 June) and with a beach seine at Reference B (16 March - 10 August) was performed. Additional beach seine samples were made at the Outside and Reference A sites during the Flux Study dates in April, May, and June.

Several sampling techniques were used to evaluate fish community structure and salmonid presence and habitat use, pre- and post-restoration. Different sampling methods were necessitated by the physical constraints of the sites:

- At Vera Slough where channels were restricted, either a $5 \mathrm{~m} \times 1.5 \mathrm{~m}$ pole seine or a $7 \mathrm{~m} \times 2 \mathrm{~m}$ pull-seine was used (both had $6.5 \mathrm{~mm}$ stretch mesh webbing). During channel sampling, the seine was deployed along one shoreline, then pulled 5 to $7 \mathrm{~m}$ (depending on channel width) to the opposite shore. The area swept was between 25 and $35 \mathrm{~m}^{2}$ for the pole seine and from about 36 to $49 \mathrm{~m}^{2}$ for the pull seine.

- In unconstrained open areas inside Vera Slough, the seine was swept in a semicircular pattern with one end anchored on shore $\left(\sim 77 \mathrm{~m}^{2}\right)$.

- At Kandoll, a $5 \mathrm{~m}$ x $1.5 \mathrm{~m}$ pole seine, a $7 \mathrm{~m}$ x $2 \mathrm{~m}$ pull-seine, and a larger $50 \mathrm{~m}$ x $3 \mathrm{~m}$ beach seine were deployed for outside channel sampling, and a pole seine and trap net were deployed for sampling inside the restoration area. Trap nets were set at high tide and fished for the ensuing ebb tide; catches are reported as catch/tide.

As a result of the varied channel morphologies and techniques used to sample within them, catch data are gear-dependant and therefore not readily standardized; however, we do calculate catch per unit effort for each gear type. The fish abundance data were used to assess general patterns of community structure and presence/absence at different sites.

Sampled fish were concentrated in the net center and dip netted into holding containers. Salmonids were anesthetized with a $50 \mathrm{mg} / 1$ solution of tricaine methane sulfonate (MS-222) before measurement. All fish were identified to species, counted, and the standard length of up to 30 per species was determined. Fish were also checked for passive integrated transponder and coded-wire tags. Salmon weights were determined during the 2006 flux study dates. Stomach lavage was performed on a subset of salmon in 2006, and stomach contents were identified by the lowest practical taxon (see Chapter 6). Fish were allowed to recover before release to the local area. For each site and date, we pooled data from all seine or trap net samples to compare presence/absence, salmon size, and fish species composition between Inside, Outside, and Reference habitat sites before and after tide gate replacement. Community structure was evaluated using two standard measures, the number of species (S) and the Shannon-Wiener species diversity index $\mathrm{H}^{\prime}=\sum\left[-\mathrm{P}_{\mathrm{i}} *\left(\ln \mathrm{P}_{\mathrm{i}}\right)\right]$, where $\mathrm{P}_{\mathrm{i}}$ is the proportion of the $\mathrm{i}^{\text {th }}$ species in the community. Length-weight regressions for salmonids were generated to access allometric relationships.

\subsection{Results and Discussion}

In total, 12,740 fish at Vera sites and 23,180 fish at Kandoll sites were sampled. These totals include all sampling sites and both pre- and post-restoration conditions (2005 and 2006). Three species of salmon were collected: Chinook (Oncorhynchus tshawytscha), chum (O. keta), and coho (O. kisutch). 


\subsubsection{Species Composition}

Species composition was dominated by threespine stickleback (Table 7.1 and 7.2). This preponderance of stickleback tended to reduce diversity $\left(\mathrm{H}^{\prime}\right.$ generally $\left.<1.0\right)$. Other abundant resident fish were sculpin, peamouth, starry flounder, and killifish. Staghorn sculpin and killifish were the next most common fish at Vera, and peamouth and prickly sculpin were the next most common fish at Kandoll. Sculpins were not found inside of either tide gate controlled areas prior in 2005. No fish other than stickleback were found at Kandoll inside the tide gate controlled area. Species richness was higher at Vera (12 species) than Kandoll ( 9 species). Note that killifish is an introduced species.

\subsubsection{Salmon PresencelAbsence and Size}

Catches of juvenile salmon at Vera and Kandoll Inside, Outside and Reference sites are presented in Tables 7.1 and 7.2, respectively. In 2005, few salmon were captured at either site, partially due to the late sampling date (most salmon would have migrated through the system by then), and high water temperatures.

At Vera Slough in 2005, three coho, one Chinook and one chum salmon were captured in May and none in June; all were less than $45 \mathrm{~mm}$ (Table 7.1). All salmon were captured outside of the tide gate or in the reference area; none were captured inside the area eventually to be affected by restoration. During 2006 sampling, after tide gate replacement two Chinook and one coho salmon were captured at outside or reference sites, and two coho and one Chinook salmon were captured at the Inside site. These catch numbers are low compared to other sites in the estuary, and may reflect the distant location of Vera Slough relative to migration pathways.

At Kandoll Farm during the 2005 sampling, one coho salmon was captured in May (46 mm) and four were captured in June (80-81 mm); all these fish were present outside the tide gate (Table 7.2) and were collected with beach seines. Trap netting inside Kandoll was not carried out in 2005. During the postbreach period, the trap net samples collected 15 Chinook, 66 coho, and 51 chum inside the restoration site (Table 7.2; Figure 7.1). Inside the restoration site, Chinook salmon were present April-June with a peak in May; chum and coho had narrower residences and peaked in April and May, respectively. Salmon were present in the trap net samples for a shorter temporal window than at the Outside or Reference sites. Time series of salmon catches at Reference B followed a similar temporal pattern to the trap net pattern, although abundance peaks were only coincident for coho salmon. During the flux study, most Chinook salmon were captured during the June sampling. Coho salmon were present during all sampling dates and at both Outside and Reference sites. Chum salmon were only found in April and were at low abundance.

Mean salmon size at Kandoll tended to increase with time at all sites, although size ranges at a given date were large for Chinook and coho salmon. At the trap net site, Chinook salmon size ranged $\sim 40$ to 80 $\mathrm{mm}$, with the exception of one yearling fish. Chum ranged $\sim 40$ to 70 , with the largest chum at the trap net site. Overall, chum appeared to exit the system while $<60 \mathrm{~mm}$ (fry migrants). Both yearling and subyearling coho were captured. Subyearling coho ranged in size from $<40$ to $90 \mathrm{~mm}$, and size-at-date patterns appeared similar between trap net (inside) and reference sites (outside).

In summary, the data to date indicate that the Grays River system supports three species of migrating juvenile salmon: Chinook, chum and coho. Salmon presence was species specific, but extended from March (or earlier) through June. At the Kandoll restoration site, we captured few salmon before tide gate 
removal, but relatively high numbers post-removal; however, effort was greater after removal. All three salmon species utilized the habitat after tidal reconnection. In contrast, fish community structure and salmon presence at the Vera Slough tide gate replacement exhibited a more modest change between preand post-tide gate replacement. We captured few salmon either year, which we suspect is because the site lies off of the main migration route from the Youngs Bay system. However, a few salmon were found inside the tide gate post-replacement. Future sampling will allow us to evaluate benefits to salmon of the improved physical/biological conditions.

\section{Kandoll 2006}

\section{Catch}
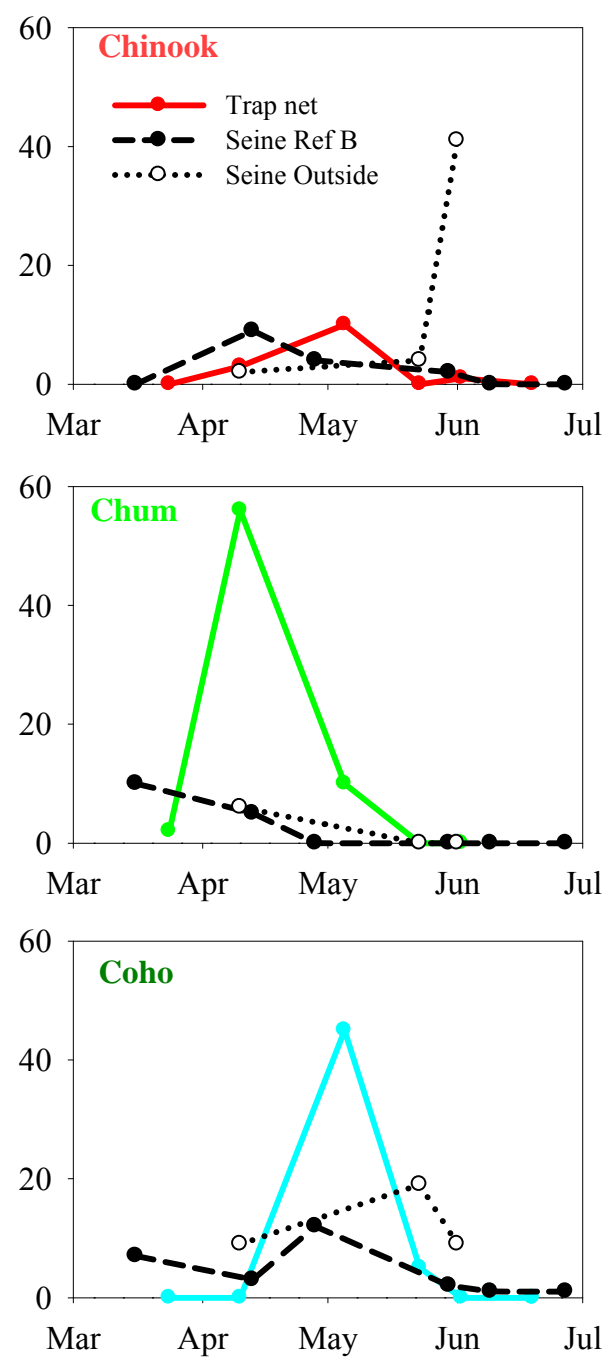

Mean FL (sd)
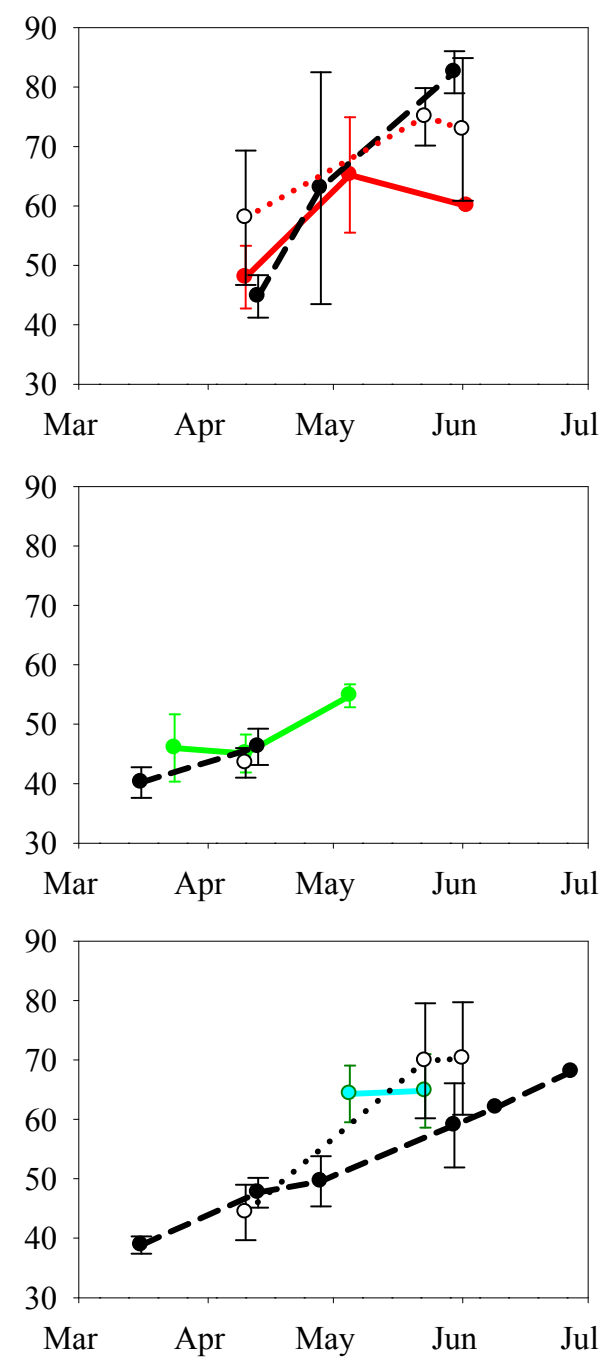

\section{Date in 2006}

Figure 7.1. Salmonid Catch and Mean Size ( \pm s.d.) at Kandoll Farm Restoration and Reference Sites in 2006. (FL $=$ fork length) 
Table 7.1. Vera Slough Catch, Number of Individuals (N), Number of Species (S) and Shannon-Wiener Diversity Index (H'). Data are for trap net and seine samples collected at Vera Slough restoration and references sites during 2005 (before) and 2006 (after) tide gate replacement.

\begin{tabular}{|c|c|c|c|c|c|c|c|c|c|c|c|c|c|c|c|c|}
\hline Station & Before & Chin & Coho & Chum & Stick & Killi & Stag & Prick & ESole & Pea & Star & Shin & Bass & $\mathbf{N}$ & $\mathrm{S}$ & $\mathbf{H}^{\prime}$ \\
\hline \multirow[t]{2}{*}{$\mathrm{IN}$} & $5 / 13 / 05$ & & & & 634 & 15 & & & & & & & 4 & 653 & 3 & 0.15 \\
\hline & $6 / 14 / 05$ & & & & 341 & 10 & & & & & & & 2 & 353 & 3 & 0.16 \\
\hline \multirow[t]{2}{*}{ OUT } & $5 / 13 / 05$ & & 2 & 1 & 1406 & 75 & 93 & & 2 & & & & 4 & 1583 & 7 & 0.45 \\
\hline & $6 / 14 / 05$ & & & & 1439 & 91 & 44 & & & & & & & 1574 & 3 & 0.35 \\
\hline \multirow[t]{4}{*}{ REF } & $5 / 18 / 05$ & 1 & 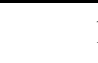 & & 440 & & 134 & 2 & & 1 & & & & 579 & 6 & 0.6 \\
\hline & $6 / 14 / 05$ & & & & 307 & 4 & 33 & & & & & 1 & & 345 & 4 & 0.4 \\
\hline & TOTAL & 1 & 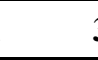 & 1 & 4567 & 195 & 304 & 2 & 2 & 1 & ( & 1 & 10 & 5087 & & \\
\hline & After & & & & & & & & & & & & & & & \\
\hline \multirow[t]{7}{*}{ IN } & $4 / 3 / 06$ & & & & 44 & & 3 & & & & & & & 47 & 3 & 0.24 \\
\hline & $4 / 12 / 06$ & & & & 185 & & 2 & & & 1 & & & & 188 & 3 & 0.09 \\
\hline & $4 / 21 / 06$ & & & & 132 & 7 & & & & & & & & 139 & 2 & 0.2 \\
\hline & $5 / 4 / 06$ & & 2 & & 44 & 1 & 1 & & & & & & & 48 & 4 & 0.37 \\
\hline & $5 / 12 / 06$ & & & & 57 & & & & 1 & & & & & 58 & 2 & 0.09 \\
\hline & $5 / 24 / 06$ & & & & 702 & 61 & 3 & & & & & & 10 & 766 & 4 & 0.36 \\
\hline & $6 / 3 / 06$ & 1 & & & 1272 & 91 & 2 & & & & & & & 1366 & 4 & 0.27 \\
\hline \multirow[t]{5}{*}{ OUT } & $4 / 3 / 06$ & & & & 5 & & & & & & & & & 5 & 1 & \\
\hline & $4 / 21 / 06$ & 1 & & & 8 & & 8 & & 3 & & & & & 20 & 4 & 1.17 \\
\hline & $5 / 4 / 06$ & & & & 6 & & & & & & & 9 & & 15 & 2 & 0.67 \\
\hline & $5 / 24 / 06$ & 1 & & & 1895 & 1 & 25 & & & & 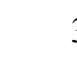 & & & 1925 & 5 & 0.09 \\
\hline & $6 / 3 / 06$ & & & & 214 & 70 & 91 & & & & 3 & & & 378 & 4 & 1.02 \\
\hline \multirow[t]{7}{*}{ REF } & $4 / 3 / 06$ & & & & 57 & & 31 & & & & & & & 88 & 2 & 0.65 \\
\hline & $4 / 12 / 06$ & & & & 326 & & 19 & & & & & & & 346 & 3 & 0.23 \\
\hline & $4 / 21 / 06$ & & & & 189 & & 43 & & & & & & & 232 & 2 & 0.48 \\
\hline & $5 / 4 / 06$ & & & & 556 & & 100 & & 28 & 4 & & & & 688 & 4 & 0.61 \\
\hline & $5 / 24 / 06$ & & & & 865 & & 313 & & & & 13 & & & 1191 & 3 & 0.63 \\
\hline & $6 / 3 / 06$ & & & & 66 & & 82 & & & 2 & 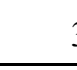 & & & 153 & 4 & 0.83 \\
\hline & TOTAL & 3 & 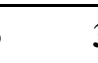 & $\mathbf{0}$ & 6623 & 231 & 723 & $\mathbf{0}$ & 32 & 7 & 2 & 9 & 10 & 7653 & & \\
\hline
\end{tabular}


Table 7.2. Kandoll Farm Catch, Number of Individuals (N), Number of Species (S) and Shannon-Wiener Diversity Index (H'). Data are for trap net and seine samples collected at Kandoll Farm restoration and references sites during 2005 (before) and 2006 (after) tide gate removal.

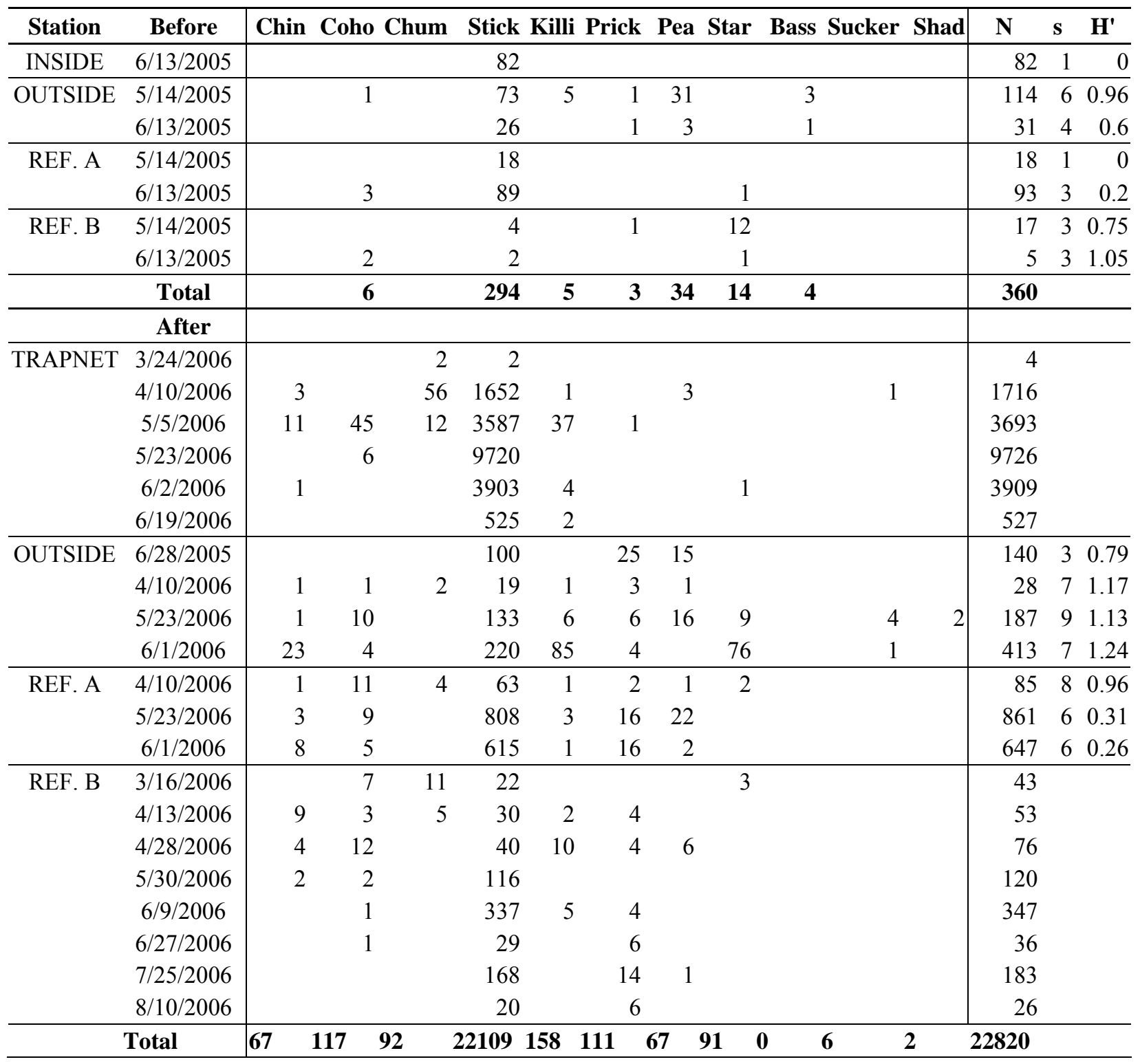

\subsection{Literature Cited}

Bottom, D.L., C.A. Simenstad, J. Burke, A.M. Baptista, D.A. Jay, K.K. Jones, E. Cassillas, and M.H. Schiewe. 2005. Salmon at River's End: the Role of the Estuary in the Decline and Recovery of Columbia River Salmon. NOAA Tech. Memo. NMFS-NWFSC-68, NOAA National Marine Fisheries Service, Seattle, Washington. 


\title{
8.0 Material Fluxes through Restored Wetlands
}

\author{
Ronald M. Thom ${ }^{\mathrm{a}}$, G. Curtis Roegner ${ }^{\mathrm{b}}$, John Vavrinec III ${ }^{\mathrm{a}}$, and Blaine D. Ebberts ${ }^{\mathrm{c}}$
}

\subsection{Introduction}

Among the key functions of tidal wetland systems is their ability to trap, process, and export various materials. These materials include suspended sediments, nutrients, organic matter, and organisms. In this role, tidal wetlands contribute to the overall trophic conditions and productivity of the broader estuary, while supporting their own productivity and wetland-associated wildlife. Diking and levee construction, with subsequent conversion of tidal wetlands into pastures and agricultural production, have removed approximately $70 \%$ of the tidal wetland area from the estuary. Loss of tidal wetlands is believed to have resulted in a significant loss of marsh macrodetritus input to the estuary. It has been hypothesized that this loss, coupled with the enhanced production of plankton in the reservoirs, has resulted in a shift in the food web structure in the estuary from marsh-based to plankton-based (Bottom et al. 2005). It is generally thought that restoration of sources of macrodetritus and the processing of nutrients, trapping of sediments, and export of invertebrate fish prey can be achieved through restoration of tidal exchange and subsequent re-development of productive tidal wetland systems. As yet this outcome has not been tested in the Columbia River estuary, and there are minimal studies throughout the world that focus on exchange from restored tidal wetland systems.

The purpose of this study is to understand effects of hydrological reconnections on water properties inside and outside of restored wetlands. A main goal is to develop sets of data that can be used to measure and predict the cumulative effect of multiple restoration actions on the flux of ecosystemrelevant materials from the restored sites to the estuary. In order to extrapolate results from our study sites, we are developing a data set that relates in a simple way aspects of the wetland, such as average daily wetted area and mass flux of materials. Ultimately we hope to answer the question "At what point do restoration actions for tidal wetlands have a detectable effect on the broader estuarine ecosystem?" This question is important for several reasons, in particular because of the fact that restoration of ecosystems can be expensive and is not universally supported. Knowing the level of effort required to make a true difference in an ecosystem would help us better plan for ecosystem restoration programs. Second, being able to quantify the incremental effects of multiple projects provides a means to provide needed data to support the expenditure of scarce funds. Finally, developing predictive tools that are simple and cost-effective to apply but provide insight into key processes and functions is a fundamental and critical need in restoration ecology.

\footnotetext{
${ }^{a}$ Marine Sciences Laboratory, Pacific Northwest National Laboratory, Sequim, WA

${ }^{\mathrm{b}}$ Pt. Adams Biological Station, National Marine Fisheries Service, Hammond, OR

${ }^{\mathrm{c}}$ Portland District, U.S. Army Corps of Engineers, Portland, OR
} 
The focus of this paper is on basic comparisons of water properties inside and outside of the restored wetlands. The water properties we studied included total organic carbon (TOC), inorganic nutrients (NO3, NO2, NH4+, OPO4, Si), and chlorophyll a. These are commonly measured water properties that are affected largely by biochemical processes in the water column, soil and sediment. Using a conductivity-temperature-depth (CTD) instrument, we also measured temperature, salinity, and chlorophyll fluorescence at various locations inside and outside of the restored sites.

This data report outlines methods and summarizes activities and data results through 2006. Full analyses are not complete at this time.

\subsection{Methods}

\subsubsection{Discrete Sampling during a Tidal Cycle}

We measured the instantaneous concentration of material, horizontal velocity, and cross-sectional area of the mouths of tidal sloughs draining wetland restorations sites. These data are used to calculate instantaneous fluxes, and we sampled over both ebb and flood tides to assess net transport of material. We compare fluxes at restoration sites to those from nearby reference sites. Experiments were conducted before (2005) and after (2006) tide gate removal (Kandoll Farm) or tide gate replacement (Vera Slough) to evaluate the influence of restoration on the quality and quantity of material fluxes. Several types of material were targeted. Discrete water samples were used to measure dissolved constituents (inorganic nutrients and TOC) and phytoplankton-derived chlorophyll a and phaeopigments. A neuston net was used in 2006 to sample surface-oriented macrodetritus, insects, and fishes.

Our primary goal was to access the flux of dissolved nutrients, TOC and chlorophyll through each site. Discrete water samples were collected over the course of the ebb and flood tide. Surface water (to $\sim 0.2 \mathrm{~m}$ ) was collected from the center of the tidal channel in a bucket, and the water within was subsampled for dissolved and particulate constituents. For chlorophyll samples, $50 \mathrm{~mL}$ of water was filtered through a GF/C $(0.5 \mu \mathrm{M})$ Whatman glass microfiber filter and stored on ice in darkness. Pigment concentration was determined from acetone-extracted samples with a Turner Designs fluorometer following standard protocols (Parsons et al. 1984). Forty $\mathrm{mL}$ of water was filtered into plastic screw cap jars for nutrient analysis, and $20 \mathrm{~mL}$ of unfiltered water was placed in acid-cleaned vials for analysis of TOC. Nutrient and total organic carbon samples were analyzed by the University of Washington, Ocean Technical Services Laboratory.

\subsubsection{Neuston Net Samples}

During 2006, the surface concentration of macrodetritus, insects, and fishes was sampled with a Manta style neuston net ( $1.5 \times 0.5 \mathrm{~m}$ mouth dimensions, $500 \mu \mathrm{m}$ mesh net). The net was passively deployed at restoration sites, and we sampled water entering or leaving the system. The volume of water filtered through the net was measured with a General Oceanics flowmeter. Material concentration was standardized by volume filtered to yield individuals per $\mathrm{m}^{3}\left(\# / \mathrm{m}^{3}\right)$ for fish and insects and mass per $\mathrm{m}^{3}$ $\left(\mathrm{kg} / \mathrm{m}^{3}\right)$ for macrodetritus. These data are not fully analyzed to date. 


\subsubsection{Velocity}

Horizontal water velocity during the time of the discrete water samples was measured with a handheld Marsh-McBirney current meter. Measurements were collected at surface, bottom (where possible), and middle water column. These velocity measurements are used to calculate instantaneous flux.

\subsubsection{Hydrographic Patterns}

The instantaneous measurements described above are augmented by two additional data sources: 1) time series of water-level, temperature, and salinity recorded by data logging instruments, and 2) horizontal transects of vertical conductivity, temperature, and depth (CTD) profiles. We established longterm, geo-referenced hydrological stations to record water-level and water property cycles within the study sites. These time series data are described more fully in Chapter 2. Data for 2006 are not yet recovered from field deployments. The time series of elevation are used to determine the instantaneous filled cross-sectional area of the sample sites. Eventually, the time series of elevation will be used to scale up our short-term measurements to model large-scale effects.

\subsubsection{Calculations of Flux and Net Transport}

For each discrete water sample, we computed the instantaneous mass flux of material $\mathrm{F}\left(\mathrm{mg} \mathrm{m}^{-2} \mathrm{~s}^{-1}\right)$ as $\mathrm{F}=\mathrm{C} * \mathrm{U}$, where $\mathrm{C}$ is the concentration of a constituent $\left(\mathrm{mg} \mathrm{m}^{-3}\right)$ and $\mathrm{U}$ is the vertically averaged horizontal velocity $(\mathrm{m} / \mathrm{s})$. By convention positive fluxes are into the system (flood tides) and negative fluxes are out of the system (ebb tides).

Instantaneous mass transport, $\mathrm{Q}\left(\mathrm{kg} \mathrm{s}^{-1}\right)$, is the instantaneous flux integrated by channel area, $\mathrm{Q}=\mathrm{F} \mathrm{A}$, where $\mathrm{A}\left(\mathrm{m}^{2}\right)$ is the tide-dependant cross sectional area. For each measurement, A was calculated from the channel profile and corresponding water level.

Finally, we integrated $Q$ for each ebb and flood period to derive the total mass transport $(\mathrm{kg})$ per tide, $\mathrm{T}=\int \mathrm{Q} d \mathrm{t}$.

\subsubsection{Horizontal Transects}

In order to provide a snapshot characterization of water properties at the restored sites, we collected samples at several stations positioned along a transect running from well inside to outside of each site. This sampling consisted of collection of surface water samples and processing the samples as above. We also conducted CTD profiles at most sites. Fourteen stations were sampled at Kandoll Farm on 10 August 2006, and 11 stations were sampled at Vera Slough on 11 August 2006. In contrast to pointsource measurements, the horizontal transect data provides a system-wide perspective of water properties.

\subsection{Results and Discussion}

\subsubsection{Discrete Sampling during Tidal Cycle}

Concentrations for carbon and inorganic nutrients are given below and summarized for ebbing and flooding tides. There were only a few samples during slack tides and those data are not included in the summaries. Overall concentrations of dissolved nutrients tended to be significantly higher than values reported at another Pacific Northwest estuary (Puget Sound, as reported in Thom 1989 and Thom and Albright 1990). In comparing our two restoration sites, Vera sites (both the reference and restoration sites) have generally higher concentrations than the Kandoll sites. 
Total Organic Carbon (TOC): The average TOC concentrations can be found in Table 8.1. Kandoll sites did not appear to have major differences between the ebb and flood tides while Vera sites had higher concentrations during the ebb. There may be a slight increase with the warming seasons, but the differences are not large.

Table 8.1. Average Concentrations (SD) of Total Dissolved Carbon for Kandoll and Vera Sites in Three Sampling Periods in 2006. All concentrations are in $\mathrm{mg} \mathrm{l}^{-1}$.

\begin{tabular}{cccccc}
\hline Month & Tide & KI & KR & VS & VR \\
\hline \multirow{2}{*}{ May } & Ebb & $2.65(1.3)$ & $2.06(0.5)$ & $4.56(1.7)$ & $3.98(0.7)$ \\
& Flood & $2.75(0.7)$ & $2.10(0.8)$ & $2.65(0.2)$ & $3.72(1.4)$ \\
\multirow{2}{*}{ June } & Ebb & $2.75(1.1)$ & $3.98(1.5)$ & $5.36(2.4)$ & $4.12(0.8)$ \\
& Flood & $2.75(1.0)$ & $3.85(3.4)$ & $3.46(0.04)$ & $2.86(0.2)$ \\
\multirow{2}{*}{ July } & Ebb & $3.30(1.3)$ & $3.19(0.5)$ & $4.52(0.3)$ & $6.97(0.8)$ \\
& Flood & $2.40(2.1)$ & $3.90(0.8)$ & $5.23(3.1)$ & $4.24(0.03)$ \\
\hline
\end{tabular}

Phosphate (PO4): Concentrations of PO4 (Table 8.2) are 2 to 20 times higher than the 1.5 to $2.3 \mu \mathrm{M}$ reported in Puget Sound during the same time of year (Thom 1989; Thom and Albright 1990). Months with high values are highly variable and may indicate how quickly phosphorus can be taken up when available in such a system. Vera concentrations are often much greater than those at Kandoll in the same month, and in general the reference site concentrations are greater than those of the restoration sites.

Table 8.2. Average Concentrations (SD) of Phosphate for Kandoll and Vera Sites in Three Sampling Periods in 2006. All concentrations are in $\mu \mathrm{M}$.

\begin{tabular}{cccccc}
\hline Month & Tide & KI & KR & VS & VR \\
\hline \multirow{2}{*}{ May } & Ebb & $7.77(1.6)$ & $9.00(1.9)$ & $5.28(0.1)$ & $31.36(27.7)$ \\
& Flood & $5.16(2.9)$ & $6.95(0.3)$ & $20.57(1.3)$ & $34.91(16.1)$ \\
\multirow{2}{*}{ June } & Ebb & $9.02(1.2)$ & $11.38(0.7)$ & $33.72(25.9)$ & $23.90(13.8)$ \\
& Flood & $8.84(2.3)$ & $8.92(2.9)$ & $7.87(6.6)$ & $20.88(0.1)$ \\
& Ebb & $7.24(0.6)$ & $9.62(2.7)$ & $17.98(9.7)$ & $61.40(38.5)$ \\
& Flood & $7.03(1.3)$ & $5.38(1.4)$ & $18.44(4.5)$ & $36.11(14.3)$ \\
\hline
\end{tabular}

Silicate (SiO4): Published literature for $\mathrm{SiO}_{4}$ in Puget Sound (Thom 1989, Thom and Albright 1990) report concentrations between 30 and $120 \mu \mathrm{M}$. Collections at both sites in the CRE show average values that are two orders of magnitude higher in all months (Table 8.3). At this point it is unclear if this dramatic difference is due to supply from inland or differential use by organisms such as diatoms, but such a discrepancy is not likely caused by differences in the marine source. Locally, $\mathrm{SiO} 4$ concentrations are at least 200 times greater than all other nutrients with the exception of nitrite. There do not appear to 
be many differences between sites, months, or tides, although this signal could be masked by the high variability in the numbers. If true, however, the lack of a seasonal signal may support the notion that the $\mathrm{SiO} 4$ is not being utilized by diatom blooms and being allowed to build up in the system.

Table 8.3. Average Concentrations (SD) of the Silicate $\left(\mathrm{SiO}_{4}\right)$ for Kandoll and Vera Sites in Three Sampling Periods in 2006. All concentrations are in $\mu \mathrm{M}$.

\begin{tabular}{cccccc}
\hline Month & Tide & KI & KR & VS & VR \\
\hline \multirow{2}{*}{ May } & Ebb & $3819.23(1108.3)$ & $4075.45(540.6)$ & $2811.17(1881.1)$ & $6071.4(680)$ \\
& Flood & $3825.96(683.6)$ & $3817.87(802.5)$ & $5041.83(451.1)$ & $5088.6(485.2)$ \\
\multirow{2}{*}{ June } & Ebb & $4723.96(674.1)$ & $4335.51(465.5)$ & $5143.51(1505.8)$ & $4639.93(1529.8)$ \\
& Flood & $3182.42(1488.9)$ & $4833.89(407.2)$ & $4953.23(1340.2)$ & $5127.39(17.3)$ \\
\multirow{2}{*}{ July } & Ebb & $1919.91(1822.4)$ & $3078.97(1128.6)$ & $3460.73(1941.9)$ & $6715.31(1246.6)$ \\
& Flood & $3146.44(754.7)$ & $4179.67(383.7)$ & $2783.6(2381.9)$ & $5919.15(96.8)$ \\
\hline
\end{tabular}

Nitrite $\left(\mathrm{NO}_{3}\right)$ : As with the $\mathrm{SiO} 4$ concentrations, $\mathrm{NO}_{\underline{3}}$ concentrations in the study sites (Table 8.4) are much higher than those reported in Puget Sound. These values are generally one to two orders of magnitude higher, although some values are close to the high of $50 \mu \mathrm{M}$ reported earlier (Thom 1989; Thom and Albright 1990). Concentrations appear to decrease with the season, most likely in response to increased biological activity with the warmer waters, but do not show obvious trends when comparing tidal cycle or sites. Levels are never limiting to phytoplankton.

Table 8.4. Average Concentrations (SD) of the Nitrite for Kandoll and Vera Sites in Three Sampling Periods in 2006. All concentrations are in $\mu \mathrm{M}$.

\begin{tabular}{cccccc}
\hline Month & Tide & KI & KR & VS & VR \\
\hline \multirow{2}{*}{ May } & Ebb & $212.63(96.8)$ & $213.66(72.1)$ & $162.96(7.7)$ & $137.39(102.7)$ \\
& Flood & $206.91(77.0)$ & $233.01(73.3)$ & $310.89(20.7)$ & $254.43(71.3)$ \\
& Ebb & $110.93(53.0)$ & $85.94(19.0)$ & $86.59(48.0)$ & $68.93(59.2)$ \\
June & Flood & $120.57(48.4)$ & $137.46(48.1)$ & $52.26(43.1)$ & $111.29(9.6)$ \\
& Ebb & $107.32(57.2)$ & $93.01(29.7)$ & $75.02(103.7)$ & $89.93(43.7)$ \\
\multirow{2}{*}{ July } & Flood & $78.12(16.9)$ & $132.86(48.0)$ & $76.6(88.5)$ & $96.13(47.5)$ \\
\hline
\end{tabular}

Nitrate $\left(\mathrm{NO}_{2} 2\right)$ : In a similar pattern to other nutrients, $\mathrm{NO}_{2}$ concentrations at the two sites (Table 8.5) range from the upper limits reported for Puget Sound to an order of magnitude greater. They are the lowest nutrient values reported in the report, but this is typical given the rapid uptake by biological organisms. It is not known why these values are high, and may indicate a good source or reduced primary 
productivity, although the latter would probably not produce the elevated $\mathrm{NH}_{4}$ levels seen below. There does not appear to be a strong seasonal component to the levels.

Table 8.5. Average Concentrations (SD) of the Nitrate for Kandoll and Vera Sites in Three Sampling Periods in 2006. All concentrations are in $\mu \mathrm{M}$.

\begin{tabular}{cccccc}
\hline Month & Tide & KI & KR & VS & VR \\
\hline \multirow{2}{*}{ May } & Ebb & $0.87(0.2)$ & $0.95(0.2)$ & $1.83(1.7)$ & $3.54(0.4)$ \\
& Flood & $1.08(0.2)$ & $0.88(0.2)$ & $3.35(0.5)$ & $3.60(0.1)$ \\
\multirow{2}{*}{ June } & Ebb & $1.65(0.1)$ & $1.67(0.1)$ & $3.72(3.5)$ & $2.31(1.5)$ \\
& Flood & $1.65(0.1)$ & $1.68(0.1)$ & $2.36(1.1)$ & $2.10(0.1)$ \\
\multirow{2}{*}{ July } & Ebb & $2.25(0.4)$ & $2.42(0.2)$ & $2.1(1.3)$ & $5.90(2.3)$ \\
& Flood & $2.32(1.4)$ & $2.35(1.2)$ & $2.21(0.9)$ & $4.13(1.0)$ \\
\hline
\end{tabular}

Ammonia $\left(\mathrm{NH}_{4}\right)$ : Levels of $\mathrm{NH}_{4}$, like the other nutrients, are higher in the CRE sites (Table 8.6) than in the Puget Sound studies (1 to $3.5 \mu \mathrm{M}$; Thom 1989; Thom and Albright 1990). The variability in the values is high, but the data suggest that concentrations at the reference sites is usually higher than the restoration site during the ebbing tide, possibly suggesting more productivity in the more "mature" sites. Values are more similar during the flood, most likely due to the shared source of the water.

Table 8.6. Average Concentrations (SD) of the Ammonia for Kandoll and Vera Sites in Three Sampling Periods in 2006. All concentrations are in $\mu \mathrm{M}$.

\begin{tabular}{cccccc}
\hline Month & Tide & KI & KR & VS & VR \\
\hline \multirow{2}{*}{ May } & Ebb & $22.67(9.4)$ & $23.41(5.5)$ & $38.42(32.3)$ & $64.62(9.2)$ \\
& Flood & $57.87(42.0)$ & $27.31(7.7)$ & $34.87(2.4)$ & $71.67(38.9)$ \\
\multirow{2}{*}{ June } & Ebb & $28.87(7.3)$ & $40.61(6)$ & $96.05(92.0)$ & $80.16(46.3)$ \\
& Flood & $42.80(21.0)$ & $36.82(7.6)$ & $59.53(15.4)$ & $53.99(3.8)$ \\
\multirow{2}{*}{ July } & Ebb & $35.62(22.2)$ & $57.11(25.1)$ & $62.73(28.9)$ & $134.19(24.2)$ \\
& Flood & $45.40(17.3)$ & $34.85(11.8)$ & $45.18(7.5)$ & $71.18(48.2)$ \\
\hline
\end{tabular}

Nitrogen to Phosphorous Ratio (N:P): Changes in the N:P ratio are plotted in Figures 8.1 and 8.2. Vera sites track fairly well with each other, especially in April and June, and have ratios well over 16. The ratios at the Kandoll sites indicate a more complicated pattern that may have a seasonal component. Kandoll Farm is generally more stable throughout the tidal cycle in any month although mean values change between months (moderate in April, high in May, low in June). In contrast, the ratio at Kandoll Reference is always low except for a few peaks in April. 

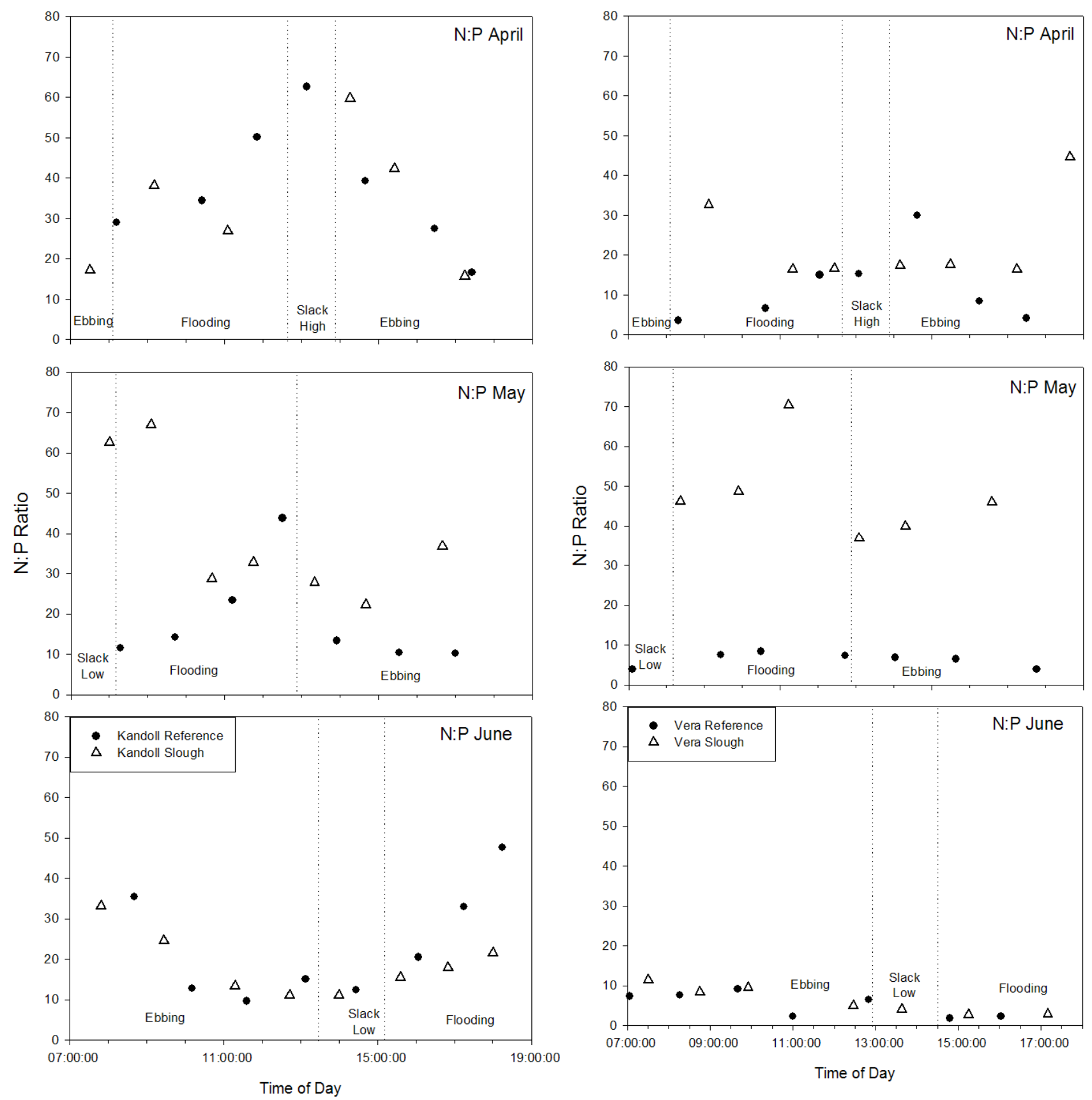

Figure 8.1. Nitrogen:Phosphorus Ratios for the Kandoll Sites in Three Sampling Periods in 2006

Figure 8.2. Nitrogen:Phosphorus Ratios for the Vera Sites in Three Sampling Periods in 2006 


\subsubsection{Horizontal Profile Sampling}

The Kandoll transect included four samples within the Kandoll Farm restoration site, five stations in Seal Slough, and four stations in the Grays River over a 9-km transect (Figure 8.3). Most variation occurred between Seal Slough and Grays River stations. Vertical temperature gradients were isothermal with depth $\left(<0.5{ }^{\circ} \mathrm{C}\right)$, and ranged between $18{ }^{\circ} \mathrm{C}$ and $22{ }^{\circ} \mathrm{C}$ along the horizontal axis. The coolest temperatures were found within the restoration site and the warmest temperatures were at the confluence of the Grays River and Seal Slough. Chlorophyll patterns varied both vertically and horizontally; concentrations ranged from 0.1 to $6.7 \mathrm{mg} \mathrm{m}-3$. Relatively lower chlorophyll concentrations were found within the restored site relative to the adjacent Seal Slough water.

Concentrations of dissolved nutrients exhibited strong spatial trends. PO4 concentration was slightly elevated and NO3 was greatly enhanced in the Grays River relative to Seal Slough. NH4 ranged from 25 to $75 \mathrm{uM}$ except for a spike near a subsidiary channel in Seal Slough. Except for NO2, nutrient concentrations were relatively high and non-limiting to phytoplankton growth.

The Vera Slough transect was composed of ten stations over a $2.5-\mathrm{km}$ transect, but not all stations were sampled for both water properties and dissolved constituents (Figure 8.4). There was strong horizontal heterogeneity in dissolved and particulate constituents due to the presence of the tide gate, while surface- $0.5 \mathrm{~m}$ water properties were fairly uniform and indicated brackish conditions to the furthest station sampled. All dissolved constituents had maxima within $0.25 \mathrm{~km}$ inside the tide gate, and nitrogen species were at low concentrations within the system. In contrast, chlorophyll maxima were located at the furthest stations within Vera Slough; chlorophyll and nutrients were negatively correlated. These data suggest Vera was a source for remineralized nutrients and that phytoplankton dynamics may be influencing nutrient concentrations. 

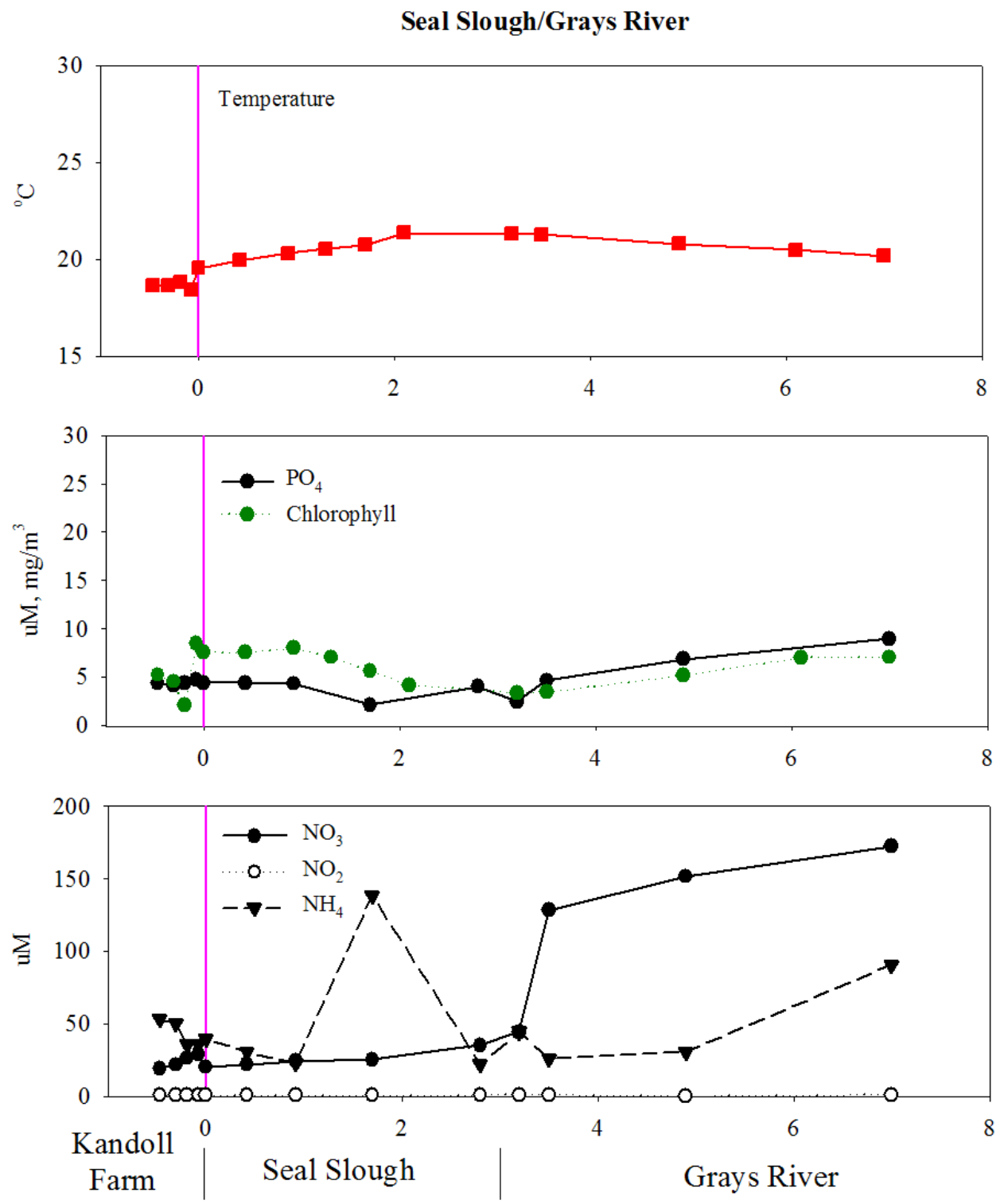

River km

Figure 8.3. Transect of the Seal Slough/Grays River System: Temperature (top); $\mathrm{PO}_{4}$ and chlorophyll a concentration (middle); and $\mathrm{NO}_{3}, \mathrm{NO}_{4}$, and $\mathrm{NH}_{4}$ concentration (bottom). Pink vertical line denotes breach site. 

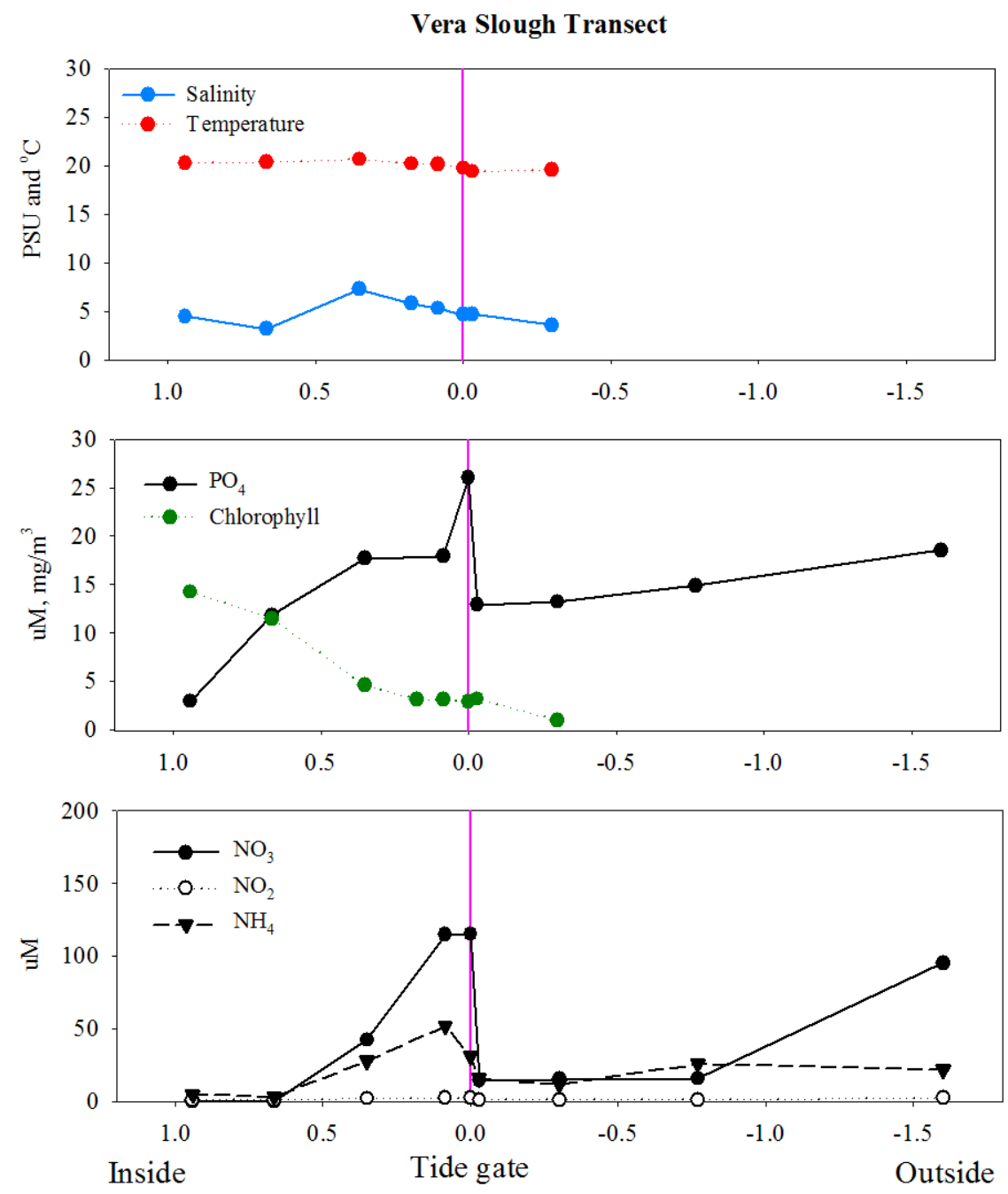

River km

Figure 8.4. Transect of the Vera Slough System. Temperature (top); $\mathrm{PO}_{4}$ and chlorophyll a concentration (middle); and $\mathrm{NO}_{3}, \mathrm{NO}_{4}$, and $\mathrm{NH}_{4}$ concentration (bottom). Pink vertical denotes tide gate.

\subsection{Literature Cited}

Bottom, D.L., C.A. Simenstad, J. Burke, A.M. Baptista, D.A. Jay, K.K. Jones, E. Casillas, and M. Schiewe. 2005. Salmon at River's End: The role of the estuary in the decline and recovery of Columbia River salmon. U.S. Department of Commerce, NOAA Technical Memorandum, NMFS-NWFSC-68.

Parsons, T.R., M. Takahashi, and B. Hargrave. 1984. Biological Oceanographic Processes. Pergamon.

Thom, R.M. 1989. Plant standing stock and productivity on tidal flats in Padilla Bay, Washington: a temperate North Pacific estuarine embayment. NOAA Technical Report Series OCRM/MEMD, FRI-UW-8909.

Thom, R.M. and R.G. Albright. 1990. Dynamics of benthic vegetation standing-stock, irradiance, and water properties in central Puget Sound. Marine Biology 104:129-141. 


\title{
9.0 Summary and Management Implications
}

\author{
Gary E. Johnson ${ }^{\mathrm{a}}$, Blaine D. Ebberts ${ }^{\mathrm{b}}$, and Douglas A. Putman ${ }^{\mathrm{b}}$
}

This chapter contains a summary of the 2006 work on the Cumulative Effects Study and an explanation of the management implications of the study.

\subsection{Summary of Key Findings}

The overall objectives of the 2006 study were to continue to develop techniques to assess cumulative effects, refine the standard monitoring protocols, and initiate development of an adaptive management system for USACE's habitat restoration monitoring efforts in the CRE. We addressed these overall objectives with field work in 2006 that, coupled with previous field data, had specific objectives and resulted in some important findings that are summarized here by chapter in this report.

Chapter 2 - Hydrology -- Monitor hydrological variation at two study locations before and after tidal reconnection.

In the Grays River system, data-logging sensors have been continuously monitoring water level and temperature since summer 2005. Tide gate removal and dike breaching activity had an immediate effect on water-level fluctuations within the Kandoll site. In the restored area upstream of the new culverts, water-level fluctuations changed from a weak tidal signal to a full semidiurnal pattern and maximum amplitudes increased from $\sim 1.0 \mathrm{~m}$ to $\sim 3.0 \mathrm{~m}$. As a result of this tidal reconnection, the tidal prism, inundation levels, and flux of water through the system were greatly increased. Also, temperatures at all stations rapidly coincided, indicating widespread hydrologic reconnection. The storm events of winter 2005-2006 were clearly recorded in our hydrography measurements and appeared to be important hydrologic factors.

The Vera Slough project was a tide gate replacement designed to increase connectivity with Youngs Bay and the Columbia River while maintaining flood protection. The tide gates were replaced on 12 October 2005. Measurements were initiated in May 2005 and are ongoing. Tide gate replacement resulted in an increase in tidal amplitude from $0.50 \mathrm{~m}$ to about $0.75 \mathrm{~m}$ inside Vera Slough, indicating improved access to the wetland for juvenile salmonids that are present in the area. The truncated vertical amplitudes indicate the effectiveness of the tide gates at limiting full tidal connection. During the postreplacement period, mean daily water temperature deviation between restoration and reference sample sites was generally $<1{ }^{\circ} \mathrm{C}$.

Chapter 3 - Longitudinal Channel Structure -- Examine the effects of large wood on tidal forested wetland channel morphology.

\footnotetext{
${ }^{a}$ Marine Sciences Laboratory, Pacific Northwest National Laboratory, Sequim, WA

${ }^{\mathrm{b}}$ Portland District, U.S. Army Corps of Engineers, Portland, OR
} 
Wood accumulations in the tidal forested wetland channels at the Kandoll reference site were dense. In contrast, upper Seal Slough within Kandoll Farm, an area of pastureland sparsely forested in places with Picea sitchensis and Alnus rubra, contained no log jams prior to the implementation of restoration actions for hydrological reconnection in 2005. Since culvert replacement at Kandoll in 2005, however, the developing channel network in the non-forested restoration area has exposed previously buried logs. In the tidal forested wetland channels, pools are located immediately upstream of each log jam or beaver dam. The shallower area or "tail-out" of each pool is usually located upstream of the pool (downstream of the next log jam or beaver dam). This suggests that the incoming flood tide, in plunging over the log jams and beaver dams once the water-level exceeds their elevation, plays a larger role in structuring channels longitudinally than does the ebb tide. We conclude that the morphology of forested tidal channels of a tributary to the Columbia River estuary may be viewed as a special case of the forced steppool class, which has been defined and documented in high-gradient forest systems with unidirectional flow, although it must be cautioned that results of our surveys be interpreted in light of the highly regulated condition of the Columbia River.

\section{Chapter 4 - Early Morphological Change -- Document cross-sectional dimensions of tidal channels in} the Columbia River estuary immediately before and after tidal reconnections.

Before and after cross-sectional dimensions were measured at the restoration and reference sites. The reference channels show little change from before to after implementation of restoration actions in adjacent areas. At the restoration sites, tidal channel incision was greatest inside of the culvert, less inside of the tide gate, and even less inside the dike breach. However, these examples are not on exactly comparable channels, and the tide gate is in a different watershed than the culvert and dike breaches. Future reports will include channel geometry and carbon dating data.

Chapter 5 - Vegetation -- Characterize the plant communities at tidal swamp and marsh habitats before and after tidal reconnection restoration actions.

At Kandoll, species richness increased at the site from 27 species in 2005 (pre-restoration) to 41 in 2006 (post-restoration). Six species had an average percent cover greater than $10 \%$, although many species $(51 \%)$ had an average percent cover of less than $1 \%$. We observed low similarities between the Kandoll restoration plots and the Kandoll reference site, reflecting major differences between these areas in 2006. At Vera, the assemblages at the restoration and reference sites were only $24.5 \%$ similar using a weighted similarity coefficient in 2005. This indicates a major difference between the Vera restoration and reference sites, both in species composition and in species abundances. The permutational multivariate analysis of variance showed that the treatment (site) and covariable (elevation) both had significant effects on herbaceous species composition (in all cases, $\mathrm{p}=0.0002$ ).

In the Kandoll reference site, a forested tidal swamp, three tree species dominate, with one standing out above the others. Picea sitchensis has the highest density, frequency, and basal area of any tree on the site. Thuja plicata (Western redcedar) is next with four times lower relative dominance than the Sitka spruce. Although Western redcedar has lower frequency and density than the third tree, Alnus rubra (red alder), it makes up for this with greater basal area; red alder is the second most frequent and dense tree species in the forested wetland. 
The sample plots at Kandoll Farm included a broad range of species with varying degrees of wetlandadapted characteristics. Elevation differences were related to differences in the depth, frequency, and duration of hydrologic inundation, which in turn affected growing conditions for plant species. Additionally, the hydrologic regime changed considerably from 2005 to 2006 due to the increase in tidal flow as a result of the restoration action. In response to these changes plant species composition is shifting from more upland and wet pasture species to plants that are adapted to wetter conditions.

Chapter 6 - Spruce Swamps as Salmon Habitat -- Measure temperature and water velocity and determine prey resources for juvenile salmonids within tidal forested spruce swamps in the Gray's River watershed in southwestern Washington, USA.

A total of 9 Chinook, 1 chum and 15 coho salmon stomachs were collected over the course of three sampling days $(4 / 10,5 / 23$, and 6/1) in 2006. At Kandoll restored and reference sites, Chinook salmon were eating Chironomidae. At Seal, two of the Chinook salmon were eating Corophium. Chum and coho diets included Chiromonidae, Heteroptera, and other insects. Data remain to be analyzed for this chapter.

Chapter 7 - Fish -- Describe salmonid presence and fish community structure in two restoration sites undergoing tidal reconnection.

In total, 12,740 fish at Vera sites and 23,180 fish at Kandoll sites were collected. These totals include all sampling sites in both pre- and post-restoration (2005 and 2006). Species composition was dominated by threespine stickleback. The data to date indicate that the Grays River system supports three species of migrating juvenile salmon: Chinook, chum, and coho. Salmon presence was species specific, but extended from March (or earlier) through June. At the Kandoll restoration site, we captured few salmon before tide gate removal, but relatively high numbers post-removal. All three salmon species utilized the habitat after tidal reconnection. In contrast, fish community structure and salmon presence at the Vera Slough tide gate replacement exhibited a more modest change between pre- and post-tide gate replacement. We captured few salmon either year, which we suspect is because the site lies off of the main migration route from the Youngs Bay system. However, a few salmon were found inside the tide gate post-replacement, so salmon opportunity appears to be increased, albeit modestly. Future sampling will allow us to evaluate benefits to salmon of the improved physical/biological conditions.

Chapter 8 - Flux -- Determine the flux of nutrients and organic matter after tidal reconnections at dikes in the Columbia River estuary.

The instantaneous concentration of material, horizontal velocity, and cross-sectional area of the mouths of tidal sloughs draining wetland restorations sites were measured. Overall, concentrations of dissolved nutrients tended to be significantly higher than values reported at another Pacific Northwest estuary (Puget Sound). In comparing our two restoration sites, Vera sites (both the reference and restoration sites) have generally higher concentrations than the Kandoll sites.

\subsection{Management Implications}

Ultimately, the Cumulative Effects Study will serve to consolidate our understanding of the effects of a variety of management actions on ecosystem processes and habitat structures and functions in the Columbia River estuary. This is critical because the CRE system is highly important to potentially competing uses such as agriculture, shipping, and recreation. The study will provide a comprehensive 
guide to actions that may help to ameliorate the ecosystem effects of these uses. This study also has direct and indirect management implications for resource management agencies, environmental organizations, and other state and federal agencies in the Columbia River basin.

\section{Decisions to Implement CRE Habitat Restoration Projects}

There is enormous potential to establish effective habitat restoration strategies, as well as management of the Columbia River Estuary system as a whole, using a comprehensive dataset developed from the standard set of monitoring protocols produced by this study (Roegner et al. 2006). Given the standard protocols, the application of the data in an adaptive management scheme with a definitive programmatic infrastructure will be instrumental to 1) coordinate among groups conducting habitat restoration projects; 2) promulgate the protocols to encourage continuing standardized data collection; 3) compile and analyze the data at various spatial scales; and 4) develop specific management recommendations for the ecosystem restoration program on the Columbia River estuary as well as specific existing and planned projects. The details of such a process are not established at this point of the study. However, representation in decision-making for ecological restoration on the estuary at this time encompasses non-governmental organizations, universities, and state and federal agencies. In short, the analyses produced by this study, and through the adaptive management program, may be expected to provide insight regarding the effects of restoration actions on ecosystem processes that will inform resource managers and regulators. Provided mechanisms are in place that are transparent and understood, managers can apply this information as important "lessons learned" for future restoration treatments and regulatory guidance, e.g., coastal zone management, shoreline master plans, and flood hazard mitigation.

\section{Evaluation of the Overall CRE Habitat Restoration Effort}

Developing and implementing appropriate indicators and methods is critical to enabling estuary managers to track the effectiveness of their large investments in estuary habitat restoration projects and to improve conservation and restoration measures over time. The Cumulative Effects study is directed at showing whether projects have a "signal" in the ecosystem. For example, one signal in the Mississippi River delta is the amount and rate at which marsh area is regenerating or being lost (Louisiana Coastal Wetlands Conservation and Restoration Task Force 2001). This signal has direct and indirect implications for maintaining ecological functions in the system and reducing threats to infrastructure, such as roads, on the delta. In a similar way, restoration of ecosystem complexes in the CRE has direct and indirect implications for key processes and functions, such as organic matter production, biodiversity, and juvenile salmon fitness. Analogous to the protection of roads in Louisiana is the protection of roads, homes, and businesses through the flood storage capacity afforded by tidal wetlands and swamps in the CRE. The cumulative effects methodologies we are developing are intended to allow managers the capability to measure the effects of the CRE habitat restoration effort on a collective basis, using an additive model in GIS together with information about between-project synergies detected through our paired studies, hydraulic modeling, and statistical tests. Measures fundamental to ecosystem productivity and aquatic food webs include the production and export of macrodetritis, and measures fundamental to salmonid habitat opportunity include the length of channel edge connected to the mainstem as well as wetted area. 


\section{Water Resources Development Act: Restoration in the Columbia River Estuary}

The USACE has been tasked with developing restoration projects in the CRE under several national authorities, including Section 1135 of the Water Resources Development Act (WRDA) of 1986, Project Modification for Improvement of the Environment; Section 206 of WRDA 1996, Aquatic Ecosystem Restoration; Section 536 of the WRDA 2000, Lower Columbia River Ecosystem Restoration; and Section 306 of WRDA 1990, General Investigation Studies for Environmental Restoration. Work under these four USACE authorities will benefit from the Cumulative Effects study because the study provides standard monitoring methods, the reduction of critical uncertainties through site-specific field research, improved understanding of restoration trajectories in the CRE, and an adaptive management system tailored to the needs of the USACE, Portland District.

- Section 206 provides authority for the USACE to restore aquatic ecosystems that are not associated or connected with Corps projects.

- Section 306 provides authority to the USACE to undertake studies and build projects for environmental restoration and for water and related land resources problems and opportunities in response to directives, called authorizations, from the Congress. Presently the USACE has one ongoing General Investigation Study involving ecological restoration in the CRE.

- Section 536 provides authority for the USACE to carry out ecosystem restoration projects necessary to protect, monitor and restore fish and wildlife habitat under consultation with the Lower Columbia River Estuary Partnership.

- Section 1135 provides the authority to modify existing USACE projects to restore the environment and construct new projects to restore areas degraded by USACE projects.

These USACE authorities require a sponsor to provide, at a minimum, land easements and rights of way necessary for the project, and to perform operations and maintenance for the life of the project. In all authorities except Section 536, sponsors are non-federal governmental or national non-profit entities. Under Section 536, federal government entities may be the project sponsor. Sponsors for projects not on federal land are generally required to provide 50\% cost-sharing for studies and 25\%-35\% cost-sharing for construction.

Restoration projects developed under any of the four USACE authorities can apply the results of this analysis. Additionally, other USACE and national ecosystem restoration programs will likely benefit from this work. It is not to say that this will be the blueprint for the evaluation of all ecosystem restoration activities, however, it has the potential to serve as an outline and guiding documentation for additional works to come.

\section{Columbia Basin-Wide Cumulative Effects Assessments}

The Northwest Power and Conservation Council's (NPCC) Fish and Wildlife Program involves the implementation of over $\$ 100 \mathrm{M}$ annually on projects for on-the-ground habitat restoration, monitoring, and research in the Columbia River basin. In any given subbasin, multiple habitat restoration projects are conducted, many of which are impractical to monitor individually because of small scale, limited funds, and other reasons. This necessitates monitoring action effectiveness in the form of cumulative effects at the subbasin scale (Jordan et al. 2003). Analysis methods for cumulative effects are currently being developed for the NPCC's Fish and Wildlife Program (Hillman 2004). The objectives of these efforts are 
analogous to those of the cumulative effects study in the estuary in that both intend to establish the effects of habitat restoration actions on salmon. However, due to inherent differences in the ecological systems, the statistical sampling designs and the sampling methods necessarily differ. Nevertheless, by producing comparable scientific results describing the cumulative effects of restoration actions, managers will be able to assess the relative benefits of monies spent among various habitats from freshwater streams to the estuarine wetlands. Likewise, although metrics will differ (i.e., productivity and survival rates in the tributaries, presence/absence and growth and residence time in the estuary), managers will be able to use the combined data to track basin-wide effects of actions undertaken from the headwaters to the estuary.

\section{Collaborative Planning for Large-Scale River Systems Restoration}

A recent analysis by the National Research Council (NRC), clarifying the Corps' ecosystem restoration mission, demonstrates the complexity of factors that need to be considered in order to restore the hydrologic and geomorphic processes of large river and coastal systems. The NRC (2004a-d) recommended the Corps adopt strategies including the following: integrated large-scale systems planning, adaptive management methods, expanded post-project evaluations, and a collaborative approach. Multijurisdictional environments complicate large-scale river basin and coastal systems planning (e.g., multiple states and tribes in the Columbia River basin), necessitating a collaborative approach. In earlier assessments (Harrington and Feather 1996), the identification and inclusion of stakeholders in the planning process was also cited as a means of strengthening the knowledge base in the project planning process. More recently, the Corps in 2006 adopted 12 Actions for Change, which include a collaborative approach and a systems-based approach to "shift the focus from isolated, individual projects to interdependent groups of projects... from local solutions for immediate problems to regional solutions for longer term problems." The Chief of Engineers' Environmental Advisory Board (EAB) in 2006 recommended that the Corps overcome obstacles to long-term monitoring and adaptive management.

With this study, the Portland District is demonstrating the implementation of national-level guidelines - large-scale systems planning, adaptive management, post-project evaluation, and a collaborative approach - in the Pacific Northwest region on the estuary of one of the largest rivers in the nation. In effect, standardizing data collection throughout the estuary is critical for analyzing changes following restoration treatments, and the development of a regional protocols manual by the Corps contributes to this end. This cumulative effects study has brought together restoration project managers from a variety of organizations and included their input in the development of recommendations for minimum monitoring metrics and in the selection of monitoring methods. The scope of this study is large-scale and ecosystem process based. The recommendations of the $\mathrm{NRC}$ and $\mathrm{EAB}$ are guiding this effort to assess the cumulative effects of restoration in the Columbia River estuary.

\subsection{Conclusion}

In conclusion, with substantial work already underway to restore aquatic habitats in the CRE to help recover salmon populations, detecting the cumulative effects of multiple restoration projects on the CRE ecosystem is a challenging yet critical problem. Restoration projects are typically expensive, and the return on investment in terms of benefits to the ecosystem often is not well documented or understood. In systems where restoration is conducted at a variety of sites, however, these projects may add up to produce a system-wide benefit. Assessing cumulative effects is critical to understanding whether there 
has been a net improvement in the ecosystem from restoration actions or whether actions are only effective in a site-specific manner. The problem lies primarily in how to document this effect, especially in large and complex ecosystems like the CRE. This study is undertaking a systematic approach to develop a cumulative effects assessment methodology for multiple restoration projects in the Columbia River estuary. The key management implication from this study will be the capability to assess whether CRE habitat restoration is having a measurable, cumulative effect on the CRE ecosystem and, ultimately, contributing to the recovery of listed salmonids in the Columbia River basin.

\subsection{Literature Cited}

Harrington, K.W. and T.D. Feather. 1996. Evaluation of environmental investments procedures: interim overview manual, IWR Report 96-R-18, prepared for Institute for Water Resources, U.S. Army Corps of Engineers, Alexandria, VA.

Hillman, T.W. 2004. Monitoring strategy for the upper Columbia basin. Draft report prepared for the Upper Columbia Regional Technical Team, Upper Columbia Salmon Recovery Board, Wenatchee, Washington, February 1, 2004. Prepared by BioAnalysts, Inc., Eagle, Idaho.

Jordan, C., J. Geiselman, M. Newsom, and J. Athearn (eds.). 2003. Research, monitoring, and evaluation plan for the NOAA-Fisheries 2000 Federal Columbia River Power System biological opinion. Draft. September 11, 2003. Available at http://www.salmonrecovery.gov/implementation

Louisiana Coastal Wetlands Conservation and Restoration Task Force. 2001. The 2000 evaluation report to the U.S. Congress on the effectiveness of Louisiana coastal wetland restoration projects. Louisiana Department of Natural Resources, Baton Rouge, Louisiana.

National Research Council. 2004a. Adaptive management for water resources project planning. Panel on Adaptive Management for Resource Stewardship, Committee to Assess the U.S. Army Corps of Engineers Methods of Analysis and Peer Review for Water Resources Project Planning, The National Academies Press, Washington, DC.

National Research Council. 2004b. Analytical methods and approaches for water resources project planning. Panel on Methods and Techniques of Project Analysis, Committee to Assess the U.S. Army Corps of Engineers Methods of Analysis and Peer Review for Water Resources Project Planning, The National Academies Press, Washington, DC.

National Research Council. 2004c. River basins and coastal systems planning within the U.S. Army Corps of Engineers. Panel on River Basin and Coastal Systems Planning, Committee to Assess the U.S. Army Corps of Engineers Methods of Analysis and Peer Review for Water Resources Project Planning, The National Academies Press, Washington, DC.

National Research Council. 2004d. U.S. Army Corps of Engineers water resources planning: a new opportunity for service. Coordinating Committee, Committee to Assess the U.S. Army Corps of Engineers Methods of Analysis and Peer Review for Water Resources Project Planning, The National Academies Press, Washington, DC.

Roegner, C., H.L. Diefenderfer, A.H. Whiting, A. Borde, R.M. Thom, and E. Dawley. 2006. Monitoring protocols for salmon habitat restoration projects in the lower Columbia River and estuary. PNNL-15793. Working draft report prepared by PNNL, NMFS, and CREST for the U.S. Army Corps of Engineers, Portland District. 
